\title{
Accounting and Equity-Based Compensation
}

On the Influence and Effectiveness of IFRS 2

\author{
Dissertation \\ zur Erlangung des wirtschaftswissenschaftlichen Doktorgrades \\ der Wirtschaftswissenschaftlichen Fakultät \\ der Universität Göttingen
}

vorgelegt von

Alexander Merz, M.Sc.

aus Münster

Göttingen, 2014 
Erstgutachter: Prof. Dr. Olaf Korn

Georg-August-Universität Göttingen

Platz der Göttinger Sieben 3

37073 Göttingen

Zweitgutachter: Prof. Dr. Robert Gillenkirch

Universität Osnabrück

Rolandstraße 8

49069 Osnabrück

Drittgutachter: Prof. Dr. Michael Wolff

Georg-August-Universität Göttingen

Platz der Göttinger Sieben 3

37073 Göttingen

Tag der mündlichen Prüfung: 24.03.2014 


\section{Contents}

List of Tables $\quad$ vii

List of Figures $\quad$ vii

1 Introduction 1

2 Principal-Agent Conflicts and Equity-Based Compensation 9

2.1 The Principal-Agent Conflict in Firms . . . . . . . . . . . . . . . 9

2.2 Optimal Contracting as a Possible Solution . . . . . . . . . . . . . . 11

2.2 .1 Stocks . . . . . . . . . . . . . . . . . 13

2.2.1.1 Time-Vested Stocks . . . . . . . . . . . . . 13

2.2.1.2 Performance-vested Stocks . . . . . . . . . . . . . . 14

2.2 .2 Stock Options . . . . . . . . . . . . . . . . . 17

2.2.2.1 Evolution of Stock Option Use . . . . . . . . . . 18

2.2.2.2 Design Elements . . . . . . . . . . . . . . . . . 20

2.2.3 A Comparison of Stock Options and Stocks from an Optimal Contracting Position . . . . . . . . . . . . . . 25

2.3 The Pay Setting Process as an Extension of the Principal Agent Conflict 28

2.3.1 The Managerial Power Approach . . . . . . . . . . . . . . . . 28

2.3.1.1 Observed Compensation Contracts and Their Incompatibilities with Optimal Contracting . . . . . . . . 31

2.3.1.2 Criticism of the Managerial Power Approach . . . . . . . 33

2.3.2 The Perceived Cost Hypothesis . . . . . . . . . . . . . . . . . . 35

2.3.3 The Role of Transparency and Disclosure . . . . . . . . . . . . . . 37

3 Accounting for Equity-Based Compensation 39

3.1 US-GAAP . . . . . . . . . . . . . . . . . . . . . . . . . . 39

3.1.1 Accounting Principles Board Opinion No. 25 . . . . . . . . . . 39

3.1 .2 SFAS $123 \ldots \ldots \ldots \ldots$. . . . . . . . . . . . . . . 40

3.1 .3 SFAS $123 \mathrm{r} \ldots \ldots \ldots \ldots$. . . . . . . . . . . . . . . . 42

3.1.4 On the question of disclosure versus recognition . . . . . . . . . 43 
3.2 German Accounting Rules . . . . . . . . . . . . . . . . . . . 45

3.2.1 German Commercial Code . . . . . . . . . . . . . . . . . 45

3.2 .2 IFRS $2 \ldots \ldots \ldots \ldots$. . . . . . . . . . . . . . . . . . . 47

3.3 Comparison of Accounting for Equity-Based Compensation in the United States and Germany . . . . . . . . . . . . . . . . . . 49

3.4 Enforcement and Corporate Governance in Germany in Comparison to the U.S. . . . . . . . . . . . . . . . . . . . . . 5 52

4 The Influence of IFRS 2 on Equity-Based Compensation in Germany 55

4.1 Development of Hypotheses . . . . . . . . . . . . . . . . . 55

4.2 Previous Findings and Research Gap . . . . . . . . . . . . . . 58

4.3 Data Set and Study Design . . . . . . . . . . . . . . 60

4.4 Testing for the Effect of IFRS 2 on Stock Options . . . . . . . . . . . . 62

4.4.1 Explanatory Variables . . . . . . . . . . . . . . 62

4.4 Results....................... 66

4.4.2.1 Descriptive Statistics . . . . . . . . . . . . . 66

4.4.2.2 Regression Results . . . . . . . . . . . . . . . 69

4.4.2.3 Robustness Checks . . . . . . . . . . . . . 71

4.5 Testing for the Effects of IRFS 2 on the Choice of New Equity-Based Instrument . . . . . . . . . . . . . . . . . . . . . . . . 75

4.5.1 Explanatory Variables . . . . . . . . . . . . . . 75

4.5.2 Results and Robustness _. . . . . . . . . . . 76

4.6 Summary of Main Results . . . . . . . . . . . . . . . . . . . . 78

5 The Effectiveness of IFRS $2 \quad 81$

5.1 Previous Findings on Underreporting of Option Values . . . . . . . . . 81

5.2 Data Set and Descriptive Statistics on Plan Design . . . . . . . . . . . 83

5.3 Analysis of Disclosure and Underreporting . . . . . . . . . . . 86

5.3.1 Empirical Findings on Disclosure Practices . . . . . . . . . . . . 86

5.3.2 Empirical Findings on Underreporting . . . . . . . . . . . . . 89

5.3.2.1 Calculating Option Values . . . . . . . . . . . . . 89

5.3 .2 .2 Underreporting . . . . . . . . . . . . . 90

5.3.3 Determinants of Inadequate Reporting . . . . . . . . . . . . . . 93

5.3.3.1 Methodology and Explanatory Variables . . . . . . . . 93

5.3.3.2 Determinants of Incomplete Disclosure . . . . . . . . . . 97

5.3.3.3 Determinants of Underreporting. . . . . . . . . . . 100 
5.4 Summary of Main Results . . . . . . . . . . . . . . . . . . . . . . 103

$\begin{array}{llr}6 & \text { Conclusion } & 107\end{array}$

$\begin{array}{ll}\text { Bibliography } & 111\end{array}$ 



\section{List of Tables}

3.1 Comparison of accounting regimes in the U.S. and Germany . . . . . . . 51

4.1 Stylized Reactions to the Accounting Change and Their Underpinnings . 57

4.2 Summary Statistics I . . . . . . . . . . . . . . . . . . 67

4.3 Summary Statistics II . . . . . . . . . . . . . . . . . . . . . . 68

4.4 Regression results explaining the switch from stock options to a different form (or no form) of equity-based compensation. . . . . . . . . . . . . . 70

4.5 Robustness check with probit regression explaining the change from stock options to a different form (or no form) of equity-based compensation. . . . . . 74

4.6 Probit regressions explaining the choice of performance shares over restricted stock. . . . . . . . . . . . . . . . . . . 77

5.1 Descriptive Statistics of ESO Performance Conditions . . . . . . . . . . . 84

5.2 Disclosure of Valuation and Parameters over Time . . . . . . . . . . . . . 87

5.3 Disclosure of Valuation and Parameters per Plan Category . . . . . . . . 88

5.4 Underreporting by Year . . . . . . . . . . . . . . . . . . . . . 91

5.5 Underreporting by Plan Category . . . . . . . . . . . . . . . . . 93

5.6 1st stage Heckman: participation regression . . . . . . . . . . . . . 99

5.7 2nd stage Heckman: explaining underreporting . . . . . . . . . . . . . . . 101

5.8 Robustness Check: Panel Estimation . . . . . . . . . . . . . . . . . . . . 104

\section{List of Figures}

2.1 Performance Share Number per Target Achievement . . . . . . . . . . . . . 16

2.2 Performance Share Payoff Structure _ . . . . . . . . . . . . . . . . . 17

4.1 Development of equity-based compensation in Germany . . . . . . . . . . . . 61 



\section{Introduction}

"Few issues in the history of the modern corporation have attracted the attention garnered by executive compensation in United States companies. Once relegated to the relative obscurity of business periodicals, executive pay has become a [sic] international issue debated in Congress and routinely featured in front-page headlines, cover stories, and television news shows."

Although this quote was written almost fifteen years ago, it has not lost any of its topicality. Executive compensation is still at the forefront of not only academic research, but also policy initiatives, news stories, and nationwide discussions. The phenomenon is not limited to the United States either as the example of a recent referendum in Switzerland shows. In November 2013 citizens were asked to vote on a cap for management compensation at twelve times the average salary in a corporation. Surprisingly to many, the referendum failed.

Much of the intensity of the discussion has been caused by the steep increase in executive pay, especially over the 1990s when total realized CEO compensation almost quadrupled (Murphy, 1999). "Realized" pay in this case includes all payoffs from equity-based remuneration, which consists of stocks and stock options, among other things. Especially the latter have effected much of the escalation in executive pay (Hall and Liebman, 1998) and ever since there has been a seemingly endless debate over the usefulness of equitybased instruments.

For proponents, they represent a tool that can help reduce agency costs in companies that arise from the separation of ownership and management. The importance of the problems associated with this separation have already been described in the 1930s (Berle and Means, 1932) and have been formalized in Jensen and Meckling (1976). As a result, many researchers have extolled stocks and/or stock options as a means of aligning the interests of the shareholders and the managers, a process often referred to as optimal contracting. And indeed, empirical research has demonstrated the positive effects. For example, manufacturing firms with equity-based compensation have been shown to

\footnotetext{
${ }^{1}$ Murphy (1999, p. 2486)
} 
have higher firm performance when the structure of incentives is appropriately designed (Mehran, 1995).

Paying managers with equity-based compensation makes their income dependent on stock price, much in the same way that the owners' wealth depends on stock price. This conveys incentives to managers who are thusly encouraged to abandon any selfish acts in favor of increased effort in their work. The relationship between equity prices and higher payoffs when the firm performs well is called pay for performance sensitivity (PPS) and has been used as one of the most prominent yardsticks to evaluate compensation design. The relationship between PPS and "good" contracts is not that straightforward, however, as more PPS is not always better. Mishra, Gobelia, and McConaughy (2000), for instance, show that higher PPS also entails higher risk being shifted to risk-averse managers. Increasing the sensitivity of pay beyond a certain point will then have a negative impact on their chosen effort level, which will in turn have a detrimental effect on firm performance. This is exacerbated if the company already has high business risk.

Opponents on the other hand have long decried what they see as an excessive use of equity-based compensation and especially options. Bebchuk, Fried, and Walker (2002) and Bebchuk and Fried (2003), for instance, argue that options are oftentimes used by managers to extract rents from their employers. The more power a manager has, the more likely it is that he or she can 'capture' the pay setting process and dictate the terms of the payment. This becomes supposedly apparent by the huge increases in overall executive pay and low pay for managerial performance sensitivity. Bebchuk and Fried (2003) argue that simply measuring performance as stock price increases is not sufficient to evaluate managerial performance and will lead to high payoffs even when managerial actions have not been optimal. ${ }^{2}$ During an economic boom, for example, there will likely be payoffs from the options even though the stock price increase may just have been due to overall economic conditions. This pay for luck is said to be one reason why managers use options. Another one lies in the fact that for a long time companies did not have to record an accounting charge and thus seemingly had no cost when granting options. Because of that, recorded or disclosed pay seemed much lower than it actually was.

For Murphy (2002) and Hall and Murphy (2003), who also oppose the rampant overuse of stock options, it was this preferential accounting treatment that led to the proliferation

2 This will be elaborated in Chapter 2. 
of this particular instrument, much more so than any bargaining power on the part of a manager could ever have. According to Accounting Principles Board (APB) Opinion Number 25, the accounting charge was determined by the intrinsic value of the option, so long as the terms of the option were fixed. So if the exercise price was set equal to the stock price at the grant date, there was no accounting charge and this part of the compensation package appeared to be without any cost. Consequently, many companies chose plain-vanilla at-the-money options over all other forms of equity-based payment forms, even though several of those would have provided more efficient incentives (e.g., Johnson and Tian, 2000b).

Meanwhile, however, the accounting rules have seen a fundamental change that occurred in two steps in the United States. First, in 1995 the Financial Accounting Standards Board (FASB) issued Statement of Financial Accounting Standard (SFAS) 123, which was initially intended to make fair value accounting mandatory for all forms of equitybased compensation. After heavy resistance from lobbying groups this was attenuated to allow companies a choice: they could either expense the options at their fair value or they could continue to apply the intrinsic value method, but then they would have to also provide a pro forma income statement showing what the effect of fair value accounting would have been. In either case, they had to disclose the valuation model and the most important valuation parameters. In 2005 this choice was revoked when the FASB issued SFAS 123r, which eliminated the choice and finally made fair value accounting mandatory.

This accounting change has created two new strands of literature within the already vast field of executive compensation. The first one investigates the changes in compensation packages sparked by the new regulations. With executive compensation attracting the kind of attention that it does, the question of what actually shapes contract design is among the most important ones and the accounting event enabled tackling two aspects. First, the studies analyze if accounting standards have an influence on compensation at all as hypothesized by, for example, Hall and Murphy (2003). Second, the findings allow for drawing some conclusions about the underlying motives that led to option grants in the first place. In particular, the authors deduce that optimal contracting has not been the sole reason and that the preferential accounting treatment under APB 25 drove much of the expanded option use. Overwhelmingly, these articles find that companies reduce the use of plain-vanilla at-the-money options in favor of restricted stocks, performance shares and more complex, performance-vested stock options (Carter, Lynch, and Tuna, 
2007; Bettis, Bizjak, Coles, and Kalpathy, 2010; Brown and Lee, 2011; Hayes, Lemmon, and Qiu, 2012; Skantz, 2012; Bettis, Bizjak, Coles, and Kalpathy, 2013).

The second strand of literature is focused on the question of whether employee/ executive stock options (ESO) are valued correctly in the financial statements. SFAS 123(r) has the goal of making payment transparent for investors and shareholders. Yet if managers engage in rent extraction, they have an incentive to hide the true extent of their remuneration and so whether the standard is effective in revealing the true expense is crucial to preventing rent extraction or misperceptions about the cost of the options. Knowing the cost of the instruments is also critical for the efficient use of options. However, valuation is complicated by the fact that such options differ in several aspects from standard exchange-traded call options and that SFAS 123r allows for a large degree of discretion in determining the model inputs for the valuation. Empirical research has shown multiple times that managers use this leeway in order to bias option values downwards and make compensation appear less than it actually is (Botosan and Plumlee, 2001; Balsam, Mozes, and Newman, 2003; Aboody, Barth, and Kasznik, 2004a, 2006; Hodder, Mayew, McAnally, and Weaver, 2006; Johnston, 2006; Bartov, Mohanram, and Nissim, 2007).

This thesis aims to contribute to both these strands of literature by exploiting a similar accounting event. The introduction of International Financial Reporting Standard (IFRS) 2 also presented an exogenous shock that revolutionized accounting for equitybased payment in Germany. It also makes the same requirements for valuation and disclosure of stock options as SFAS 123r, which means that there is also a possibility of influencing the reported option price and avoiding robust valuation (Korn, Paschke, and Uhrig-Homburg, 2012). The event also allows for evaluating both the influence of accounting standards on compensation and the effectiveness of the standard in its stated goal of making option valuation more transparent and reproducible. Thus, this thesis can provide international evidence from a country where the relevance of compensation for companies is similarly high as in the U.S. Even though overall compensation has always been below of what can be observed in the United States (Elston and Goldberg, 2003), it still accounts for a substantial part of companies' earnings (Haid and Yurtoglu, 2006). Compared to the U.S., stock options for employees have a relatively short history in Germany. Only since a reform of the Stock Corporation Act (Aktiengesetz) in 1998 have companies been allowed to issue 'naked' stock options for compensation purposes, yet ever since their popularity and the popularity of equity-based compensation in gen- 
eral have steadily increased among traded corporations. By 2006, 37\% of all companies listed in the Prime Standard had some form of equity-based compensation; in the largecap index DAX the percentage stood at 83\% (Rapp, Schaller, and Wolff, 2011). CEO pay has also seen strong increases over the years. For example, during the period from 1997 - 2007 it went up by 350\% (Fabbri and Marin, 2012).

In addition to the new international evidence, and more importantly so, the German setting enables research beyond what has previously been carried out. Four important differences account for this opportunity, of which three relate to IFRS 2. Firstly, unlike in the United States the change in the accounting regimes was more direct as there was no transition period in which two sets of rules were in effect at the same time. Thus, Germany went from a no-expense regime to a full-expense regime immediately. This minimizes the risk of companies changing their compensation packages in the transition period and it circumnavigates the issue of whether disclosed values, which were already available under SFAS 123, are equal in their effect to recognized and expensed values. ${ }^{3}$ This is of direct consequence to the question of whether accounting rules influence payment design. Any effect the new accounting regime potentially has, should be more clearly visible in a setting without such blurring influences.

Secondly, there is a potential confounding effect in the United States as the accounting change did not just move to a full-expense regime with increased transparency. Prior to the new accounting standards, there was already expensing of options, simply just not of all types. A clearly preferential treatment was granted to options that had fixed terms and an intrinsic value of zero. SFAS 123(r) required expensing and disclosure of the valuation. At the same time, however, the new regulation led to an equal treatment of all kinds of options. Thus, it is not clear which of the two changes is responsible for the observed changes in equity-based compensation form. In Germany, there was no preferential treatment for a certain type of option before the change in accounting regimes and so if changes in equity-based pay can also be observed around the introduction of IFRS 2, they can be more clearly and more explicitly be traced back to the expensing and the accompanying transparency.

Thirdly, there are some subtle but important differences between SFAS 123r and IFRS 2 in the disclosure requirements for other equity-based instruments, in particular performance shares, which are subject to a lower transparency standard than stock options.

\footnotetext{
${ }^{3}$ For a discussion on whether disclosed values are equally effective in conveying information, especially about ESO, see for example Bodie, Kaplan, and Merton (2003) and Section 3.1.4.
} 
As a result, it will be possible to not only see if there is a reaction to the new accounting rules, but in what way equity-based pay will be influenced. Because if these rationales (optimal contracting, rent seeking, perceived cost hypothesis) hold and accounting does have an effect on the design of equity-based pay, there should be different stylized reactions to the introduction of IFRS 2 and the new accounting regime, which in turn should allow for drawing more specific conclusions about how exactly accounting influences corporate actions in the field of compensation.

Finally, German law has always required companies to attach some form of performance condition to stock options. There has never been a dominance of at-the-money options, the experience with performance-based equity awards is much greater and plans already resemble what is now becoming more and more prevalent in the U.S. This is important when testing the effectiveness of disclosure and transparency generated by the two standards. Having more complex features in the options also means that there are more valuation parameters and more opportunities to influence the value. This study will be the first to investigate underreporting of performance-vested ESO, which will be more meaningful in Germany, given the longer history of performance-vested ESO. And it will be the first to do so under a full-expense regime.

All in all, the research presented here will address two very current and very relevant issues regarding transparency and management compensation. First, it will investigate if the introduction of a new accounting standard has an influence on equity-based payment practices. If that is the case, the new standard will allow for a study of the fine structure of the use of equity-based instruments which may even enable conclusions about the three latent rationales behind the popularity of executive stock options. Second, it will analyze the effectiveness of IFRS 2 in terms of making option-based compensation more transparent and reproducible. By doing so, it will present new empirical evidence that will extend the literature to a new international setting by using data on German executive compensation and an institutional setting that is in many ways different from previous U.S.-based studies, but more representative of (continental) European countries. At the same time, it extends the knowledge about the economic consequences of accounting standards as it exploits the immediate transition, the differential treatment of certain instruments, and the longer history of performance-vested shares in Germany. Taken together this will generate insights into the effects and consequences of IFRS 2 that can be of interest to shareholders, managers, standard setters, enforcement agencies, and policy makers. 
In order to answer the research questions the thesis will proceed as follows. Chapter 2 will describe the economic conflict brought about in companies by the separation of ownership and management. It will also outline how optimal contracting can be used to alleviate this conflict with the help of equity-based compensation contracts. Moreover, it will also present alternative explanations that see managerial remuneration not as a solution, but as an extension of the principal agent conflict. All three rationals will be depicted based on previous research findings. ${ }^{4}$

Chapter 3 is dedicated to the accounting rules governing executive compensation in the United States, where most of the prior literature originated, and in Germany. In addition, the institutional and corporate governance backgrounds will be juxtaposed, which will serve as further motivation for the choice of Germany as the country of the study. Chapters 4 and 5 contain the empirical analyses. The former uses data on equitybased compensation from before and after the introduction of IFRS 2 to check for any influence the switch to a new accounting regime may have had in Germany. The latter uses data on option contracts granted after the IFRS 2 introduction only, in order to investigate its effectiveness. Chapter 6 concludes this thesis.

\footnotetext{
4 Although the bibliography to this thesis and to Chapter 2 in particular is quite extensive, it makes no claim to be complete or exhaustive in any way. For that, the research on executive compensation is simply too vast.
} 



\section{Principal-Agent Conflicts and Equity-Based Compensation}

This chapter will describe the principal-agent conflict in firms that arises from the separation of ownership and management and its relationship to equity-based pay. Compensation instruments such as stock options or restricted stocks are often touted as a possible tool for aligning the interests of the parties involved, a practice known as optimal contracting. Critics see compensation design not as a solution but as an extension of the agency problem that has led to the rampant and inefficient use of equity-based compensation. Two prominent manifestations of this view, the managerial power approach and the perceived cost hypothesis, will be covered in this chapter.

\subsection{The Principal-Agent Conflict in Firms}

The principal-agent theory is part of the new institutional economics and defines an agency relationship as one "between two (or more) parties when one, designated as the agent, acts for, on behalf of, or as representative for the other, designated the principal, in a particular domain of decision problems" (Ross, 1973, p. 134). One prominent example of such a relationship and the one focused on in this chapter is the one between the owners of a company and the managers to whom the job of running said company has been delegated. ${ }^{5}$

Berle and Means (1932) describe the phenomenon of widely dispersed ownership in American companies and its effect on corporate control. They note that many large companies have tens of thousands of shareholders of which nearly all control less than one percent of the outstanding shares, a situation that still persists today. With this separation of ownership and control two distinct groups of people emerge that traditionally were only one: "[...] owners without appreciable control and the control [group] without appreciable ownership" (Berle and Means, 1932, p. 121). Shareholders (the principals)

\footnotetext{
${ }^{5}$ Other examples are the relationship between insurer and insuree (Spence and Zeckhauser, 1971), landowner and farmer (Stiglitz, 1974), and shareholder and bondholder (Myers, 1977).
} 
are just too numerous and dispersed to coordinate in any sensible way. Therefore, they hire managers (the agents) and delegate the task of running the company to them. This division of roles and responsibilities may however lead to conflicts as the two groups potentially have different interests, which is usually the case (Jensen and Meckling, 1976). Agents are generally not motivated by their personal stake in the shares of the company, but by monetary gain derived from their employment, leading to interests opposed to those of the principals who have to pay the agents (Berle and Means, 1932). At the same time, agents are usually not as diversified in their income generation as principals and are therefore more risk averse (Eisenhardt, 1989). Additionally, in running the company they are in a way managing other people's money. Adam Smith already noted that managers will not exert as much effort in caring for someone else's money as they would for their own. ${ }^{6}$ Moreover, exerting higher effort will reduce the agent's utility and thus in the absence of incentives, he or she will put in a minimum amount of effort (Holmström, 1979).

The principal, on the other hand, needs the manager to exert the best possible effort as his utility will rise with increases in the company's profit that is distributed to him. The manager affects this in two ways: first in a direct way because the principal has to pay the manager and the salary will be subtracted from gross profits; and second, the manager's actions influence the distribution function of the profits (Lambert, 2001). Unfortunately, it is not feasible for all shareholders to monitor the managers' actions at all times and this unobservability creates a situation of moral hazard (Harris and Raviv, 1979). The only thing that is observable is the outcome of the actions. Yet whether it is company profits or share prices, it is a random variable that is affected by many more factors besides the manager's effort (Holmström, 1979). Therefore, owners cannot draw conclusions about what actions exactly the managers have taken (Lambert, 2001). However, higher effort by the manager will increase the likelihood of positive outcomes thus shifting the probability mass of the distribution of that random variable to the right, which is always preferred by the principal (Mirrlees, 1976; Rees, 1985). A simple fixed pay contract will not suffice as it provides to the agent a de facto insurance against bad outcomes that will not induce effort to avoid such outcomes (Sappington, 1991). Thus, the principal needs to design a compensation contract that will induce higher effort on the part of the manager, while it at the same time it will share the risk inherent in the

\footnotetext{
${ }^{6}$ Adam Smith, The Wealth of Nations, p. 700, as quoted by Jensen and Meckling (1976) and many others.
} 
random variable "company value" adequately between the two parties. This is the goal of optimal contracting, which will be described in the following section.

\subsection{Optimal Contracting as a Possible Solution}

An intuitive solution to the described problem is to let the agent also profit from an increase in company value to motivate higher effort (Spreemann, 1989). Since company value is a random variable, higher effort will only make a higher outcome more likely, it cannot guarantee it. Therefore, a contract also needs to incorporate risk-sharing between the principal and the agent, which optimal contracting ${ }^{7}$ strives to do.

A common reference point for the optimal contract is the so-called first-best solution. ${ }^{8}$ This can be defined as choosing "the contract and the actions to maximize the principal's expected utility subject to meeting the agent's acceptable level of utility" (Lambert, 2001, p. 12). Incentives are not part of this contract because both agent and principal work together cooperatively and there is no selfish behavior. If this assumption is relaxed and optimal effort needs to be incentivized, the first-best solution is more difficult to obtain. If the agent's actions are observable or if the outcome of the target variable (e.g., profits) allows for an unambiguous deduction about the actions taken by the agent, then a forcing contract is possible that penalizes any deviations from the effort selected under the first-best solution. This is, however, often not the case and thus most contracts will be second-best solutions, i.e., contracts that are optimal given the information that is available to the principal and the agent (Barnea, Haugen, and Senbet, 1985). Put differently, these contracts trade off the additional risk that must be imposed on the agent in order to motivate him, and the cost of doing so, i.e., the higher expected pay. These agency models also assume that the parties' utility functions are known. ${ }^{9}$

\footnotetext{
${ }^{7}$ Besides optimal contracting, there is also the notion of incentive-compatible contracts (Ross (1974) uses the term preference similarity) born out of agency considerations. In setting up those contracts incentive effects for the manager only stem from monetary aspects of the contract. Utility-reducing effects such as effort are ignored, which lowers information requirements. For a more detailed description, see Velthuis (2004).

8 This paragraph closely follows Lambert (2001) unless otherwise indicated.

${ }^{9}$ Many authors assume von Neumann-Morgenstern utility functions, which allow for different levels of risk aversion (see, for example, Ross (1973), Mirrlees (1976), and Grossman and Hart (1983)). Under the relevant assumptions, an agent will choose his actions so that they maximize his or her expected utility. However, they operate strictly under the expected utility theory; contradictions to the underlying axioms such as ambiguity aversion are not incorporated. This will be relevant in explaining some of the observed behavior in executive compensation analyzed in Chapter 4.
} 
The principal has to take into account two conditions when designing a compensation contract that maximizes his or her own utility: first, the contract has to exceed the agent's reservation level of utility. That means that a manager has a certain utility threshold level below which he will not accept a contract. This can be thought of as an alternative employment offer from another company, providing said utility. And second, it must fulfill the incentive condition (Lambert, 2001). This point refers to the fact that the agent will choose the action that will maximize his or her own utility and the principal has to ensure that that is also the action that will maximize his respective utility. Therefore, a contract must be devised that achieves best possible incentives for the agent, which implies best-possible risk-sharing. Such an optimal contract is found when it minimizes all agency $\operatorname{costs}^{10}$ (Bebchuk et al., 2002).

It is often assumed in theoretical models that this contract is offered to the managers by the principal or his representative; managers then decide whether to accept or decline the contract. ${ }^{11}$ Once the manager accepts the contract, he or she will then choose the action that will maximize both the principal's and the agent's expected utilities.

One important aspect of the contract is the performance measure. It is generally conceivable to resort to accounting figures such as annual profit or earnings per share. However, there is an issue with this approach, as accounting figures may not accurately reflect the true present value of a corporation. ${ }^{12}$ The measure should ultimately be one that conveys the most useful information about the managers' actions to the shareholder (Holmström, 1979). An alternative to the accounting measures is provided by the shareholder value approach: A company's success is measured by its stock price plus any paid dividends (i.e., the total shareholder return (TSR)), which is easily observable and not subject to accounting influences (Rappaport, 1998). A fundamental idea is that the owners want to maximize the shareholder value in order to maximize their utility derived from the income they can spend on consumption. In perfect markets, managers can therefore operate under the goal of maximizing the TSR without having to know each individual owner's preferences. ${ }^{13}$ Hence, stock prices make for an ideal performance measure and

\footnotetext{
10 Agency costs are defined as the sum of the bonding and monitoring costs as well as the residual loss incurred by the principal whenever the agent's actions do not maximize the principal's welfare (Jensen and Meckling, 1976).

11 This is also denoted a "take-it-or-leave-it" offer (Laux, 2006, p. 199).

12 For example, there may be different methods of allocating costs and revenues between different subsidiaries and the time value of money is not reflected in accounting earnings (Rappaport, 1998).

13 This has become known as the Fisher Separation Theorem (Fisher, 1930).
} 
basing manager's compensation on it helps align the principal's and the agents' goals (Rappaport, 1998). If the incentive contract is based upon share price, the agent will directly participate in the success in the same way the principal does.

The shape of the optimal contract hinges on the principal's and the agent's risk aversion and the stochastic production function translating effort into output; therefore, depending on the specific situation, a convex, a concave, or a linear contract can be the optimal one (Lambert, 2001). Two equity-based contracts frequently found in reality and as the subject of academic research are stocks and stock options. Both are discussed next.

\subsubsection{Stocks}

Stocks represent a linear form of compensation that can be awarded by companies. Most of the time, common stocks are used for this purpose, in rarer instances firms give out preferred stocks. In either case, they are subject to vesting restrictions that can either be time-based or performance-based. The latter has an impact on the linearity of the instrument, as will be discussed shortly. Stocks also have the effect that they directly convey ownership to the managers, bringing the two different groups of owners and managers closer together. Managerial ownership has also been shown to lead to better company performance (McConnell and Servaes, 1990; Morck, Shleifer, and Vishny, 1988).

\subsubsection{Time-Vested Stocks}

The most common restriction on stocks is a vesting period, usually of two or three years in which recipients are not allowed to sell their shares. This is supposed to make sure that managers focus on long-term improvements rather than artificial short-term share price boosts. These instruments are commonly referred to as restricted stocks. ${ }^{14}$ It is also possible for companies to not give out actual shares but pay the market value at the end of the vesting period. This is referred to as restricted stock units or phantom shares and eliminates the ownership transfer through actual shares.

The popularity of these instruments has increased drastically in recent years. Petra and Dorata (2012) report that executives' holdings of restricted stock in the U.S. have gone up $88 \%$ between 2004 and 2008. This increase is attributed by many to the new

14 Other names used in the literature are time-vested or non-vested shares. 
accounting standards ${ }^{15}$ (e.g., Carter et al., 2007; Brown and Lee, 2011), yet there is also evidence that it may be due to shareholders' desire for cash dividends: Aboody and Kasznik (2008) show that restricted stocks, which are generally dividend-protected, are used more relative to options when shareholders prefer payouts over stock buybacks. ${ }^{16}$

An important consideration in setting equity-based pay is the risk of insulating executive pay from consequences of negative outcomes. Since a negative salary is generally not possible, managers cannot lose anything if they perform poorly. This is a de facto insurance (Sappington, 1991). Because of their linear payoff, stocks also provide incentive at lower stock prices and they penalize bad performance (Dittmann and Maug, 2007). On the other hand, risk-averse CEOs will perceive this as excess risk they will have to bear which may in turn lead them to be overly cautious when making investment decisions (Bryan, Hwang, and Lilien, 2000).

Kahl, Liu, and Longstaff (2003) show in a theoretical model that restrictions on the sale of stocks constitute a cost to the executive who may have to engage in the stock market to hedge the risk. They argue that restricted stock is worth far less to the recipient than to the firm ${ }^{17}$ and is therefore an inefficient means of compensation.

\subsubsection{Performance-vested Stocks}

Equipping common stock with performance-vesting conditions can create two different instruments: performance-restricted stock and performance shares. Technically, performance-restricted stocks are granted right away yet only vest to the degree that the performance criteria are met. Performance shares are only initially promised, the actual number to be issued is determined at the end of the service or vesting period and depends on fulfillment of the performance criteria. As Walker (2011) correctly points out this does not constitute a significant economic difference, which is why for the remainder of this text the two will be subsumed under the much more common term performance shares.

These instruments have come to be widely used in practice only fairly recently, even though they were first used during the 1970s and already described by Larcker (1983,

\footnotetext{
${ }^{15}$ See also Chapter 3 and the analysis in Chapter 4.

${ }^{16}$ Also see the discussion for options in Section 2.2.2.

${ }^{17}$ Silber (1991) estimates that the liquidity restrictions for common stock lead to a discount of up to $30 \%$.
} 
p. 8) who notes that all "performance plans exhibit option-like characteristics [...] in that the pay-off is bounded by zero from below and increases as the performance measure exceeds some target." ${ }^{18}$ Put differently, they are no longer linear in their payoff. In addition, he finds that adopting performance plans influences managers' investment decisions and leads to increased shareholder wealth as evidenced by the capital market reactions to those plans.

Early versions of performance vested equity grants in the U.S. used an "all-or-nothing" vesting criterion (Bettis et al., 2010), yet since then the provisions have become more complex. As outlined above, an executive will be promised a certain number of shares at the beginning of the vesting period. At the same time, three goals will be stipulated in the contract: if the target goal is met, $100 \%$ of the shares will vest and the executive is free to sell them. There will also be a threshold goal and a stretch goal. The former describes a lower boundary for the performance goal. Should it not be met, no shares will vest. Contrarily, the stretch goal represents a cap as it lies above the target goal and, if met, allows the executive to receive additional shares on top of the $100 \%$. Between the threshold goal and the stretch goal, the number of shares that vest is calculated linearly (Holden and Kim, 2012). This is illustrated in Figure 2.1. The payoff is then determined by multiplying the share price at maturity with the number of shares that have vested. Figure 2.2 visualizes the result.

The use of performance shares has increased rapidly in recent years. In their sample of 1,469 firms, Bettis et al. (2013) identify only 172 performance-vested stock awards in 1998, while in 2008 there were already 500 such grants. The actual performance measure used as a target varies among companies. Holden and Kim (2012) report that roughly one fifth of grants in their sample, collected between 2006 and 2010, are tied to total shareholder return and earnings per share, respectively. Bettis et al. (2013), who do not distinguish between performance-vested options and stock, report that the use of stock price as a measure is declining and more and more companies use accounting measures. Out of these, earnings is the most popular measure.

Performance vesting also has an impact on the value of the equity grant in that on average the grant date value is diminished by $45 \%$ (Bettis et al., 2013). Recently, two alternatives for valuation have been presented. Bizjak, Kalpathy, and Thompson (2012) use a risk-neutral framework and "sidestep a host of technical issues" in order to arrive

\footnotetext{
18 Larcker uses "performance plan" to include both performance shares and performance share units.
} 
Figure 2.1: Performance Share Number per Target Achievement

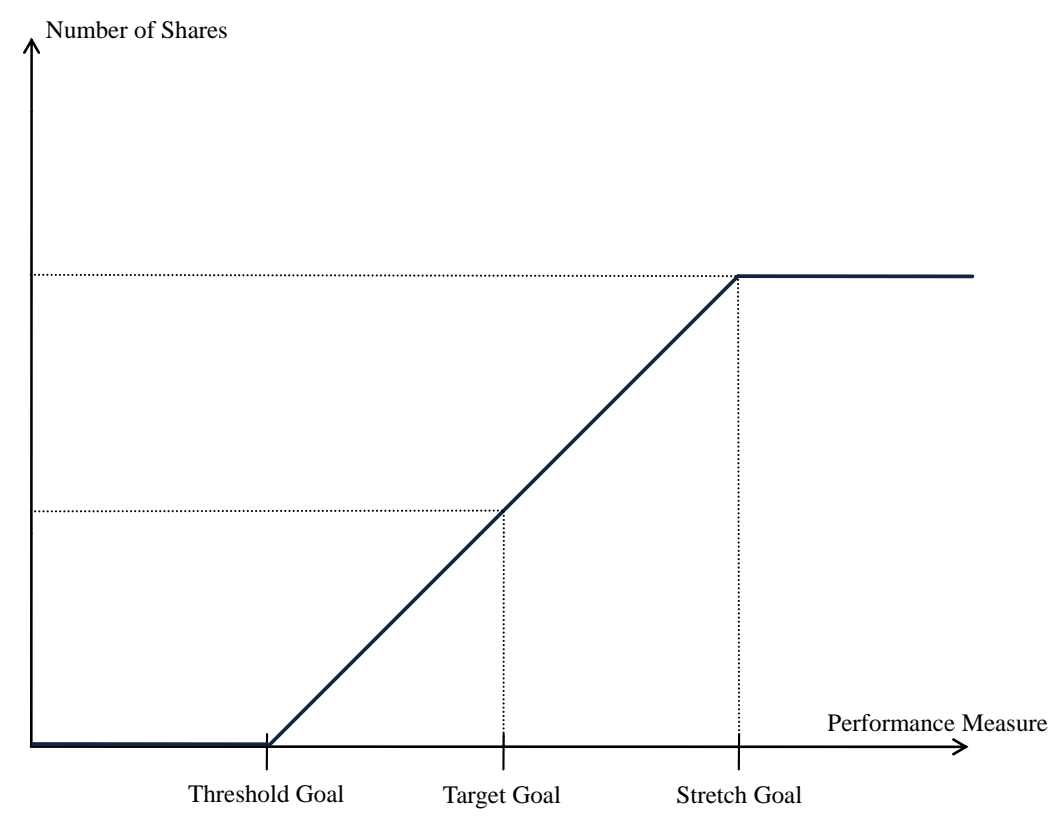

The graph shows the relationship between the number of performance shares that are awarded/vest in relation to the goal that has been met. (Adapted from Holden and Kim (2012).)

at an approximate present value of the award. While the authors admit that this represents only an initial step to future research, their model is flexible enough to allow for valuation of performance-vested stock and options with either an accounting or a stock price target or both. Holden and Kim (2012) on the other hand develop closed-form solutions specifically for performance shares with either a non-traded or a traded performance measure. Both papers focus highly on performance hurdles based on accounting numbers, such as earnings per shares, which are the most used in the U.S. ${ }^{19}$

Performance-based vesting conditions have generally been found to have a positive effect on managerial incentives. Both Bettis et al. (2010) and Bettis et al. (2013) find strong positive stock and accounting performance after the adoption of performance-vested equity plans. ${ }^{20}$ In addition, Bettis et al. (2010) assert that the performance hurdles are challenging and meaningful and are not mere "window dressing" to ward off criticism.

19 For more on performance hurdles see Section 2.2.2.2 where they are discussed in the context of stock options.

20 Neither study investigates whether performance-vested stock or options are more effective in increasing incentives. The conclusions refer to performance vesting in both forms of equity-based compensation. Yet as Bettis et al. (2013) point out, stocks are more and more replacing options and because of the option-like character of performance shares, shareholders can also use them to induce risk-taking 
Figure 2.2: Performance Share Payoff Structure

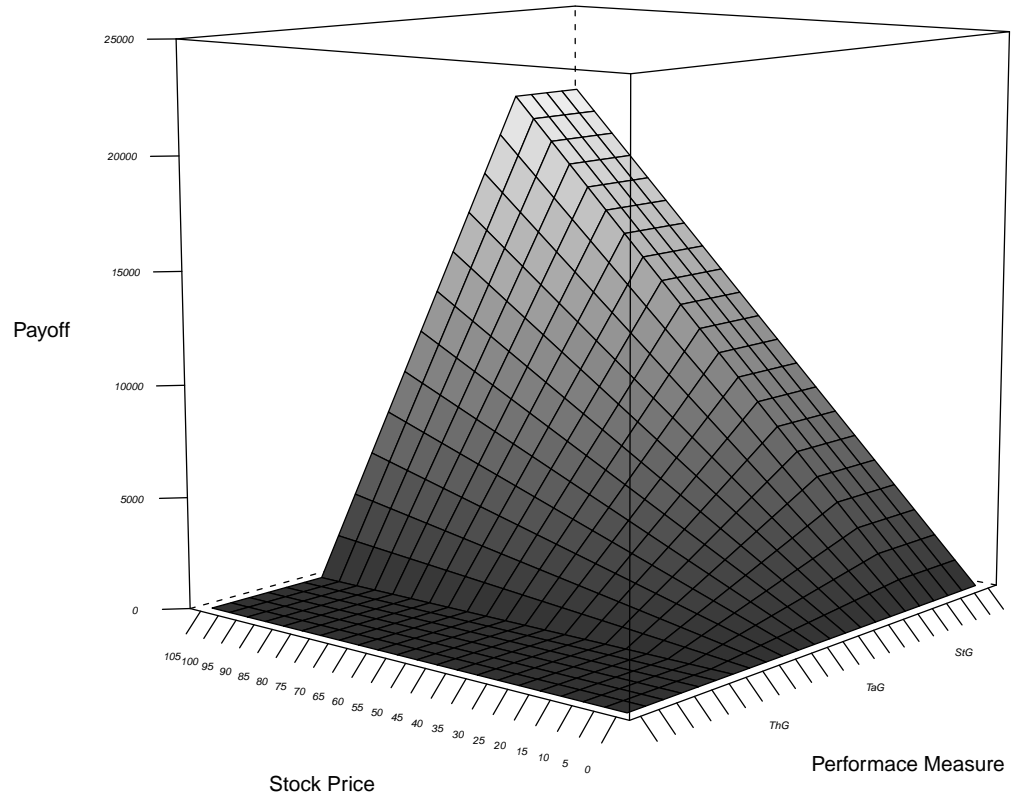

The graph shows the payoff structure at vesting for a performance share. The performance measure that introduces the non-linearity in this case is EPS. At any given level of this performance measure, the instrument is therefore still linear in stock price. The target achievement yields zero shares below the threshold goal (ThG), 100 shares at the target goal (TaG) and 200 shares at the stretch goal (StG). (Adapted from Holden and Kim (2012).)

This is supported by De Angelis and Grinstein (2010) who only find weak evidence that performance vested instruments constitute a deviation from optimal contracting, and only so when shareholder oversight is lacking.

\subsubsection{Stock Options}

Call options, which are used for compensation purposes, give "the holder the right to buy the underlying asset by a certain date for a certain price" (Hull, 2012, p. 7). The underlying asset in this case is the company stock and since the option's value increases with rising stock prices, managers can directly benefit from value-increasing actions. Eventually, the higher the share price is at exercise, the higher the payoff for the manager will be. In contrast to regular financial options, employee/executive

behavior by conveying more vega. Therefore, it seems logical to assume that the overall incentive effect is at least partly driven by performance shares. 
stock options (ESO) underlie certain restrictions. First of all, managers are barred from exercising the options for a period of time at the beginning of the life of the options, known as the vesting period. Second, employees are usually not allowed to sell their options. ${ }^{21}$ Third, when employees leave the company they have to immediately exercise their outstanding options if they are in the money, and if they are out of the money or the vesting period has not passed yet, they lose their rights to the options (Hull, 2012).

Option plans used by companies run for several years and typically each year a new tranche of options will be granted. In virtually all cases the options are given out for free even though they represent an opportunity cost to the company. ${ }^{22}$ On the other hand, vesting is conditional on the option holder remaining employed, so the option premium is paid in a sense in work effort.

ESO come in two general categories: real options and virtual options, also known as stock appreciation rights (SAR). For real options, managers have to pay the exercise price to the company and in exchange, they receive a share which they can then either keep or sell off directly in the market. There is a noteworthy issue here: the company will receive a cash inflow upon exercise by the manager, yet it will have no direct cost. The cost of the exercise is born by the current shareholders whose stock holdings are being diluted through the issue of new shares (Achleitner and Wichels, 2002). ${ }^{23}$

SARs, on the other hand, do not require giving actual shares to the employee. Instead, the company will simply pay the difference between the current market value of the stock and the exercise price, i.e., the intrinsic value. Thus, the company has a cash outflow without an increase in equity or a dilution of the stock price (Achleitner and Wichels, 2002).

\subsubsection{Evolution of Stock Option Use}

Stock options mainly became a prominent form of compensation in the United States during the 1990's. Up until 1985 the median value of option grants to a CEO was zero, by

21 An exception is Finland, where recipients are free to sell stock options on an exchange once they have vested (Ikäheimo, Kuosa, and Puttonen, 2006).

22 See, for example, Bodie et al. (2003) and Chapter 3.

23 There is evidence to suggest that managers engage in stock buybacks to undo the dilution effect on stock prices (Dittmar, 2000) and on diluted earnings per share (Bens, Nagar, Skinner, and Wong, $2003)$. 
1994 it had reached $\$ 324,989$ (Hall and Liebman, 1998). From 1992 to 2000 the average value of an option grant saw a nine-fold increase from $\$ 800,000$ to $\$ 7,200,000$, which was the main driver behind the overall explosion of executive pay in that time (Hall and Murphy, 2003). Frydman and Jenter (2010) report that during the 1990's, stock options made up 32\% of CEO pay, while between 2000 and 2005 it already accounted for 37\% of overall CEO pay.

Ironically, this immense boom in stock options (and thus in CEO compensation) was caused by a law that was intended to rein in excessive pay. In 1993, the U.S. Congress enacted Section $162(\mathrm{~m})$ of the tax code, which limited deductibility of pay to $\$ 1,000,000$, unless it was performance-based. This law had, however, many loopholes, such as no requirement to accurately specify performance goals ${ }^{24}$ or to document how companies complied with the law (Holmberg and Austin, 2013). As long as stock options were not in-the-money at grant date, they fulfilled the conditions of the new law and became the instrument of choice for many companies. Standard time-vested restricted stock, on the other hand, does not qualify as performance-based (Balsam, 2012).

One effect of Section 162(m) was that many firms, and especially those that paid close to $\$ 1$ million, curtailed fixed salaries at that threshold; it did not, however, stop overall compensation growth (Rose and Wolfram, 2002). This is also reported by Perry and Zenner (2001) who in addition also find an increased responsiveness of overall pay to stock prices after the new tax code was enacted.

In Germany, the situation evolved differently than in the U.S. Prior to the passage of the Act of Control and Transparency of Enterprises (Gesetz zur Kontrolle und Transparenz im Unternehmensbereich (KonTraG)) in 1998, it was very nearly impossible for companies to award naked options as the law required that recipients make a capital contribution. Therefore, companies had to rely on convertible bonds or warrant-linked bonds which were rather unpopular precisely because employees had to purchase them (Siddiqui, 1999). With the new law, stock option programs saw a sudden rise in popularity. In 1998 alone, 27 programs were started (Winter, 2000) and by 2002 over 60\% of the DAX 100 companies were using (virtual) stock options to pay (and incentivize) managers (Kahlert and Würz, 2003). By 2005, 73\% of DAX 30 companies had stock option plans (Paschke, 2008). This shows that stock options quickly developed into the

24 This led to rather questionable performance conditions such as "individual achievement of personal commitments" or maintaining a "fun" workplace (Epstein and Javers, 2006, p. 64). 
most popular equity-based compensation instrument in Germany and they achieved a similar significance as in other countries such as the U.S. or the U.K.

KonTraG also had two other consequences: first, it allowed companies to use treasury stock to service stock options, reducing the need to get a three-quarter majority for a conditional capital increase at the annual meeting. Second, it required that naked options have some sort of performance goal, though without actually specifying what that should be (Crasselt, 2008). Another regulation, the German Corporate Governance Code (GCGC), also has an impact on stock options. Within the framework that spells out guidelines for "good" corporate governance one can find the call for meaningful and challenging performance goals to be included in equity-based pay. ${ }^{25}$ Although the GCGC is a "comply or explain" regulation and although it does not specify either what those performance goals should be, together with the KonTraG it has led to a markedly different form of stock option design in Germany: plans have traditionally been much more complex than, for instance, in the U.S. as they have included, among other things, absolute or relative exercise hurdles and caps (Crasselt, 2008).

\subsubsection{Design Elements}

ESO are almost always American-style options and especially in the U.S. the overwhelming majority of options were issued at the money. For example, Murphy (1999) reports that of 1,000 firms surveyed in 1992, more than $90 \%$ set the exercise price equal to the then current market value of the shares. This is often attributed to the accounting rules under Accounting Principles Board Opinion no. 25, which favored such plans. ${ }^{26}$ Yet with changes in accounting rules, the design of stock options became more elaborate. ${ }^{27}$ The most important design elements and their effects shall be discussed here.

\section{Maturity, Vesting, and Early Exercise}

ESO often have maturities of seven years or more with exercise being prohibited at first. The so-called vesting period is meant to ensure that managers focus not on short-term stock price inflation but on long-term, sustainable profitability increases. In Germany,

\footnotetext{
25 Similar rules also exist in, for instance, the U.K. where the Greenbury Report outlines comparable recommendations.

26 See Chapter 3 for more details.

27 Both Gerakos, Ittner, and Larcker (2007) and Bettis et al. (2013) report more and more performancevesting in the U.S.
} 
this period was usually set to two years, but after a heated public discussion about the excessiveness of stock option grants, the Act on the Appropriateness of Management Board Compensation (Gesetz zur Angemessenheit der Vorstandsvergütung (VorstAG)) mandated a four-year vesting period.

Theoretically, the only point in time when it can be optimal to exercise an American option before maturity under standard no-arbitrage pricing is right before a dividend payment; if the option is dividend-protected ${ }^{28}$ or if the company does not pay dividends, it is never optimal to exercise the option early (Hull, 2012). Nonetheless, managers frequently engage in early and potentially non-optimal exercise (Carpenter, 1998).

Besides the dividend induced exercise, Maris, Maris, and Yang (2003) identify four more reasons that could lead a manager to exercise his or her options early. Since executives are not allowed to sell the option, exercising and subsequently selling off the share may be reasonable if they have a need for cash. They may want to diversify their portfolio or they may be forced to exercise upon being let go or resigning. And finally, they may have information about negative future events that make exercise now profitable. Empirical results by Huddart and Lang (2003) seem to support the last point, yet they only look at aggregate option exercise within a company and find that fewer options are exercised before stock price increases. In contrast, Aboody, Hughes, Jing, and Wei (2008) also look at whether the acquired shares are immediately sold off by the executives. Their data show only weak evidence for the abuse of adverse insider information. Contrarily, they find strong evidence that managers exercise options early and then hold the shares for at least 30 days if they have positive private information about the company's future prospects.

The long time to maturity typically granted for stock options has a strong influence on their value and if exercise is uncertain, it can cause problems for the valuation. ${ }^{29}$ If the effective time to maturity (i.e., time to exercise) is known, this can rather easily be incorporated in standard no-arbitrage valuation models, whose values will converge

28 A dividend protection ensures that the manager will be compensated for the value decrease in his or her option holdings following a dividend payment. For ways to accomplish dividend protection, see Arnold and Gillenkirch (2005). Empirical research shows that only few plans in the U.S. have dividend protections at all (Fenn and Liang, 2001) and managers substitute cash dividends by stock repurchases in order to protect the value of their option holdings (Lambert, Lanen, and Larcker, 1989).

29 See, for example, Maris et al. (2003). For more general recommendations on how to incorporate characteristics such as a vesting period into the valuation, see Hull and White (2004). 
on those of more elaborate utility-based models that value options from the employee's perspective (e.g., Ammann and Seiz, 2004; Bettis, Bizjak, and Lemmon, 2005).

\section{Exercise Price}

As stated above stock options were traditionally granted with the exercise price equal to the current market value of the shares to avoid accounting charges. Setting the exercise price higher than the market price, i.e., giving an out-of-the-money option, can have advantages. These so-called premium options are less valuable than at-the-money options, so if companies want to hold the total value of the option grant constant, they can give out more out-of-the-money options. For a set of reasonable base-line parameter values, Johnson and Tian (2000b) calculate that firms can grant about 1,5 premium options per one traditional at-the-money option. This increases the incentive effect to increase stock prices as measured by the option delta by about $24 \% .{ }^{30}$ Increasing the difference between exercise price and stock price can increase this incentive effect, yet it also increases the incentive to increase stock volatility and so shareholders have to find the right trade-off.

Theoretically, companies could also set the exercise price below the current market value and grant in-the-money options. This would however create a windfall profit for executives who would benefit without having to increase their effort. Hence, those options are not reconcilable with the optimal contracting idea (Bebchuk and Fried, 2003).

\section{Performance-Vesting Conditions}

In addition to simple time-vesting provisions, stock options, like stocks, can also be equipped with performance vesting conditions. Research has shown that this can lead to strong incentive increases (e.g., Johnson and Tian, 2000b; Bettis et al., 2010), and they are seen as positive by the market (Langmann, 2007), yet overly ambitious performance goals can have an adverse effect as managers become discouraged (Kuang and Qin, 2009). Performance vesting conditions can be implemented with several design elements.

\section{Absolute Hurdles:}

One easy way to set a hurdle, is to simply grant out-of-the money options which would mean that a performance is necessary before exercise is possible. ${ }^{31}$ Regardless of how

\footnotetext{
30 Johnson and Tian (2000b) assume a stock price of $\$ 100$ and an exercise price of $\$ 150$.

31 While this is technically not a vesting condition, it has the same effect: exercise is not meaningful before the stock price exceeds the exercise price.
} 
the exercise price has been set, many stock option contracts require that the stock price exceed a certain barrier before managers can exercise the options. The option thereby becomes a knock-in barrier option. This idea is similar to the premium option, yet barrier options can still be granted at-the-money. That could mean that the stock price only had to exceed the barrier once, could subsequently fall again, and managers still had the right to exercise. Nonetheless, options with absolute hurdles still have better incentive effects than plain-vanilla at-the-money options (Johnson and Tian, 2000b). During the fiscal years 1999/2000, this performance condition was the most used one for German stock option plans (Winter, 2003).

Another way to include a hurdle is by granting an at-the-money option yet requiring that the stock price exceed some target price at exercise. This is commonly known as an absolute performance option and amounts to a portfolio of a plain-vanilla call option with an exercise price at the target price and a digital option that pays the difference between the share price at grant date and that target price.

\section{Relative Hurdles:}

Only focusing on whether a company's stock price rises above a certain threshold may not necessarily be indicative of "good" managerial effort. The increase may result from general market or sector trends and have absolutely nothing to do with how well the manager did. The literature refers to this as "pay for luck" and authors often call for "indexing" options in order to filter out such windfall profits (e.g., Rappaport, 1999). Two versions of this exist in practice. The first one basically works like an exchange option where the payoff is the difference between the benchmark index ${ }^{32}$ and the stock price. In other words, this option has a variable strike price. ${ }^{33}$ The second option uses an external barrier so that it only vests if and when the stock price outperforms the benchmark. This can be problematic in bear markets because the option will never vest, even if the stock price falls less than the benchmark. Despite this disadvantage, the barrier type has all but displaced the exchange-type options in Germany (Winter, 2003).

For the exchange-type option, Johnson and Tian (2000b) calculate that companies can give out almost three indexed options for every traditional at-the-money option when

32 This can be a general market index such as the DAX, a specific industry index, or a tailor-made index that includes close competitors.

33 It could be argued that this is not necessarily a vesting condition as the outperformance of the index does not constitute a barrier, but simply decides whether the option is in the money or not. For the purpose of this discussion, this technical difference shall be ignored. 
holding overall compensation constant. They also report that the delta of an indexed option is $93 \%$ higher and the vega is almost 4.3 times higher than those of an atthe-money option, making indexed options the strongest incentive- and risk-inducing instrument in their comparative study. ${ }^{34}$ Duan and Wei (2005) decompose the total risk measured by the volatility into the idiosyncratic and systematic part and then use GARCH option pricing models to analyze the respective effects. They find that, holding total risk constant, plain vanilla options become more valuable when systematic risk increases, whereas the opposite is true for indexed options. The authors argue that a mix of the two types could lead managers to choose effort to achieve the desired riskiness.

\section{Accounting-based Vesting:}

Finally, option vesting can be tied to some accounting figure, such as earnings per share, or the return on equity. This is, however, somewhat troublesome as managers have the opportunity to influence accounting results more than market results (Healy and Wahlen, 1999). Abernethy, Kuang, and Qin (2013) therefore consider accounting-based vesting conditions to be less challenging than market-based ones. Cronqvist and Fahlenbrach (2013) use a sample of firms that underwent a leveraged buyout financed by private equity companies and argue that these represent financially savvy principals. They find that those principals also do not use easily manipulated figures such as earnings as performance goals, but rather cash flows or stock prices. There is also some evidence, that performance-based vesting is a cause of accounting manipulation: Kuang (2008) shows that managers who receive performance-vested options are more likely to manage accruals so that it makes vesting more likely. Bettis et al. (2010) do not find such evidence in the U.S., yet they do find that company performance increases more when ESO have hurdles based on stock prices as opposed to accounting earnings. In Germany, accounting hurdles traditionally only played a smaller role for option vesting (Winter, 2003; Langmann, 2007).

Caps

ESO can also be equipped with caps which are supposed to prevent excessive pay for irregular, unforeseeable events. That is why the GCGC recommends using caps. From an optimal contracting point of view, the benefit of inclusion is, however, doubtful. First, optimal contracting does not mean that high pay is detrimental per se (Jensen and Murphy, 1990a). Second, caps introduce concavity into the payoff structure that

34 The incentive advantage of indexed options only holds as long as the options are not deeply out of the money (Johnson and Tian, 2000a). 
will reduce the PPS in the upper stock price areas. ${ }^{35}$ Nonetheless, caps are now included in roughly half of all ESO plans in Germany. ${ }^{36}$

\subsubsection{A Comparison of Stock Options and Stocks from an Optimal Contracting Position}

While stock options have been the subject of many studies, (restricted) stock as a form of compensation has long escaped similar scrutiny (Bryan et al., 2000). Most papers focus on the question of whether stocks or options can better align managers' and owners' interests and lead to better performance. Given that companies have different characteristics, such as size, available capital, business foci, and along with it, different requirements in managerial actions (Kole, 1997), and that managers differ in their wealth and risk aversion (Nohel and Todd, 2004), it is not likely that there will be only one optimal form of compensation. It may also explain why research results are often contradictory.

A possible starting point for any analysis could be the costs the company incurs when giving out stocks or options. As stated before, this is the opportunity cost of the instrument and since American call options can never be more valuable than the underlying stock (Hull, 2012), they are generally cheaper than stocks. Hall (1998) shows that replacing stock holdings by options with the same value almost doubles the pay for performance sensitivity for the median CEO.

One must, however, also recognize that executives often value options below the cost to the company because of the restrictions on trading and hedging. Companies will always incur the full fair value as an opportunity cost. When granting options, they also incur a "deadweight cost", that is the difference between the cost and the value assigned to it by the manager. ${ }^{37}$ Meulbroek (2001b) reports that undiversified managers value options at about $50 \%$ of their costs to the company. ${ }^{38}$ So to provide payment at or above

35 For annual bonus plans, Murphy and Jensen (2011) show that this can lead to too little risk-taking by the managers.

36 See Table 4.3 .

37 As pointed out before, the same holds true for restricted stocks.

38 A fully diversified manager of a large company values his or her options at up to $88 \%$ of market value. Hodge, Rajgopal, and Shevlin (2009) do not find such a deadweight cost for entry- or mid-level employees. In fact, they see stock options as more valuable than restricted stock grants with the same fair value. 
the manager's next best alternative, companies will have to grant more options than stocks. While Meulbroek's analysis ignores incentive effects of options, she concludes that options are likely not a cost efficient means of compensation.

Hall and Murphy (2002) use a certainty-equivalent approach and find that managers who have their wealth tied up in the company value options at only half of the fair value. Under the assumption that overall pay is fixed (i.e., higher equity-based compensation leads to reductions in cash and/or bonuses of the same value), restricted stocks will maximize incentive efforts. ${ }^{39}$ Options will only be chosen if grants are given on top of current compensation packages, in which case stocks are more expensive. ${ }^{40}$ Finally, they show that in this situation at-the-money options will yield high incentive efforts.

A similar result is obtained by Jenter (2002) who concludes from his model that because of the substantially reduced option value the manager sees and the fact that PPS overstates incentive effects of options due to a negative correlation with marginal utility, they are an inefficient means of compensation when compared with restricted stock. Feltham and $\mathrm{Wu}$ (2001) show in their model framework that when managers only influence the mean of the output, stocks dominate options. In the case that managers can also influence the operational risk, this is no longer the case and options can be optimal.

These studies, whose results naturally depend to a large degree on the model assumptions have been criticized by other authors. Lambert and Larcker (2003), for example, note that neither Meulbroek (2001b), nor Hall and Murphy (2002), nor Jenter (2002) specify a full equilibrium model, as they either exclude the full costs of the options or the value to the employee and the provided incentive effects. They go on to set up a full model that in contrast to Feltham and $\mathrm{Wu}$ (2001) also allows for stocks and options to be given simultaneously and more general forms of utility functions. That way they can show that stock options generally fare better than stocks. And not only that, they also show that premium options should be part of the optimal payment contract.

A similar conclusion is presented by Arnold and Gillenkirch (2007) who show that the assumptions made by Hall and Murphy (2002), Feltham and Wu (2001), and Jenter (2002) drive their results, as they all imply a concave compensation contract, which

39 Arnold and Gillenkirch (2007) point out that the maximum incentive level is not necessarily the optimal one.

40 See Lambert, Larcker, and Verrecchia (1991) for a discussion on how the portfolio effect impacts value and incentives of different executive compensation components. 
stocks approximate better than options. When limited liability on the part of the manager is introduced in the standard agency model, stock options dominate stocks in the optimal compensation contract (Arnold and Gillenkirch, 2007).

Dittmann and Maug (2007) also employ a standard agency model and then calibrate it with actual compensation data from U.S. listed companies. The predictions made by the model that CEOs should have lower base salaries, more stock and close to no options does not comport with reality. They are not able to explain real-world option holdings and raise the question whether they can be efficient and effective in an optimal contracting view. Dittmann, Maug, and Spalt (2010), however, include loss aversion on the part of the manager and in such a setting their agency model can explain the high base salaries and the large option holdings very well. This confirms earlier results by several other authors. Bryan et al. (2000) analyze compensation contracts for a large U.S. sample and find that restricted stocks do not provide sufficient incentives to managers to engage in risky positive net present value projects. Likewise, Dodonova and Khoroshilov (2006) argue that loss aversion is the critical characteristic that makes convex payment structures as provided by options necessary. Dittmann and Yu (2011) make a similar point by demonstrating that options serve to induce risk-taking behavior and not merely as effort incentives. For that purpose, options granted at the money are optimal. $^{41}$

A different approach to the comparison is undertaken by Irving, Landsman, and Lindsey (2011). They, like many others, note that restricted stocks have recently been becoming more relevant and they evaluate market reactions to the two instruments. Results show that markets seem to value stock option grants as intangible assets whereas they see restricted stock as a liability.

It should be noted that when giving options to managers who already have large stock holdings, they can undo some of the effects of options by selling off their previously owned shares. Therefore, the incentive effect will be higher for managers with low company ownership, unless there are selling restrictions on company shares (Ofek and Yermack, 2000). One negative aspect that both shares and options have in common is that high dependence of compensation on stock price has been found to be linked to higher earnings management (Bergstresser and Philippon, 2006).

41 This holds when taxes are included in the deliberations. Otherwise it would be optimal to use in-the-money options. 
All in all, research seems to point to the fact that options and especially well-designed options can have strong incentive effects that dominate those of restricted linear stock. It will be interesting to see if this verdict will change now that performance-vested stock presents an accepted non-linear alternative.

\subsection{The Pay Setting Process as an Extension of the Principal Agent Conflict}

Several authors have noted that actual payment practices appear to be incompatible with the optimal contracting idea. They argue that it cannot be assumed that the board of directors, or the supervisory board in two-tier systems, will automatically act in the shareholders' best interest. In fact, the board members are also representatives of the shareholders and this gives rise to another principal agent conflict (Bebchuk et al., 2002). Two rationalizations of equity-based pay, the managerial power approach and the perceived cost hypothesis, that are based on this consideration are explained in this section.

\subsubsection{The Managerial Power Approach}

The prevalence of stock options in executive compensation and the stark increase in overall pay in the 1990's, which has been driven mainly by stock options, has led many people to start questioning the validity of optimal contracting. Most notably, Bebchuk et al. (2002) argue based on observations of real-world pay packages that it cannot be the sole explanation. Under what they call the managerial power approach" ${ }^{42}$, "executives can receive pay in excess of the level that would be optimal for shareholders; this excess pay constitutes rents" (Bebchuk et al., 2002, p. 754). Unlike under optimal contracting where compensation contracts are supposed to reduce agency costs, the pay setting process itself is seen as an agency problem, since there is no reason to believe that directors are trying to maximize shareholder value. Inside directors report to the CEO anyway and might shy away from contradicting their superior; outside directors will most likely want to be reappointed to the board and thus need to be nominated by

42 Alternative names are skimming approach (Bertrand and Mullainathan, 2000) and managerial rent seeking (Hall and Murphy, 2003). 
the CEO. So rather than acting as a control mechanism, they might try to ingratiate themselves with the CEO who as a consequence might have significant influence over the board (Bebchuk and Fried, 2003).

The managerial power approach is not meant as an alternative explanation to optimal contracting but as an additional one. As the name suggests, a manager's ability to capture the pay setting process and extract higher rents hinges on his or her power. Bebchuk et al. (2002) identify five critical issues that contribute to that power: the extent to which managers are protected from takeovers (i.e., how entrenched they are), the relative strength and effectiveness of the board, how many shares a CEO owns, the number of institutional shareholders, and whether a strong blockholder is present. More generally speaking, weak corporate governance structures are conducive to managerial rent seeking (Bertrand and Mullainathan, 2000; Brown and Lee, 2010).

CEOs in firms that have adopted measures against takeovers have been receiving higher pay (Borokhovich, Brunarski, and Parrino, 1997). The reason for this is that antitakeover measures greatly contribute to managerial entrenchment (Bebchuk, Cohen, and Ferrell, 2009), which in turn enhances managerial power and the potential to obtain higher pay (Shleifer and Vishny, 1989).

Board effectiveness depends to a large degree on its size: Yermack (1996) finds that U.S. firms with larger boards are less valuable, which is attributed to wanting oversight by the board. The same relationship has been found for Finnish and U.K. firms (Eisenberg, Sundgren, and Wells, 1998; Ozkan, 2011, respectively). Overall, larger boards make efficient and effective communication harder, leading to free-rider problems (Lipton and Lorsch, 1992; Hermalin and Weisbach, 2003) that managers can exploit.

The board's strength is affected by how many outside board members there are. Jensen (1993) suggests that inside members also report to the CEO and therefore might not be willing to oppose him or her in board meetings. Moreover, the interconnectedness of all board members plays an important role, as other casual or business relationships might hinder effective control even by outside managers (Core, Holthausen, and Larcker, 1999). And it has even been shown that interlocked executives have received higher pay than those that did not sit on multiple boards (Schmidt, 2012). The more equity a CEO holds, the more power he accumulates and is therefore able to get his will (especially in pay negotiations or in suggesting future board members). This relationship has been confirmed by Cyert, Sok-Hyon, and Kumar (2002). 
Institutional investors have been found to act as monitors of executive pay. Hartzell and Starks (2003) find that the more concentrated ownership is in institutional investors, the higher the pay-for-performance sensitivity and the lower overall pay is. Finally, large blockholders also use their influence to closely monitor and limit executives' abilities to extract rent, which has been shown by Cyert et al. (2002), Bertrand and Mullainathan (2000), and, for Europe, by Sautner and Weber (2011).

In addition, managers control a large amount of the information flow that reaches the board. This includes, among other things, the recommendations made by compensation consultants. In general, the managers will have an information advantage over the directors that they can use during negotiations to increase their pay (Bebchuk et al., 2002).

Of course, even if managers are powerful, they cannot extract limitless rents. Compensation packages that are being perceived as too lavish could lead to "outrage" costs for the company (Bebchuk et al., 2002). This could be in the form of reputational repercussions or in shareholders voting against the wishes of the CEO in annual meetings (Bebchuk and Fried, 2003). Core, Guay, and Larcker (2008) find that the financial press reports negatively about excess pay and large options exercises and both Johnson, Porter, and Shackell-Dowell (1997) and Kuhnen and Niessen (2012) show that companies react to negative coverage of their remuneration packages. ${ }^{43}$ The former study shows that pay increases tended to be smaller after negative reactions in the media and the latter study shows that companies reduce the amount of that component of the pay package (i.e., stock options, stock, or fixed pay) that was criticized in favor of a different one; yet overall pay was not reduced. This hints at a central aspect of the managerial power approach: In order to avoid outrage, managers must aim to make rent extraction appear to be adequate pay and better yet, the outcome of optimal contracting, a process that Bebchuk et al. (2002) refer to as "camouflage". Options suit this purpose well for at least two reasons: first, their incentive effects are being used as an argument to justify granting them (Weisbach, 2007) and second, they do not make clear at granting what the manager will eventually receive, another aspect of camouflaging. ${ }^{44}$ Furthermore, accounting rules in the U.S. and many other countries contributed to the narrative that

${ }^{43}$ Surprisingly, Core et al. (2008) do not observe substantial reactions by companies to negative press releases.

${ }^{44}$ Other components of pay that fit this description are consulting contracts, retirement benefits, and deferred compensation, all subsumed under the phrase "stealth compensation" (Bebchuk and Fried, 2003, 2004). 
options were in fact not very costly to the companies or did not result in huge payouts; at-the-money options did not have to be expensed and seemed to be worth very little to outsiders (and possibly insiders as well) because of their intrinsic value of zero. ${ }^{45}$ Many real-life payment practices arguably contradict the optimal contracting idea, even when supposedly efficient options are used.

\subsubsection{Observed Compensation Contracts and Their Incompatibilities with Optimal Contracting}

Throughout their papers, Bebchuck, Fried and the occasional co-author argue that many of the observed compensation practices are incompatible with the optimal contracting idea. Some examples relating to equity-based compensation shall be presented here. ${ }^{46}$ Most of all, they decry the lacking pay-for-performance sensitivity in executive compensation, which encompasses the use of inadequate risk-sensitivities, the asymmetry of pay, and what Bebchuk and Fried (2006) call the one-size-fits-all approach. ${ }^{47}$

\section{Inadequate Pay-for-Performance Sensitivity}

A steady decline in PPS in the United States has already been reported by Jensen and Murphy (1990b) who investigated over 2,000 CEOs with a data-set spanning 50 years. They find that incentives from options are small and that stock holdings, which generate the largest incentives, are declining. ${ }^{48}$ Yermack (1995) uses a sample of CEO compensation for large U.S. firms for the years 1984 - 1991 and also concludes that options are not used in an efficient way. Among other things, the study reveals that stock options are neither used to align the interests of owners and managers, as executives should receive fewer options when their stock holdings increase, which is not the case in the sample. Additionally, Yermack finds no indication that options are used to reduce the agency costs created by issuing debt. Some companies try to increase PPS by simply granting more options, but Habib and Ljungqvist (2005) quantify the damage created by

45 See Chapter 3 for more on accounting for stock options.

46 A more complete analysis of payment practices, including non-equity-based payment forms, and how they contradict the optimal contracting idea can be found in Bebchuk and Fried (2006).

47 Besides these, they also bemoan the early unwinding of options and the use of reload options. Since these features are not relevant for the analyses in Chapters 4 and 5, they will not be discussed here. An elaboration can be found in Bebchuk and Fried (2006).

48 Jensen and Murphy's methodology has been criticized by, for example, Hall and Liebman (1998) for underestimating the sensitivity by relating CEO wealth changes to changes in firm value, not changes in stock prices. Nonetheless, their findings are still often cited as evidence of a decline in PPS. 
inefficient incentives and conclude that companies on average trade $\$ 1.4$ million below the market value they would have had, had investment decisions been optimal. This stems from the fact that the marginal utility generated by the last option is far outweighed by the cost of that option. Tian (2004) also shows that too many options can actually lead to negative incentives.

Asymmetry of Pay and Pay for Luck

Bebchuk and Fried (2006) argue that share prices may not be the best signal after all if there is no adjustment to market movements. A company may give out options that will eventually end up in the money simply because the market as a whole moves up. Therefore, the company incurs a cost to pay the manager for something that was not really his effort. This "pay for luck" has another effect that is directly related to options: because of the payoff structure managers are rewarded far more for good luck than they are punished for bad luck.

Bertrand and Mullainathan (2001) show that this does frequently occur and more so when corporate governance is not strong enough to prevent it, a result confirmed many times in the literature. ${ }^{49}$ The asymmetry has been quantified empirically by Garvey and Milbourn (2006). They study pay for performance against industry benchmarks and find that the loss from bad luck is up to $45 \%$ lower than windfalls from good luck.

Bebchuk and Fried call for indexing of options and the inclusion of performance conditions to remedy this problem. ${ }^{50}$ Especially the former has received a lot of attention by researchers. It is said to help filter out market effects beyond the managers control (Johnson and Tian, 2000a) and it can also make the option less costly to the company (Johnson and Tian, 2000b). In order to completely filter out market or sector influences, Meulbroek (2001a) suggests using a portfolio of company stock hedged against market influences.

Some of the benefits of performance vesting conditions have already been outlined above. Bertrand and Mullainathan (2001) argue that options contain a "gift element", since they will have a positive value that is due to the volatility of the stock, even when the manager remains inactive. Including performance hurdles would mean that the stock price must be raised above levels it achieves by chance. It is however important that they

\footnotetext{
${ }^{49}$ See, for example, Core, Guay, and Larcker (2003), Ozkan (2007), or Brown and Lee (2010).

${ }^{50}$ See also Section 2.2.2.2.
} 
are correctly specified. Recent evidence from the U.K. shows that powerful managers either avoid performance conditions (Qin, 2012) or only have weak or less challenging hurdles (Abernethy et al., 2013).

\section{One-Size-Fits-All Approach}

Under optimal contracting stock option design should take both company and manager characteristics into account. Empirical evidence, however, points to something else, namely very little differentiation between firms and executives. The most striking example is that most options are granted at the money (Hall and Murphy, 2003), although out-of-the-money options could increase PPS by 27\% (Hall, 1998). Others also find that executives in a firm by and large receive the same PPS in their compensation packages, regardless of their stock holdings (Jensen and Murphy, 1990b). Another puzzling finding is that within a company, executives often receive the same number of stock options, which contradicts the optimal contracting idea (Walker, 2011).

Bebchuk and Fried (2006) argue that the managerial power approach can explain this phenomenon best, as at-the-money options provide the best way to combine windfall profits with low outrage costs. Of course, in-the-money options would generate even higher rents, yet they would easily be perceived even by outsiders with little financial experience as not appropriate.

\subsubsection{Criticism of the Managerial Power Approach}

The general ability of the managerial power approach to explain the runaway use of stock options has been questioned by Murphy (2002) and Hall and Murphy (2003) who propose the low perceived cost of options as a better explanation (see the following section). Yet many of the observations that Bebchuk and Fried and their co-authors see as indications of managerial rent seeking, are actually seen by other authors as far less severe or in some cases even as positive. ${ }^{51}$ Core and Guay (2010) counter the main critique of low PPS by raising the point that looking at PPS alone will not yield meaningful insights about managerial rent extraction. They argue that PPS has to be evaluated in the context of the manager's risk aversion and, even more importantly, his overall wealth. A manager with relatively low personal wealth may be motivated

\footnotetext{
${ }^{51}$ In addition to the points discussed here, Edmans and Gabaix (2009) provide optimal contracting
} rationalizations on other issues, such as the overall level of pay or the use of debt instruments. 
more by a lower PPS than a manager who is already very wealthy. Moreover, when taking equity ownership among executives into account, incentives remain quite strong as overall wealth has become more sensitive in the more recent past (Core, Guay, and Thomas, 2005). In addition, Edmans, Gabaix, Sadzik, and Sannikov (2012) formulate a model that shows that PPS can be time-dependent so that low PPS is not necessarily a sign of rent seeking.

There is also evidence to suggest that the observed payment practices may be in line with the optimal contracting idea after all. Hall and Liebman (1998) show that options and stock grants lead to better firm performance and that especially increased use of options has strengthened pay for performance sensitivity. The relationship to higher profits has also been confirmed with newer data by Hanlon, Rajgopal, and Shevlin (2003) who also show that option grants are not related to poor corporate governance but to economic determinants. Core and Guay (1999) model optimal incentive grants and then analyze how subsequent grants are adapted to deviations from that model. They demonstrate that later grants are being used to correct for those deviations, which they take as a sign that companies follow the optimal contracting idea. Recent findings also reveal that pay-to-market-value ratios are comparable to that of the 1970 's ${ }^{52}$ and that monitoring by the board is going on, as evidenced by higher CEO dismissals when stock goes down (Kaplan, 2013).

Dittmann, Maug, and Spalt (2013) focus on the absence of indexing in equity-based payment forms. Their results indicate that indexing the strike price leads to only small improvements, but to large increases in costs to the companies. One negative side effect is the removal of the possibility of bad outcomes, whose avoidance usually motivate performance. ${ }^{53}$ Since the choice to position a company in a certain industry or market segment is a strategic one by the CEO, it can also be optimal to reward her if that sector does well (Gopalan, Milbourn, and Song, 2010). Empirically, it has been shown that even financially savvy principals do not rely on indexing of stock options (Cronqvist and Fahlenbrach, 2013).

Several authors have introduced other reasons for option grants besides incentives or risk taking. Oyer (2004), for example, shows that using broad based option plans without explicit incentive effects may be necessary when employees have outside job opportunities.

${ }^{52}$ Gabaix and Landier (2008) also attribute the rise in CEO pay to the increase in firm size.

53 Dittmann, Maug, and Zhang (2011) provide a further account of how restrictions on pay may have unintended negative consequences on incentives. 
This effect will be stronger when it is costly for firms to change existing compensation plans. Oyer and Schaefer (2005) conclude that options are too costly for the incentive effects they provide, but when retention and sorting effects are included, options become efficient again. Attracting talented employees is also given as an explanation by Conyon (2006), who in addition notes that boards and compensation committees have become more independent over time. Bizjak, Lemmon, and Naveen (2008) provide empirical evidence to the same fact; executive pay is set to be competitive in the market place as to retain talented CEOs. An evaluation of the literature in this area by Maug and Albrecht (2011) leads to the conclusion that attraction of talent is a much more successful explanation of rising wages than rent seeking.

Another explanation is provided by Fahlenbrach (2009) who finds that powerful managers have a higher pay-for-performance sensitivity, especially when corporate governance is weak. Compensation thus substitutes for other controlling mechanisms to achieve an alignment of goals between principals and agents.

Overall, it may be hard to come to a final verdict on the managerial power approach, especially since there is no accepted benchmark for what optimal pay actually is (Maug and Albrecht, 2011). Since Bebchuk et al. (2002) only claim that optimal contracting cannot be the sole rationale for current payment practices, it should be noted that the managerial power approach does at the very least have some explanatory power in the field of compensation design.

\subsubsection{The Perceived Cost Hypothesis}

Murphy (2002) and Hall and Murphy (2003) both argue that the managerial power approach cannot explain the widespread use of ESO for two reasons. First, increased bargaining power of managers may lead to higher overall pay, but that is not inefficient per se. ${ }^{54}$ Second, many companies have installed broad based plans that extend beyond the executive level (Core and Guay, 2001; Hochberg and Lindsey, 2010) and these recipients do not generally have the power to individually negotiate payment contracts with the board of directors. Plus, providing incentives to middle managers does not make much sense from an optimal contracting point since their actions will likely not influence overall company performance. Empirical evidence seems to support this last point:

\footnotetext{
${ }^{54}$ See also Jensen and Murphy (1990a).
} 
When companies reprice underwater options to provide incentives again, companies do tend to perform better afterwards. This effect only holds, though, for the repricing of executive options and not for employee options (Aboody, Johnson, and Kasznik, 2010).

Murphy (2002) assumes, like other authors, that recipients of ESO view them as highly risky and value them at less than their economic cost. As a consequence, they demand more options to be compensated for the risk they bear. Companies in turn view the costs of the options not as their economic costs but only-and incorrectly-as the accounting charges. Under APB 25, it was easy to set up options that did not lead to an accounting charge, simply by fixing the terms, such as exercise price, and granting options with an intrinsic value of zero. ${ }^{55}$ Murphy (2002) and Hall and Murphy (2003) refer to this as the perceived cost view: at-the-money options fulfill this description and are thus perceived as being rather inexpensive by shareholders. Moreover, this view can also explain why companies do not use indexed options. These would have a variable strike price and would lead to an accounting charge.

The problem lies in the fact that the shareholders and their representatives are incapable of correctly valuing the options according to economic theories. As Hall (2000, p. 112) notes: "Stock options are bafflingly complex financial instruments. [...] They tend to be poorly understood by both those who grant them and those who receive them." For employees, Farrell, Krische, and Sedatole (2011) demonstrate that the cognitively difficult task of option valuation is often reduced to heuristics. About three quarters of employees surveyed value options below their Black-Scholes values by resorting to simple "anchors" such as the intrinsic value. If shareholders fall victim to the same bias, they will end up granting too many options with unfavorable characteristics because they believe them to be cheaper than they actually are. As the new accounting standards in the U.S. and in Germany will require expensing options at their fair value and not their intrinsic value, the wide-spread use should be curtailed (Hall and Murphy, 2003).

The power of the perceived cost hypothesis to explain broad-based option plans is seen with reservation in the literature. Oyer and Schaefer (2006), for example, refute the notion that accounting rules are the main driver because the very real economic costs to a firm are too substantial to be ignored. Powerful shareholders would simply stop that practice and reap the benefits. The authors argue that options are used to provide incentives, especially when employees are optimistic about future stock performance.

55 See Chapter 3. 
Employee optimism as a driver behind the use of broad-based ESO plans is also an explanation given by Bergman and Jenter (2007) who show that employees often value options based on previous payoffs and thus prefer them when past stock price performance leads them to be (overly) optimistic about future performance.

In Finland, where neither tax nor accounting considerations favor a certain type of option, companies grant options to larger groups of employees after poor performances and when monitoring costs are high. In addition, they grant options that are more out of the money in those situations (Liljeblom, Pasternack, and Rosenberg, 2011). Both facts speak for the optimal contracting view ${ }^{56}$ and against the perceived cost hypothesis. Whether new accounting rules will then impact the use of options in Germany, will be investigated in Chapter 4.

\subsubsection{The Role of Transparency and Disclosure}

For the three rationales presented above there are different expectations about the impact of more transparency when it comes to equity-based compensation. The new accounting standards IFRS 2 and SFAS 123R not only require firms to disclose detailed descriptions about the payment plans, they also mandate that all forms of equity-based compensation are expensed at their fair value and that the valuation itself will be disclosed, along with several important input parameters.

Under optimal contracting, negotiations are made at arm's length and both parties are aware of how the other values the contract; it is assumed to be common knowledge. The additional information provided in accounting statements therefore only serves to inform third parties, but should not impact the negotiations or their outcome. Therefore, if equity instruments are being used for optimal contracting reasons, there should be no alteration after the introduction of the new rules. ${ }^{57}$

For the managerial power approach, the implications are different. It is argued that managers specifically prefer at-the-money options to extract rents, since their value is not disclosed to the public or the principals. So if that value were disclosed, one would

\footnotetext{
56 The authors acknowledge that the fact that options tend to be more at- or in-the-money after periods of good performance could also be due to managers using good past performance during pay negotiations to prevent any sort of performance hurdle. This would indicate rent seeking.

57 See, for example, Hayes et al. (2012) for a similar argument.
} 
expect a reduction in the use of stock options and as a consequence a reduction in rent seeking. On the other hand, increased disclosure means that managers will have to find other ways to camouflage rents and it has already been shown that higher disclosure can lead to information distortion by managers (Hermalin and Weisbach, 2012). Even with higher transparency, powerful managers may not fully comply with standards and it depends on further firm characteristics, especially the corporate governance (Nelson, Gallery, and Percy, 2010). Nonetheless, disclosure will be necessary to curtail excessive rents, because "[i]n executive compensation [..] the ability of plan designers to choose arrangements that favor managers depends on how these arrangements are perceived by a much wider group of outsiders. As a result, the transparency and salience of disclosure can have a significant effect on CEO compensation" (Bebchuk and Fried, 2003, p. 76).

The perceived cost hypothesis is based on the idea that accounting rules drove much of what could be observed in equity-based compensation. The new disclosure rules put the economic cost front and center and will reveal the error that companies have made in assessing them as inexpensive. It is to be expected that companies will scale back their ESO plans markedly.

It should be noted that the effect of higher disclosure may not be so straightforward that it will definitely lead to a reduction in overall pay. First of all, higher disclosure requirements also entail higher costs in that more effort is required to comply with them. Managers will expect to be compensated for that (Hermalin and Weisbach, 2012). In addition, higher transparency also makes it possible to compare executive pay with relevant peers, so that managers can claim to be underpaid relative to said peers. There is some evidence that this is one reason for the rise in executive pay (e.g., Schmidt, 2012; Faulkender and Yang, 2013). These results are, however, in some dispute, as other papers argue that the increased transparency makes it easier to assess current market values of salaries necessary to attract and retain talented executives (Bizjak et al., 2008; Bizjak, Lemmon, and Nguyen, 2011).

Chapter 4 will explore if and how the new accounting rules influence the use of equitybased pay in Germany, while Chapter 5 will investigate whether companies fully comply with the disclosure requirements or if they bias option values in order to camouflage rent extraction. 


\section{Accounting for Equity-Based Compensation}

This chapter will outline the relevant accounting rules in the United States and in Germany. It will provide not only the juxtaposition of the two developments over time, but also a reasoning for why the questions addressed in Chapters 4 and 5 are analyzed with German data.

\subsection{US-GAAP}

Stock options have a longer history in the United States of America than in Germany. Consequently, U.S. generally accepted accounting principles (GAAP) have addressed the issue of accounting for equity-based compensation contracts, or more specifically stock options, earlier and more directly. Nonetheless, these standards have not been free from controversy or debate. Both will be depicted in this section.

\subsubsection{Accounting Principles Board Opinion No. 25}

Under Accounting Principles Board Opinion No. 25, issued in 1972, the main guideline was to recognize equity instruments at their intrinsic values, that is the difference between the quoted market price and the amount that the employee is required to pay, if any. Moreover, the opinion specifies the measurement date as the date at which both the actual number of instruments that the employee will receive and the eventual price to be paid are known. Should no market price be available, the company has to provide its "best estimate" for determining the compensation cost (Accounting Principles Board, 1972).

Accounting for stocks of a publicly listed company is straightforward under these principles. If the number of shares an employee receives as compensation is fixed, the measurement date will be the grant date and since no payment has to be made to the 
company for such a plan, the intrinsic value of a stock is the quoted market price. Consequently, companies will always incur a cost for compensating with stocks, even if they are time-vested, for the parameters in that case are still fixed.

The same principle holds for stock options, yet these instruments can have several design elements that could lead to a different accounting result. First and foremost, employees have to pay an exercise price that reduces the intrinsic value. If the option were at the money at grant date, the intrinsic value would be zero and thus no accounting charge would have to be made. Issuing in-the-money options with a positive intrinsic value, on the other hand, would require that that value be charged as an expense, thereby making such an option more costly. Companies could also choose to equip options with relative or absolute performance goals, but that would mean that at grant date neither the number of options that actually vest nor (in some cases) the exercise price of the option would be known. In this situation, companies had to estimate both the eventual market price and the exercise price (if it is also variable) and accrue the estimated cost ratably over the service period. If this value changed before the option was exercised, the cost would have to be adjusted (Accounting Principles Board, 1972; Wollmert and Hey, 2002). Plain-vanilla at-the-money options thus receive a preferential treatment in that they do not result in any accounting charge. This has been cited by many as the primary driver behind the massive expansion of option usage in the United States. ${ }^{58}$

Performance shares can be thought of as restricted stock with a performance condition and therefore the number of instruments that vest cannot be known at grant date. Because of that, their usage would have resulted in an accounting expense under APB 25. These different treatments resulted in several institutions, including the Securities and Exchange Commission (SEC) and several accounting firms, petitioning the Financial Accounting Standards Board for clearer guidelines (Financial Accounting Standards Board, 1995). Statement of Financial Accounting Standards 123 was finally issued in 1995. It is discussed in the next section.

\subsubsection{SFAS 123}

The overall goal of the deliberations was to abolish the intrinsic value method and replace it with the fair value method for all equity-based instruments. In addition, the

58 See, for example, Hall and Murphy (2003). 
grant date was supposed to be established as the date of measurement for both variable and fixed plans. However, lobbying against fair value accounting was so intense, in part because it was feared that mandatory expensing would hurt small and medium enterprises, that the Financial Accounting Standards Board finally issued a less strict standard (Johnston, 2006). It even specifically referred to the controversial nature of the topic as a primary reason for the more lenient standard in the appendix of SFAS 123. While the standard does encourage expensing options at their fair value, it also gives companies a choice between that approach and continued application of the intrinsic value method according to APB 25. SFAS 123 did not change the accounting for costs arising from restricted stocks: the fair value remains the quoted market price, which is directly observable and equal to the intrinsic value of the stock.

For companies deciding to keep the intrinsic value method, however, SFAS 123 required a pro forma income statement to be added to the notes of the annual reports, showing what net income would have been, had stock options been expensed. Moreover, it outlined a list of supplemental information that had to be disclosed by all companies in order for readers of the financial statements to be able to understand how the fair value had been calculated. This list included a detailed description of the equity-based plans with all vesting conditions and maximum terms. More importantly, there was added transparency as firms also had to disclose the model used for calculating the fair value along with major assumptions such as the risk-free rate, expected option life, expected volatility, and expected dividends ${ }^{59}$ (Financial Accounting Standards Board, 1995). So not only could investors now see how much the options a manager received were worth, it was also possible to see if that value had been calculated correctly, albeit only approximately so. Nevertheless, all pertinent information was available from the financial statements.

SFAS 123 included another departure from practices under APB 25. While the fair value for a stock option plan that was to be settled with equity had to be accrued ratably over the service period without later adjustment to the fair value, fair values of plans settled with cash were to be recalculated every year until the options are either exercised or forfeited worthless.

The standard did not directly address the issue of performance shares. It did, however, state that the above mentioned disclosures had to be made for a stock-option "or its

59 The standard also addresses how these input parameters should be determined. Since IFRS 2 lays out virtually the same guidelines, this issue will be covered in Section 3.2.2. 
equivalent" (Financial Accounting Standards Board, 1995, §19). As Larcker (1983) points out, performance share plans are "option-like" instruments. Hence, there was no reason to treat them any different than options.

Notwithstanding all the changes made by SFAS 123, companies were still permitted to apply the intrinsic value method and therefore continued the preferential treatment of at-the-money options. The FASB itself noted that a disclosure-based rule would likely not achieve all the goals intended by a recognition-based rule. The companies' verdict on the issue was also very clear: both Carter et al. (2007) and Hayes et al. (2012) report that only small numbers of firms chose to voluntarily expense stock options. This choice was revoked in 2004 when the revised version SFAS 123r was issued.

\subsubsection{SFAS 123r}

SFAS 123r took effect for reporting periods beginning after June 15, 2005 and mandated the fair value accounting method for all equity-based compensation forms (Financial Accounting Standards Board, 2004), finally ending the preferential treatment given to plain vanilla stock option. As Bettis et al. (2010) note, performance shares or performance vesting in general have been gaining acceptance in executive compensation, which could be a potential consequence of the new accounting rule. ${ }^{60}$

The revision of the standard brought with it another alteration, namely the distinction between several exercising conditions. They are broadly clustered into service conditions (recipients of equity instruments having to remain employees of the company for a certain time), performance conditions (instruments can only be exercised when certain benchmarks based on accounting figures (e.g., EBITDA) are exceeded), and market conditions (instruments can only be exercised when certain benchmarks based on stock prices (e.g., TSR) are exceeded). The first two are not reflected in the fair value but in the number of instruments expected to vest. Only market conditions are to be taken into account when calculating the fair value, which has implications for performance shares. Paragraph 240 e of SFAS 123r states that the input parameters relevant to calculating or estimating the fair value of "share-based compensation awards" (i.e., options and performance shares) have to be given. If a performance share is designed with a performance condition, which is not reflected in the fair value, its fair value becomes

60 This issue will be examined in Chapter 4 . 
the quoted market price of a common share of stock (Financial Accounting Standards Board, 2004). Put differently, if the exercise condition of a performance share is based on an accounting figure and not a market figure, SFAS 123r will treat a performance share like a regular share, irrespective of its option-like features. In addition, the performance condition has an impact on the number of performance shares expected to vest, yet there is no procedure detailing how to make such an estimate. As a consequence, managers have at their disposal an instrument that behaves like an option, but is less transparent and therefore better able to help camouflage the actual level of compensation.

\subsubsection{On the question of disclosure versus recognition}

Apart from the added distinction between market and performance condition, the major change brought about by SFAS 123r was that it ended the application of the choice for the intrinsic value method. The FASB had already intended to take that step when it first issued SFAS 123 in 1995, yet it had to bow to outside pressure (Financial Accounting Standards Board, 1995). In the previous version of the standard, the board did note, however, that it did not believe mere disclosure to be an adequate substitute of recognition. A different point of view suggests that the disclosed information reduces information asymmetry between corporate insiders and other market participants ${ }^{61}$, thereby making recognition unnecessary. This is an issue that has been extensively discussed in academic literature.

Lew and Schirger (1994) called for stock options to be expensed as early as 1994. They recommend treating all kinds of options (variable and fixed) the same by expensing them like contingencies, which would include adjustments of the value until the option is exercised. Bodie et al. (2003) maintain that regardless of settlement, stock options represent a (sometimes substantial) opportunity cost to companies that could sell such options on the market. In addition, Kaplan and Palepu (2003) argue that fair value expensing would adhere to fundamental accounting principles of matching expenses with the associated revenues and Guay, Kothari, and Sloan (2003) claim that investors pay more attention to reported earnings and not enough to supplemental information in the notes. Empirical evidence on this issue is mixed. Some sources say that the information is correctly incorporated by investors into their company assessments (Aboody, 1996;

${ }^{61}$ See, for example, Healy and Palepu (2001) for an extensive discussion of information asymmetry and empirical disclosure literature. 
Aboody, Barth, and Kasznik, 2004b; Bell, Landsman, Miller, and Shu, 2002), while others argue that the focus is more on accounting earnings (Hand, 1990) or that disclosure is not an adequate substitute for recognition of option values (e.g., Espahbodi, Espahbodi, Rezaee, and Tehranian, 2002). Subramaniam and Tsay (2012) report negative market reactions around the announcement of mandatory option expensing in Canada even though firms previously disclosed information. They conclude that disclosed information has not been correctly impounded by market participants. Feng and Tian (2009) argue that recognition leads to a perceived loss even though it does not yield any incremental information. In fact, Barth, Clinch, and Shibanio (2003) posit that understanding and processing information that is merely disclosed as opposed to recognized in accounting earnings is costly. Limited attention and processing power on the part of the financial statement user may also lead to a wrong assessment of disclosed values, which could in turn lead to incorrect stock valuations (Hirshleifer and Teoh, 2003). And finally, experimental research also shows that markets react more strongly to recognized items than to those that are only disclosed (Bloomfield and Libby, 1996).

Debate over the issue extends to further areas besides stock options. Retiree benefits other than pensions are one example. Markets assign them more weight in valuations when they are recognized and not just disclosed (Davis-Friday, Folami, Chao-Shin, and Mittelstaedt, 1999) and also see them as more reliable in that case (Davis-Friday, ChaoShin, and Mittelstaedt, 2004).

Although it seems that the results favor the view that there is a difference between disclosure and recognition, the issue is not clearly resolved. More importantly, it is not clear what the effect of the ten-year transitional period in the United States had on the choice of compensation instrument. If accounting does lead companies to opt for stock options, they may have gradually adjusted their compensation packages long before the passage of SFAS 123r. Choudharay, Rajgopal, and Venkatachalam (2009), for example, show that a lot of companies accelerated vesting of existing options just prior to the implementation of SFAS 123r, most likely to avoid having to expense them. Naturally, more companies could have done so even earlier.

Previous studies seem to indicate that the change in accounting standards has had an effect on equity-based compensation in the U.S. ${ }^{62}$ If the reported changes are however solely due to the new accounting rules, is questionable. The long time period between

62 See Section 4.2 for a more detailed discussion. 
the no-expense and the full-expense regime gave companies a chance to adapt their pay packages. Whether or not accounting standards really influence the choice of equitybased instrument, can be much better tested in a setting where the change is immediate and reactions are concentrated on or at least around one particular point in time.

It is equally unclear if the results from the U.S. can be transferred to other countries where the practice of using stock options has been different. Since German companies have long availed themselves of more complex performance-vested options, it is conceivable that they have been engaging in optimal contracting all along and were not as much influenced by the accounting rules. In such a scenario, there will likely be no pronounced reaction to the new accounting regime, because all types of options have been treated equally before and after the change.

In other words, the situation in Germany enables first of all testing if the observed changes in payment practices in the U.S. are really caused by the move to a full-expense regime (as opposed to a differential treatment of different kinds of options) and if so, whether the reactions will also occur in other countries. The next section will outline the accounting rules as they are in Germany and how this enables even further investigations.

\subsection{German Accounting Rules}

Unlike in the United States, German accounting rules have only recently begun to deal with the issue of accounting for equity-based compensation, probably because, historically speaking, this has not been a relevant topic. Therefore, several issues have been very ambiguous and a matter for debate, both in academic literature and in jurisprudence. This development will be expounded in this section.

\subsubsection{German Commercial Code}

The German Commercial Code (Handelsgesetzbuch, GCC) did not explicitly address the question of whether or not stock options settled with equity had to be expensed and so diverging opinions can be found in the literature. Naumann (1998), for example, argues that equity settlements represent a cost to current shareholders only and not to the company itself. Therefore it should not be recorded as a cost in the income 
statement. Herzig (1999) and Vater (2000) offer concurring opinions in cases where the equity used for settlement stems from a conditional capital increase under the same reasoning: associated costs are incurred by the shareholders.

Pellens and Crasselt (1998a) and Pellens and Crasselt (1998b) disagree and argue in favor of expensing. They concede the legal loophole in the GCC, yet they posit that the whole notion of accounting for stock options needs to be reevaluated. Only since the introduction of the KonTraG in 1998 has granting stock options been available for companies and therefore the issue had not received all that much attention. Moreover, they argue that there already is a precedent in German GAAP, as warrant bonds ( $O p$ tionsanleihen) have to be expensed as well. Consequently, they recommend application of the fair value method according to SFAS 123, but without the possibility of using the intrinsic value method.

In his comparison of Naumann (1998) and Pellens and Crasselt (1998b), Rammert (1998) concludes that German law would at the most allow for supplemental information in the notes of the financial statements, yet not full expensing of the costs.

Regardless of those arguments, it was common practice not to record an accounting charge for stock options (when settled with equity). This view has recently been supported by the German Federal Fiscal Court in a verdict in 2010 (docket number I R 103/09), which ruled against a company that had expensed stock options in order to reduce its tax liability.

The GCC has always made an explicit mention of how to deal with virtual stock options, which are settled with cash. Since these do represent a cash outflow to the company, such stock appreciation rights have to be expensed (Knoll, 1998). It is unclear, though, whether the accounting charge should be based on the intrinsic value or the fair value. Pellens and Crasselt (2002), for instance, argue in favor of the latter, yet concede that that is not a settled issue.

While there is no reference to time-vested restricted stock (units) or performance shares (units), it seems only logical that an equivalent argument can be made, distinguishing between no recognition when the instruments are settled with equity and recognizing an expense when the instruments are settled with cash. All in all this means that the GCC is tantamount to a no-charge regime. 


\subsubsection{IFRS 2}

In 2005 International Financial Reporting Standard 2 took effect, which is very similar to SFAS 123r. It also requires expensing of all equity instruments at their fair value, yet there is one important difference: It only requires disclosure of valuation parameters (e.g., option pricing model, expected volatility, etc.) for "share options" which are defined as:

"A contract that gives the holder the right, but not the obligation, to subscribe to the entity's shares at a fixed or determinable price for a specified period of time." 63

So technically the information does not even have to be provided for virtual stock options. And it does also not apply to performance shares for which $\S 47(\mathrm{~b})$ is applicable, which states that the minimum disclosures are

"for other equity instruments granted during the period (ie other than share options), the number and weighted average fair value of those equity instruments at the measurement date, and how the fair value was measured, including:

(i) if fair value was not measured on the basis of an observable market price, how it was determined;

(ii) whether and how expected dividends were incorporated into the measurement of fair value; and

(iii) whether and how any other features of the equity instrument granted were incorporated into the measurement of fair value." ${ }^{64}$

IFRS 2 makes the same distinction between service and performance conditions on the one hand, and market conditions on the other hand that SFAS 123r makes: only the latter are incorporated into the fair value estimation. However, given that performance shares are non-traded option-like instruments, it is not sufficient to use the market value of traded shares as the fair value of a performance share (Holden and Kim, 2012); their fair value has to be determined by means of a valuation model anyway ${ }^{65}$. Yet even with

63 International Accounting Standards Board (2004, A113).

64 Ibid. p. A107

65 Such valuation models have recently been proposed by Holden and Kim (2012) and Bizjak et al. (2012). 
the distinction of the different vesting conditions, IFRS 2 does not provide any situation in which valuation parameters (with the exception of dividends) have to be disclosed. So although the fair value of performance shares has to be expensed, the requirements for disclosure of the valuation itself are lower than for share options, obfuscation of the procedure becomes easier. This lower transparency standard is crucial in order to camouflage excessive pay and leads to the supposition that MPA-companies will opt for these instruments. ${ }^{66}$

In appendix B, IFRS 2 also lists the minimum input parameters for option pricing models that have to be disclosed as well. Out of these, the price of the underlying share and the exercise price receive no further explanation, as they are assumed to be observable in the market or stated in the option contract. Contrarily, the standard contains detailed instructions on how to determine the interest rate, dividend yield, volatility of the underlying, and the expected life of the option.

The risk-free interest rate is supposed to be derived from using the implied yield of a government zero bond. The time to maturity of that bond should be equal to the contractual option life, but companies may take factors leading to early exercise into account. For the dividend yield, it first has to be established whether the employees who receive stock options are entitled to dividend payments or not. If the former is the case, dividends are no longer an issue. If, however, options are not adjusted for dividends, the company has to estimate the dividend yield (or the level of the dividend, depending on which valuation model it chooses), by relying on both historical patterns of, for instance, dividend increases as well as expected dividend payments in the future. In either case, it must only use publicly available information. The expected volatility is the annualized standard deviation of the underlying stock, based on the continuously compounded rate of return. In calculating the expected volatility, companies should use implied volatilities from traded options similar to the ones granted as payment, or, if those are not available, historical volatility for a period corresponding to the remaining expected option life. It can also incorporate any mean-reverting properties of volatility in the estimation, which would allow companies to disregard periods that were abnormally volatile, even though they have to use consistent periods and price observations per period. Finally, IFRS 2 details how the expected early exercise (i.e., the expected option life) can be estimated. It recognizes that employees oftentimes do not hold options until maturity and therefore stipulates certain conditions that are to be taken into account. First of all, the expected

66 Cf. Chapter 4 
life may not be shorter than the vesting period, as exercise of options is generally not possible then. Moreover, the moneyness of the option and volatility of the stock may induce early exercise and are therefore also relevant to the determination of expected life. And lastly, companies are allowed to consider previous exercise behavior of similar options.

\subsection{Comparison of Accounting for Equity-Based Compensation in the United States and Germany}

It is the stated goal of the FASB and the IASB to achieve a convergence of accounting standards in the United States and the "IFRS-world" and as such there are only minor differences left between SFAS 123r and IFRS 2. Both now require fair value accounting for all forms of equity-based pay and have made that valuation more transparent, especially in the case of options. Having to state the valuation model, detailed plan design elements, and the most important valuation parameters, allows readers of financial statements to at least approximately gauge whether the fair values are legitimate. The standards do, however, still treat instruments other than share options or stock (i.e., performance shares) differently by not extending the transparency requirements to them. Under US-GAAP the exercise condition is a critical element. If it is a performance or service condition, performance shares are treated as regular restricted stock for accounting purposes. That means the quoted market price of common stock will serve as the cost of such an instrument. If the performance share has a market condition, it is treated as a stock option, including all requirements for disclosure. IFRS 2, on the other hand, has no scenario in which companies have an obligation to disclose valuation parameters. It is sufficient to report the valuation method and whether or not dividends have been included in the valuation.

This distinction in the treatment of performance shares allows for a farther-reaching analysis than has previously been carried out in U.S.-based studies. Not only does the immediate transition between the two regimes enable a clearer identification of the influence of the accounting standard, this differential treatment also makes it possible to predict reactions based on what the latent rationale for granting stock options is. 
The lower transparency and non-linear payoff profile of performance shares make them the ideal instrument for any rent-seeking manager. Hence, the differential treatment can be used to gain more insight into how the accounting change does affect the use of equity-based compensation with the help of the three major theories. Since both Bebchuk et al. (2002) and Murphy (2002) doubt that the others' theory is valid, it is of particular interest to test them simultaneously and thereby add to the discussion on what impacts the choice of equity-based instruments.

Moreover, the fact that there was equal treatment of all ESO in Germany before the introduction and afterwards, any changes that occur can be more directly traced back to the effects of the new standard, namely transparency and expensing. The fact that besides that the differential treatment of options in the U.S. has been simultaneously revoked, does not impact the results in Germany. This also has a bearing on the question of underreporting/undervaluing options in the financial statements. Since performancevested options have a longer history in Germany, any underreporting will likely not stem from an unfamiliarity with those instruments, as might potentially be the case in the U.S.

An overview of the different accounting rules is provided in Table 3.1. A discussion of more subtle differences between the two standards, regarding among others forfeiture, can be found in Silliman (2005). 
Table 3.1: Comparison of accounting regimes in the U.S. and Germany

\section{Instruments}

\begin{tabular}{|c|c|c|c|c|c|}
\hline & $\begin{array}{l}\text { Before } 1995 \\
\text { APB } 25\end{array}$ & $\begin{array}{l}1995-2005 \\
\text { SFAS } 132\end{array}$ & $\begin{array}{l}\text { Since } 2005 \\
\text { SFAS } 123 \mathrm{r}\end{array}$ & $\begin{array}{l}\text { Before } 2005 \\
\text { GCC }\end{array}$ & $\begin{array}{l}\text { Since } 2005 \\
\text { IFRS } 2\end{array}$ \\
\hline $\begin{array}{l}\text { Restricted Stocks } \\
\text { (Nonvested Stocks) }\end{array}$ & $\begin{array}{l}\text { intrinsic value } \\
\Rightarrow \text { stock price }\end{array}$ & stock price & $\begin{array}{l}\text { fair value } \\
\Rightarrow \text { stock price }\end{array}$ & - & $\begin{array}{l}\text { fair value } \\
\Rightarrow \text { stock price }\end{array}$ \\
\hline $\begin{array}{l}\text { Restricted Stock Units } \\
\text { (Phantom Stocks) }\end{array}$ & $\begin{array}{l}\text { intrinsic value } \\
\Rightarrow \text { stock price }\end{array}$ & stock price & $\begin{array}{l}\text { fair value } \\
\Rightarrow \text { stock price }\end{array}$ & - & $\begin{array}{l}\text { fair value } \\
\Rightarrow \text { stock price }\end{array}$ \\
\hline Stock Options & $\begin{array}{l}\text { intrinsic value } \\
\Rightarrow \text { usually } 0\end{array}$ & $\begin{array}{l}\text { intrinsic value } \\
\text { or fair value }\end{array}$ & $\begin{array}{l}\text { fair value } \\
+ \text { parameters }\end{array}$ & no expense & $\begin{array}{l}\text { fair value } \\
+ \text { parameters }\end{array}$ \\
\hline $\begin{array}{l}\text { Virtual Stock Options } \\
\text { (Stock Appreciation Rights) }\end{array}$ & $\begin{array}{l}\text { intrinsic value } \\
\Rightarrow \text { usually } 0\end{array}$ & $\begin{array}{l}\text { intrinsic value } \\
\text { or fair value }\end{array}$ & $\begin{array}{l}\text { fair value } \\
+ \text { parameters }\end{array}$ & expensing $^{\dagger}$ & $\begin{array}{l}\text { fair value } \\
+ \text { parameters }\end{array}$ \\
\hline Performance Shares & $\begin{array}{l}\text { intrinsic value* } \\
\Rightarrow \text { stock price }\end{array}$ & $\begin{array}{l}\text { intrinsic value } \\
\text { or fair value }\end{array}$ & $\begin{array}{l}\text { w/ market cond.: } \\
\text { fair value } \\
\text { +parameters } \\
\text { else: stock price }\end{array}$ & - & $\begin{array}{l}\text { fair value } \\
\text { no parameters }{ }^{\ddagger}\end{array}$ \\
\hline Performance Share Units & $\begin{array}{l}\text { intrinsic value* } \\
\Rightarrow \text { stock price }\end{array}$ & $\begin{array}{l}\text { intrinsic value } \\
\text { or fair value }\end{array}$ & $\begin{array}{l}\mathrm{w} / \text { market cond.: } \\
\text { fair value } \\
\text { +parameters } \\
\text { else: stock price }\end{array}$ & - & $\begin{array}{l}\text { fair value } \\
\text { no parameters } \ddagger\end{array}$ \\
\hline
\end{tabular}

This table juxtaposes the timeline of the accounting changes in the United States and in Germany. It shows the transitional period in the United States that has not occurred in Germany where the change was immediate. In this period SFAS 123 allowed the continued application of APB 25 and fair values, pro forma income statements, and parameter estimates only had to be included in the notes.

* APB 25 requires that the number of instruments expected to vest be estimated and, if necessary, adjusted over the service period or until settlement.

$\dagger$ No mentioning of how to determine the value.

¥ No parameters have to be given for instruments that are not "share options", regardless of whether they have market conditions or not. 


\subsection{Enforcement and Corporate Governance in Germany in Comparison to the U.S.}

Financial reporting outcomes depend on more than just the standards: institutional and economic factors and backgrounds have a significant impact on reporting outcomes as well (Holthausen, 2009). Germany offers an institutional environment that is different in many ways from that of previous studies based on U.S. data, yet has certain similarities that allow for an interesting comparison. While Germany is comparable to the U.S. in that it has similar agency problems brought about by the separation of ownership and management (Elston and Goldberg, 2003), it has traditionally been characterized as a country with week enforcement standards by several studies: La Porta, Lopez-DeSilanes, Shleifer, and Vishny (1997) explain that civil law countries have traditionally weaker investor protection and narrower capital markets. In a further study, Germany has been ranked only as average in terms of efficiency of the judicial system and shareholder rights (La Porta, Lopez-de Silanes, Shleifer, and Vishny, 1998). Leuz, Nanda, and Wysocki (2003) find that strong investor protection curtails earnings management by executives, yet assign Germany weaker ranks than, for example, Anglo-Saxon countries. Building on the work by La Porta et al. (1998), Hope (2003) constructs an overall enforcement variable and likewise finds lower quality in this respect in Germany. Finally, La Porta, Lopez-De-Silanes, and Shleifer (2006) consistently rank Germany as below average on indicators such as disclosure requirements, liability standards, and public enforcement. The detrimental effect of those low enforcement and control mechanisms on executive compensation has already been documented by Kaserer and Wagner (2004).

Around the introduction of the international financial reporting standards, however, Germany has taken steps to reform the enforcement process ${ }^{67}$. The most important building block of these reforms was the establishment of a two-tier reporting enforcement system, comprised of the private body Financial Reporting Enforcement Panel (DPR - Deutsche Prüfstelle für Rechnungslegung e. $V$.) and the governmental institution Federal Financial Supervisory Authority (BaFin - Bundesanstalt für Finanzdienstleistungsaufsicht). The DPR investigates financial reports based on random sampling and on special request if wrongdoing is suspected. Upon detection of any infraction, companies are given a choice of concurring with the report or rejecting it. If they reject the DPR verdict

67 A more detailed overview of the reforms and their economic consequences can be found in Ernstberger, Stich, and Vogler (2012). 
or refuse to cooperate, the investigation will be handed over to the BaFin, which as a governmental institution has farther reaching authority. Ultimately, it has the power to publish its findings in the national registry (Bundesanzeiger). Research shows that this 'name and shame' principle is followed by negative market reactions, indicating that capital markets exert punishment on the company (Hitz, Ernstberger, and Stich, 2012). Overall, these reforms have risen the level of enforcement above what had previously been observed, reducing the extent of, for example, earnings management, yet failing to achieve rigorous standards maintained in the United States (Ernstberger et al., 2012).

The impact of country characteristics on companies' corporate governance is well documented in the literature ${ }^{68}$ and so it is no surprise that differences exist between U.S. and German companies. Most notably, German listed companies are required to have a two-tier board system with a supervisory board (Aufsichtsrat) and a management board (Vorstand). The latter is charged with running day-to-day operative business, while the supervisory board hires and fires managers and, among other things, sets their pay. Depending on company size, shareholders elect between half and two thirds of the supervisory board members, while the rest is made up of employee representatives. In difference to the U.S. executives cannot also hold a seat on the supervisory board, making all members of the supervisory board 'outside directors'. It is, however, common for CEOs to transfer to the supervisory board upon retirement, which has been shown to lead to a hidden cost as they have a tendency to raise their former colleagues' pay (Andres, Fernau, and Theissen, 2012). Furthermore, executives frequently sit on supervisory boards of other companies. This leads to an interconnectedness of managers/directors that has in the past led to an increase in compensation, caused by the insider information executives receive about their competitors' pay (Schmidt, 2012).

The responsibility of the supervisory board in setting executive pay has been underscored with the VorstAG of 2009. Not only is it now the responsibility of the whole board to set the pay (prior to the new law this was done by a subcommittee), members of the board can be sued by investors if remuneration is not set in an appropriate way. The disclosure under IFRS 2 makes this easier to detect and the new legal possibilities available to investors should present a deterrence to excessive pay. At the same time, it might pose an incentive to hide the exact value of pay and therefore the study presented in Chapter 5 also represents a test of this new law.

${ }^{68}$ See, for example, Doidge, Karolyi, and Stulz (2007). 
Another idiosyncrasy of German corporate governance is the heavy involvement of general banks in the corporate control. It is not uncommon for them to own shares of companies and send representatives to sit on the supervisory board. While the equity ownership has declined in the more recent past, bank representatives have been shown to serve as financial experts in non-financial firms (Dittmann, Maug, and Schneider, 2010) and they take on a monitoring role when it comes to executive compensation that leads to a decrease of pay in companies with bankers on their boards (Elston and Goldberg, 2003). Bankers' presence should have a positive influence on the reporting of option values as their expertise will certainly be helpful in the complex field of option valuation. Moreover, ownership structures in Germany are characterized by a higher ownership concentration (i.e., lower free flow) than in Anglo-Saxon countries and this structure appears to be rather stable over time (Kaserer and Moldenhauer, 2008). Surprisingly, large blockholders do not always take on a monitoring and/or disciplining role in poorly performing firms, which possibly indicates the private benefits of control ${ }^{69}$ exploited by the majority shareholders (Franks and Mayer, 2001).

Because of the relevance of enforcement and corporate governance on financial reporting outcomes, it is not clear whether the results from U.S. are transferable to other countries. And even though the reforms undertaken in Germany in recent years have elevated the quality in both areas, it may not yet have reached the Northern American levels. Thus this thesis can provide the important "German evidence" on the two major questions. And since Germany has recently been placed squarely within a group of other continental European countries, such as France or the Netherlands, in terms of corporate governance (Aggarwal, Erel, Stulz, and Williamson, 2009), results presented in the following two chapters can potentially potentially be applied to many other countries with similar institutional backgrounds.

${ }^{69}$ Broadly speaking, private benefits of control refer to the use of company resources by people in control, e.g., managers. The term is also used in connection with large blockholders who can use their influence in way that benefits only accrue to them and not also proportionally to the rest of the shareholders. For a more detailed depiction, see Dyck and Zingales (2004). 


\section{The Influence of IFRS 2 on Equity-Based Compensation in Germany}

It is the aim of this chapter to examine whether the new accounting standard has had an effect on the choice of equity based-payment instruments in firms. Unlike previous studies on this issue, all three major rationales for granting stock options - optimal contracting, managerial rent seeking, and the perceived cost hypothesis - will be considered. ${ }^{70}$

\subsection{Development of Hypotheses}

Both Bebchuk et al. (2002) and Hall and Murphy (2003) expect accounting to have an influence on the use of executive stock options. Under the managerial power approach it is the transparency and the awareness of the costs of options that will curtail rent seeking, while under the perceived cost hypothesis it is mostly the awareness that will make companies cut back on stock options. Notwithstanding the difference in reasoning, both argue that accounting does affect the use of option-based pay and a change in accounting regimes will make that effect visible. The first research question that will be investigated in this chapter is thus: Does accounting affect equity-based compensation through increased transparency and awareness?

As will be discussed in the following section, several papers have already used the introduction of SFAS 123 and SFAS 123r in order to investigate if such an effect really does occur and their results seem indicate so. However, because of the long period between the two events and the fact that they also eliminated the preferential treatment of at-the-money options, these findings need to be viewed with caution. If one really wants to analyze if accounting affects the use of equity-based pay, one needs an event that represents an immediate change from a non-expense regime to a full-expense regime with transparency, such as the introduction of IFRS 2 in Germany. Using this setting

${ }^{70}$ A variant of this study can be found in Gillenkirch, Korn, and Merz (2013). 
offers a better research opportunity than the U.S. setting, because of the direct transition and the fact that IFRS 2 only changed the expensing and the transparency but not the differential treatment of options. Moreover, because of the differential treatment of performance shares after the change, one can expect stylized reactions to the new accounting rules based on the latent rationals outlined in Chapter 2. If stock options were deemed to be part of an optimal contract before the change in accounting, the increased transparency should have no systematic impact on compensation design ${ }^{71}$ : First, according to the optimal contracting view, management compensation is the result of an arm's length negotiation between management and a board that acts in the shareholders' best interest and has sufficient expertise to correctly evaluate both the incentive effects and the costs of alternative compensation instruments, irrespective of their accounting treatment. Second, although the transition from accounting for equity instruments according to the German Commercial Code to IFRS 2 has significant consequences for financial reporting, differences in disclosure requirements refer to the transparency of compensation cost calculations to third parties, but are irrelevant to the board's choice between alternative equity instruments.

In contrast, in situations where powerful managers have used their influence to increase their compensation levels through stock options, the requirement to expense fair option values is likely to lead to a change in executive compensation design, because rent seeking managers will substitute transparent instruments with less transparent ones. The reason is that less transparency both allows discretion in the valuation of equity instruments and is likely to avoid outrage costs. It is thus to be expected that rent seeking managers increasingly use performance shares, as disclosure requirements are lowest under IFRS 2 for these instruments. The rent extraction view makes no assumptions about the expertise of shareholders. It is clear, however, that they do not have the power to prevent excessive pay; power over the pay-setting process lies with the managers.

By definition of the perceived cost hypothesis, shareholders and their representatives do not have the necessary expertise to correctly value equity instruments. If the primary reason for granting stock options has been the erroneous belief that their economic costs are equal to those recorded in income statements (i.e., zero), IFRS 2 will now reveal the fair value of stock options, and shareholders will become aware of their limited expertise in valuing complex equity instruments. Shareholders should react to this in two ways: First, they will refrain from further granting stock options, as it is very unlikely

${ }^{71}$ Hayes et al. (2012), among others, make the same argument. 
that they still believe these instruments to be optimal, given that they dramatically underestimated their true cost. Second, shareholders are expected to favor simple equity instruments with readily available and easily understandable fair values. The reason is that the decision between alternative equity instruments, from the perspective of a shareholder with limited expertise in valuing these instruments, is a decision between alternatives with different degrees of ambiguity: While the cost of a simple stock grant is readily available to the shareholder, she will not be able to verify the cost of a stock option derived from a complex valuation model, and it will be impossible for her to evaluate a performance share given the IFRS 2 disclosure requirements. ${ }^{72}$ Prior research has provided evidence for individuals to show ambiguity aversion. In particular, when being confronted with a choice between uncertain prospects with either clear or ambiguous sources of uncertainty, individuals show a strong tendency to avoid ambiguous prospects (Fox and Tversky, 1995). Furthermore, individuals avoid uncertain prospects when they have comparably low confidence in their knowledge about the prospect (Heath and Tversky, 1991), and especially when they are aware that the prospect is unfamiliar to them, but familiar to others (Chow and Sarin, 2002). As a consequence, if shareholders show ambiguity aversion, they can be expected to opt for a linear equity instrument (i.e., stock) whose value can be directly observed, and which is fully transparent and familiar to them, or to drop equity-based compensation forms altogether. Table 4.1 summarizes the stylized reactions to the accounting change of IFRS 2 under the different rationales for granting stock options. ${ }^{73}$

Table 4.1: Stylized Reactions to the Accounting Change and Their Underpinnings

\begin{tabular}{llcc}
\hline & OC & MRS & PCH \\
\hline Impact of Accounting Change & No & Yes $\rightarrow$ & Yes $\rightarrow$ \\
& & non-linear non-transparent instrument & $\begin{array}{c}\text { linear transparent instrument } \\
\text { or no instrument }\end{array}$ \\
Shareholder Power & Yes & No & Yes \\
Shareholder Expertise & Yes & Yes or No & No \\
\hline
\end{tabular}

Shareholder power and shareholder expertise under the three theories that explain the granting of stock options and expected impact of the accounting change. OC stands for optimal contracting, MRS for managerial rent seeking and $\mathrm{PCH}$ for perceived cost hypothesis.

72 On the complexity of valuing performance shares, see Holden and Kim (2012).

${ }^{73}$ Since compensation costs have to be expensed under IFRS 2, they lower a company's tax liability. This effect holds for all three forms of equity-based compensation, however, and does therefore not impact the stylized reactions. 
This leads to the second research question dealt with in this chapter: If accounting does have an effect, how does it specifically impact the use of equity-based compensation in firms? This is also particularly interesting in Germany. Since there has not been a preferential treatment of plain-vanilla at-the-money options and regulations have always encouraged including performance conditions, it is conceivable that the use has been much closer to optimal contracting than in other countries and that there might be no discernible effect from the new accounting rules.

Yet if there is an effect, it will most likely be in firms that are not following optimal contracting. Those that have used options because of rent-seeking motives are expected to choose performance shares and those that incorrectly assumed options to be far less costly than they actually are will either abandon equity-based pay altogether or move to a less complex easily understandable instruments like restricted stock.

\subsection{Previous Findings and Research Gap}

A few previous studies have investigated the influence of a change in accounting rules on the design of equity-based compensation, yet said studies were conducted with U.S. data and were based on the introduction of SFAS 123(r). Carter et al. (2007) find that financial reporting concerns (e.g., maintaining increasing earnings patterns, meeting analysts' forecasts, managing debt-equity ratios) lead companies to increase the use of options and decrease the use of stock under the U.S. pre-2005 favorable accounting treatment of options. Brown and Lee (2011) find that the removal of the accounting benefits for options in 2005 led to a decrease in options granted, and that the reduction in options increases in the accounting benefits the respective firms had from using options before 2005. On average, previous accounting benefits explain $45 \%$ of employee stock option cutbacks in their sample. Furthermore, firms that reduced options the most were firms (i) that used stock options to improve accounting numbers ${ }^{74}$, (ii) that had tighter earnings-based financial covenants, and (iii) where the CEO's cash compensation had a high correlation with reported income (i.e., cash bonuses depended on reported income). Brown and Lee (2011) also find that after the introduction of SFAS 123r options granted to employees and executives are more highly associated with firm performance and future

74 Botosan and Plumlee (2001), for example, report that the pro forma option expense has a significant negative effect on performance metrics such as earnings per share or return on assets. 
firm value, suggesting that the reduction in option-based compensation brought about by the new accounting rules may have resulted in a usage that is closer to optimal contracting benchmarks. Hayes et al. (2012) also find that companies reduced stock options following the adoption of the new U.S. accounting regime in 2005. They further provide evidence that options had not been used to reduce risk-related agency costs, i.e., to provide incentives for risk-taking: Options were not replaced by instruments with similar compensation convexity, and there was no change towards less risky investments and financial policies. Since Hayes et al. (2012) do find that firms with higher proforma options expenses under SFAS 123 exhibited a higher reduction in option use, they conclude that accounting concerns were a driving factor in the decision to issue call options. Lastly, Skantz (2012) finds that with the implementation of SFAS 123 option grants were reduced while restricted stocks were used more often. The author attributes this to the reporting benefits of stock options before the new regulation, which is seen as a confirmation of the perceived cost hypothesis. Moreover, the change in the compensation mix was less pronounced in companies with powerful managers who were able to ward off anti-rent seeking measures by shareholders. In sum, by demonstrating the influence of accounting rules on stock option grants, all four studies provide evidence against the optimal contracting view.

However, these studies provide findings that cannot be convincingly transferred to other countries with other transitions in the accounting rules, with other corporate governance, and enforcement backgrounds. In particular, there can be differences in the way accounting affects the use of equity-based pay if the accounting standards in other countries are not exactly the same. Because of the fact that there was no preferential treatment of at-the-money options, because there was complete no-expensing before the change, and because the change was immediate, the first research question will address whether accounting also has an influence in Germany. With the differential treatment of performance shares under IFRS 2, it is possible to ascertain not only if the new standard affects equity-based pay, but also how it affects it. Analyzing the transition under IFRS 2 can thus potentially lead to different results, yet these results are possibly transferable to other IFRS countries with similar enforcement and governance backgrounds as Germany. 


\subsection{Data Set and Study Design}

I investigate the research question with a sample of German companies that have been listed in either the large-cap, mid-cap, or small-cap stock index (DAX, MDAX, SDAX, respectively) during the years 2002 through 2009. From those I select all firms that have issued stock options in at least one fiscal year prior to the implementation of IFRS $2^{75}$. Other instruments were used far less often and including those companies would not significantly increase the sample size while introducing heterogeneity to it. Additionally, I require that financial statements are available for years in which stock options or other equity-based forms of compensation have been issued, or, if the use of such payment forms has been discontinued, for at least one year after the last tranche of options has been issued. I chose 2002 as the beginning of the sample period, because the International Accounting Standards Board (IASB) put accounting for stock-based compensation on the agenda in that year. Therefore, it represents the first year in which companies could have changed their compensation packages in anticipation of a rules change. Moreover, I end the sample period in 2009, since at that point companies had at least five years in order to react to the implementation of IFRS 2. It is doubtful that any changes much later than that will be a result of the change in accounting regimes. The fact that stock option plans for companies in my sample have an average time to maturity of 5.25 years supports this assumption.

Figure 4.1 provides a first impression on the potential effects of the introduction of IFRS 2 on share-based compensation. At the beginning of the investigation period the number of companies issuing stock option plans declines rapidly, whereas it appears to be leveling off at the end. Performance shares and restricted stock, on the other hand, see a strong rise right around the time of the issue of IFRS 2, yet they too seem to be leveling off afterwards.

The empirical analysis will proceed in two steps: In the first step, it will be analyzed if the new standards leads to a change in the way equity-based pay is employed by companies. Starting with the assumption that optimal contracting is the underlying motive, no change is to be expected. In order to test for the effect of IFRS 2, I will use a pooled

75 IFRS 2 took effect for fiscal years beginning on or after January 1, 2005. I define 2004, the year in which the standard was issued, as the beginning of the IFRS 2 period. This is in line with Hayes et al. (2012), who define 2005 as the first year of the post SFAS 123r period even though that standard only took effect in January 2006. Results remain largely unaffected if I use 2005 as the beginning of the IFRS 2 period. 
Figure 4.1: Development of equity-based compensation in Germany

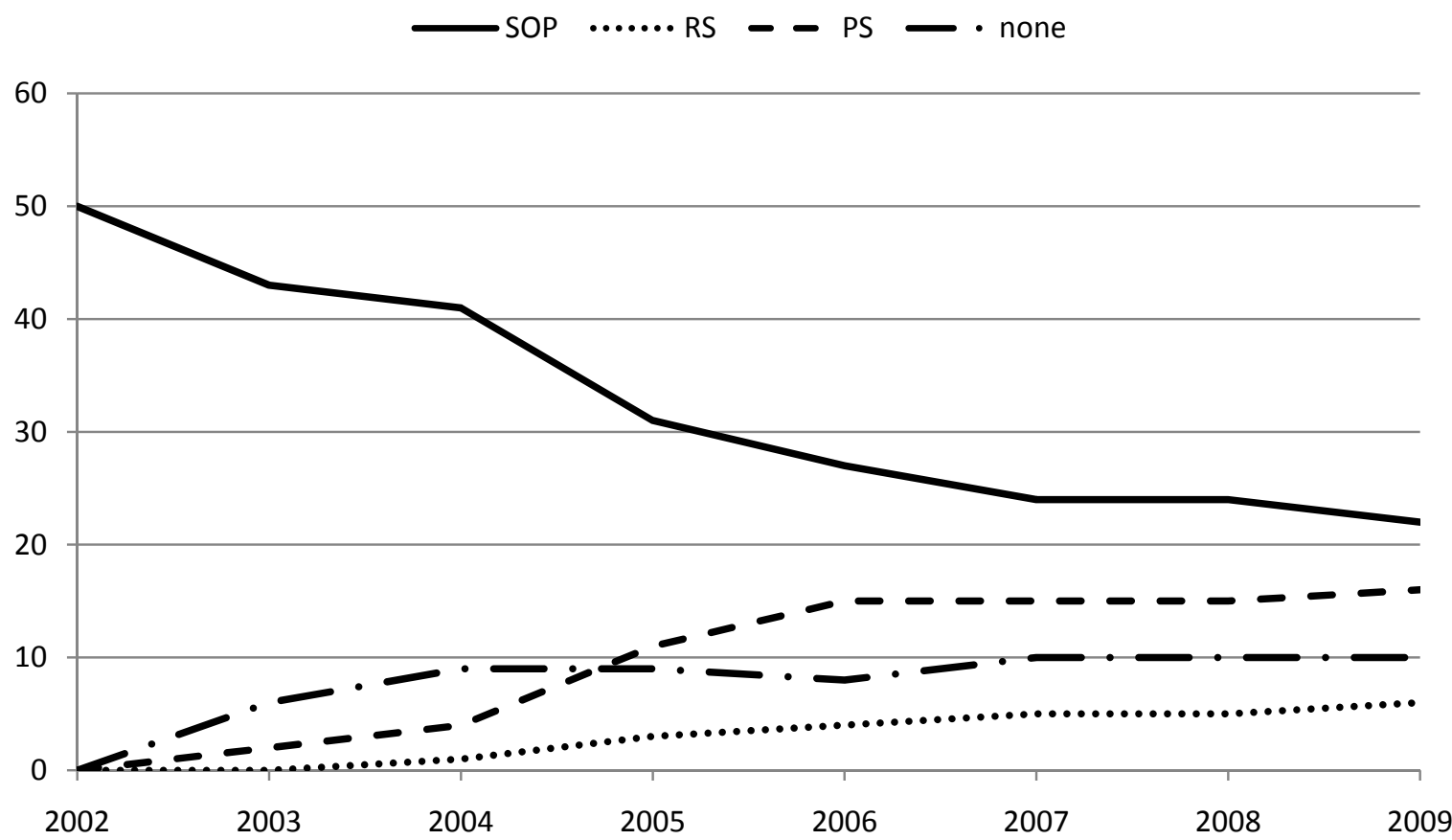

The vertical axis shows the number of companies issuing the respective equity-based instrument. SOP stands for stock option plans, RS for restricted stock, and PS for performance shares. "None" refers to companies who no longer issue any kind of equity instrument.

probit regression which includes proxies for shareholder power and plan sophistication. Both are essential in a situation where optimal contracting is supposed to be working. In a second step I will take a closer look at companies that have discontinued using stock options. This will serve to analyze how in particular IFRS 2 effects the choice of the new accounting instrument. As described, motives for those companies can be managerial rent seeking and low perceived costs. According to Table 4.1, the distinguishing factor between the two is shareholder power, for which proxies will be used in the second pooled probit regression. 


\subsection{Testing for the Effect of IFRS 2 on Stock Options}

\subsubsection{Explanatory Variables}

In the first step of the empirical analysis, I code all companies that keep issuing stock options with a zero and all other companies (i.e., that switch to either restricted stock, performance shares, or no equity-based components) with a one for all years. I thus have a binary dependent variable that I will analyze with a pooled probit model. As the new accounting rule should not have an impact on the choice of instrument if that instrument has been the result of an optimal contracting decision, the variables associated with optimal contracting should have a negative sign, or in other words, work against the likelihood of a change in compensation. For optimal contracting to work, two general conditions have to be met. First, shareholders need to have enough power ${ }^{76}$ not to let managers capture the pay-setting process and second, they also need to have the expertise to design the plans in a way that is consistent with optimal contracting.

\section{Proxies for Shareholder Power}

To generate proxies for shareholder power, I collect data on the companies' free float, the size of the supervisory board ${ }^{77}$, whether a former CEO serves as chairman of the board $^{78}$, and the tenure of the CEO.

Free float is defined by Deutsche Börse as the percentage of tradable shares not held by investors whose cumulative holdings surpass five percent of outstanding shares. I obtain the free float from annual reports and from the Thomson Reuters Database for years where companies did not disclose it. The more shares one person owns, the larger his or her interest will be and the more influence he or she will exert (Shleifer and Vishny, 1986). Consequently, the higher the ownership of the large stockholders, the harder it will be for executives to negotiate pay packages detrimental to the stockholders. This relationship has been confirmed by Bertrand and Mullainathan (2000) and Core

${ }^{76}$ I will measure shareholder power much in the same way as, for example, Abernethy et al. (2013) do.

77 The Stock Corporation Act (Aktiengesetz) mandates a supervisory board (Aufsichtsrat) composed of shareholder and employee representatives. The board has the task, among others, to appoint executives to the management board (Vorstand) and to set their compensation. See Andres et al. (2012) for a more detailed description of the institutional background in Germany.

78 Because of the two-tier board structure in Germany, it is not possible for one person to hold both positions simultaneously. 
et al. (1999). Additionally, Bertrand and Mullainathan (2000) find that managers are rewarded for luck if there is no large blockholder and both Cyert et al. (2002) and Sautner and Weber (2011) report a negative correlation between the ownership of the largest outside shareholder and CEO compensation. Elston and Goldberg (2003) show that high concentration of ownership can function as a monitoring device for executive compensation in Germany. Since high free float represents little ownership concentration and little shareholder power, I expect the sign of the coefficient to be positive.

Board Size is the number of directors on a company's supervisory board in a given year. This variable was collected from the BoardEx Database and information on companies not included in that database was hand-collected from annual reports. The more members a board has, the harder the communication process becomes and the more free-rider problems can occur (Hermalin and Weisbach, 2003; Lipton and Lorsch, 1992), which could make rent extraction for managers easier (Jensen, 1993). In Germany, law dictates a minimum number of supervisory board members, yet companies can increase the size if they want to. Two studies have found a negative relationship between board size and company performance, which has been interpreted as insufficient supervision by the board (Yermack, 1996; Eisenberg et al., 1998). Ozkan (2011) finds a positive association between board size and CEO compensation levels in U.K. firms and also interprets the finding as a sign of insufficient board control. Although these three studies investigate one-tier systems (the U.S., Finland, and the U.K., respectively), I see no reason why it should be different in my sample and expect increasing board size to speak against optimal contracting, i.e., the sign of the coefficient to be positive.

In Germany, it is not legally possible for one person to serve as both CEO of the company and be a member of the supervisory board. It is however common for CEOs to join the supervisory board upon retirement and take over as chairman of the board. Andres et al. (2012), examining 150 German companies, show that executives' pay increases when a former CEO joins the supervisory board. They interpret their finding in the way that executives feel underpaid in relation to their peer group and want to adjust pay for their successor and former colleagues, clearly causing hidden costs of the positional transfer and undermining shareholders' goals during the pay-setting process. Former CEO Chair is a dummy variable that is one if a former CEO is the chairman of the board in the respective year, and I expect the corresponding coefficient to be positive. The data come from BoardEx Database and, if not available from the database, annual reports. 
Finally, I add CEO Tenure as the number of years a CEO has served in that capacity. The variable was taken from BoardEx. Hill and Phan (1991) use CEO tenure as a proxy for the influence a CEO can exert over the board of directors and they find that with increasing tenure CEO pay becomes more aligned with CEO preferences, which includes less dependence on stock returns and a stronger reflection of firm size and firm risk in absolute pay. For a sample of UK firms, Ozkan (2011) shows that longer tenure is associated with lower pay-for-performance sensitivity, which is taken as a sign of the entrenchment effect tenure can have. I expect a positive sign for the regression coefficient.

\section{Proxies for Shareholder Expertise}

I also have to account for shareholders' expertise in designing executive compensation contracts. As proxies, I use the percentage of shares held by institutional investors and a set of variables that show the "sophistication" of the stock option plan, namely whether the plan has an absolute and/or relative hurdle, whether it has a cap, and whether it requires an initial investment from the manager.

The role of Institutional Investors has received a lot of attention in the context of executive compensation. Hartzell and Starks (2003) find that pay-for-performance sensitivity increases in institutional investor ownership. Bechmann and Hjortshøj (2009) report that having high institutional ownership leads companies to comply with disclosing requirements. These findings suggest that institutional investors use their expertise to set payment-schemes efficiently and decrease information asymmetry through disclosure. Institutional investors are especially effective in monitoring executive pay when they have a pure investment relationship with the firm (David, Kochhar, and Levitas, 1998). Bankers in particular, who are a subset of institutional investors, have been found to act as experts in supervisory boards or when their bank has an ownership stake in a company (see Elston and Goldberg, 2003; Dittmann et al., 2010). I thus expect this variable to be negatively related to a change in equity-based compensation.

Performance hurdles in executive stock options have been analyzed in the literature and have been shown to potentially improve managerial incentives, if set properly: Using relative performance hurdles, for example, insulates a manager's compensation from uncontrollable random shocks, which prevents the heavily criticized "pay for luck" (e.g., Rappaport (1999) and Carter, Ittner, and Zechman (2009)). In practice, especially institutional investors have repeatedly called for incorporating hurdles into stock option 
plans $^{79}$. In accordance with academic literature (e.g., Jensen, Murphy, and Wruck, 2004), I interpret the existence of an absolute or a relative hurdle in a stock option as an indicator for a higher level of sophistication in managerial pay design. Several regulatory initiatives concerning executive compensation have also made this point. Since 2003, the German Corporate Governance Code (GCGC), a government framework that contains guidelines on what constitutes good and transparent corporate governance, recommends that variable compensation contain caps to avoid pay for luck. As the GCGC has become an accepted benchmark for good corporate governance in Germany, I interpret a cap in a stock option plan as an additional indicator of the plan's sophistication. I therefore include Absolute Hurdle, Relative Hurdle in share prices and Cap as dummy variables. Each takes the value of one if the plans contain the respective design element and I expect them all to have negative coefficients.

Options have the drawback that if the share price falls far below the exercise price, they lose their incentive value, because managers are de facto insured against bad outcomes (Sappington, 1991). Companies can remedy this by requiring executives to invest in company shares, which will continue to have an incentive effect if prices fall (Hall and Murphy, 2003). Following the theoretical literature, and in accordance with calls from institutional investors (e.g., Union Investment, 2006), I use the indicator variable Initial Investment, which is one if executives have to purchase company stock as part of their equity-based compensation packages and zero otherwise, as an additional measure of the level of sophistication in executive compensation. I expect it to have a negative sign.

In addition to testing for shareholder power and expertise, I also add a control variable. It is conceivable that even under optimal contracting companies switch to equity-based instruments other than stock options, especially the less transparent performance shares, in order to avoid a negative public reaction to what is only seemingly excessive pay (Jensen and Murphy, 1990a). I therefore add Salary as the average salary for members of the executive board. If concerns for public outrage over the level of executive pay were the motivation for the switch, this variable would show up positively in the regression as higher overall salary would indicate a need for camouflage.

\footnotetext{
${ }^{79}$ See,for example, CalPERS (2011) and Union Investment (2006).
} 
The presented selection of explanatory variables yields the following regression model:

$$
\begin{aligned}
Y_{1 i}= & \beta_{0}+\beta_{1} \text { FreeFloat }_{i t}+\beta_{2} \text { SizeSupervBoard }_{i t}+\beta_{3} \text { FormerCEOChair }_{i t} \\
& +\beta_{4} \text { CEOTenure }_{i t}+\beta_{5} \text { InstInvestor }_{i t}+\beta_{6} \text { AbsHurdle }_{i t} \\
+ & \beta_{7} \text { RelHurdle }_{i t}+\beta_{8} \text { Cap }_{i t}+\beta_{9} \text { InitialInvestment }_{i t} \\
+ & \beta_{10} \text { Salary }_{i t}+\epsilon_{i t},
\end{aligned}
$$

where the index $i$ stands for the different companies and $t$ for time. Note that the binary dependent variable does not have a $t$-subscript. This is because I have coded companies that change compensation contracts as $Y_{1 i}=1$ and companies that do not change as $Y_{1 i}=0$ for all years in the sample. Therefore, there is no change over time for this variable. This issue will be revisited in the robustness checks.

\subsubsection{Results}

\subsubsection{Descriptive Statistics}

Table 4.2 provides a general overview of my data. In total the data set contains 54 companies that have issued stock options in at least one year prior to passage of IFRS 2 . Of those companies, 32 have chosen to change or stop that practice. In case of a change, performance shares were the preferred instruments, clearly dominating restricted stocks, though not quite equaling the number of 22 companies that still use stock options. My sample contains 425 firm-year observations, yet observations for institutional investors are a limiting factor to my analyses with only 235 observations. The relatively high mean value of $72 \%$ for institutional investors is most likely due to the fact that there is no legal obligation to disclose holdings by institutional investors so only companies whose stocks are mostly held by such investors disclose the information at all. Furthermore, it can be seen that the sample is characterized by high free float, a varying board size, and about one third of companies where the former CEO took over the role of chairman of the supervisory board.

Looking at the variables for stock option plan sophistication reveals a striking difference to option plans granted in the United States in the same period. Roughly $65 \%$ of all compensation contracts considered ${ }^{80}$ in this study contain an absolute stock price goal

${ }^{80}$ For the sake of this summary, I consider having no equity-based compensation as a form of compensation contract. 
and $45 \%$ contain a relative goal (i.e., are indexed) ${ }^{81}$. Finally, it can be seen that average executive salary is far below what has been documented in studies with U.S. data.

Table 4.2: Summary Statistics I

\begin{tabular}{|c|c|c|c|}
\hline \multicolumn{4}{|c|}{ All sample years. Number of companies: 54} \\
\hline Number of changes: 32 & $\begin{array}{l}\text { to } \mathrm{P} \\
\text { to } \mathrm{R} \\
\text { to } \mathrm{n}\end{array}$ & $\begin{array}{l}\text { Shares: } \\
\text { tock: } \\
\text { sed Instrument: }\end{array}$ & $\begin{array}{c}16 \\
6 \\
10\end{array}$ \\
\hline Variable & $\mathrm{N}$ & Mean & Std. Dev. \\
\hline \multicolumn{4}{|l|}{ Shareholder Power } \\
\hline Free Float & 422 & 0.674 & 0.253 \\
\hline Size Supervisory Board & 425 & 13.96 & 5.825 \\
\hline Former CEO Chairman & 425 & 0.311 & 0.463 \\
\hline CEO Tenure & 425 & 5.179 & 3.978 \\
\hline \multicolumn{4}{|l|}{ Shareholder Expertise } \\
\hline Institutional Investors & 235 & 0.726 & 0.194 \\
\hline Absolute Hurdle & 421 & 0.648 & 0.478 \\
\hline Relative Hurdle & 421 & 0.458 & 0.499 \\
\hline Cap & 421 & 0.356 & 0.479 \\
\hline Initial Investment & 421 & 0.252 & 0.435 \\
\hline $\begin{array}{l}\text { Control Variable } \\
\text { Salary in Mio. } €\end{array}$ & 416 & 1.704 & 1.233 \\
\hline
\end{tabular}

This table contains summary statistics for the variables included in the first regression over the whole sample period from 2002 to 2009. I have 425 firm-year observations, but the institutional investors represent the most limiting factor with only 235 observations.

Table 4.3 presents a more detailed overview broken down by years and compensation contracts. While stock options are issued by less companies over the sample period, a very high percentage of them, namely about $80 \%$, have an absolute hurdle and $50 \%$ or more have relative hurdles. Additionally, more and more companies include caps in option plans in order to limit payments to executives. All these characteristics suggest that plan sophistication is relatively high in Germany, hinting at the role optimal contracting plays in the payment process.

\footnotetext{
${ }^{81}$ However, as Bettis et al. (2013) report, there has been a steady increase of incorporating hurdles into equity instruments in the U.S. in the years 2000-2008. In 2008, the value of plans with hurdles amounts to $29 \%$ of the total value of all plans.
} 
Table 4.3: Summary Statistics II

\begin{tabular}{|c|c|c|c|c|c|c|c|c|}
\hline & 2002 & 2003 & 2004 & 2005 & 2006 & 2007 & 2008 & 2009 \\
\hline \multicolumn{9}{|l|}{ Panel A: Options } \\
\hline Companies with Optionplans & 50 & 43 & 41 & 31 & 27 & 24 & 24 & 22 \\
\hline Average Free Float & 0.64 & 0.63 & 0.67 & 0.65 & 0.68 & 0.68 & 0.66 & 0.65 \\
\hline Average Size Supervisory Board & 14.5 & 14.69 & 14.09 & 13.48 & 13.25 & 13.00 & 12.37 & 11.77 \\
\hline Percent w/ Former CEO Chairman & 0.28 & 0.33 & 0.37 & 0.39 & 0.41 & 0.46 & 0.50 & 0.36 \\
\hline Average CEO Tenure & 4.90 & 5.03 & 5.29 & 6.10 & 6.37 & 6.92 & 5.63 & 5.50 \\
\hline Percent Institutional Investors & 0.69 & 0.67 & 0.70 & 0.75 & 0.76 & 0.79 & 0.77 & 0.74 \\
\hline Percent w/ Absolute Hurdle & 0.80 & 0.84 & 0.80 & 0.77 & 0.78 & 0.83 & 0.83 & 0.82 \\
\hline Percent w/ Relative Hurdle & 0.48 & 0.54 & 0.56 & 0.61 & 0.59 & 0.67 & 0.67 & 0.68 \\
\hline Percent w/ Cap & 0.12 & 0.23 & 0.37 & 0.45 & 0.48 & 0.46 & 0.46 & 0.50 \\
\hline Percent w/ Initial Investment & 0.24 & 0.26 & 0.29 & 0.35 & 0.37 & 0.41 & 0.42 & 0.45 \\
\hline Average Salary in Mio. $€$ & 1.00 & 1.25 & 1.46 & 1.74 & 2.01 & 2.08 & 1.82 & 1.88 \\
\hline \multicolumn{9}{|l|}{ Panel B: Performance Shares } \\
\hline Companies with Performance Shares & & 2 & 3 & 11 & 15 & 15 & 15 & 16 \\
\hline Average Free Float & & 0.58 & 0.77 & 0.70 & 0.66 & 0.71 & 0.70 & 0.71 \\
\hline Average Size Supervisory Board & & 16.5 & 19.6 & 15.6 & 15.3 & 1.5 & 15.6 & 15.9 \\
\hline Percent w/ Former CEO Chairman & & 0.5 & 0.33 & 0.27 & 0.27 & 0.27 & 0.20 & 0.25 \\
\hline Average CEO Tenure & & 3.5 & 3.7 & 5.2 & 4.2 & 4.5 & 4.8 & 5.8 \\
\hline Percent Institutional Investors & & 0.78 & 0.82 & 0.69 & 0.73 & 0.75 & 0.70 & 0.76 \\
\hline Percent w/ Absolute Hurdle & & 1.00 & 1.00 & 0.73 & 0.66 & 0.66 & 0.66 & 0.69 \\
\hline Percent w/ Relative Hurdle & & 0.50 & 0.66 & 0.45 & 0.53 & 0.53 & 0.53 & 0.56 \\
\hline Percent w/ Cap & & 0.5 & 0.66 & 0.64 & 0.66 & 0.66 & 0.73 & 0.75 \\
\hline Percent w/ Initial Investment & & 0 & 0 & 0 & 0.27 & 0.33 & 0.33 & 0.75 \\
\hline Average Salary in Mio. $€$ & & 1.44 & 1.87 & 2.16 & 2.00 & 2.16 & 1.95 & 1.71 \\
\hline \multicolumn{9}{|l|}{ Panel C: Restricted Stock } \\
\hline Companies with Restricted Stock & & 0 & 1 & 3 & 4 & 5 & 5 & 6 \\
\hline Average Free Float & & - & 0.93 & 0.89 & 0.87 & 0.86 & 0.83 & 0.73 \\
\hline Average Size Supervisory Board & & - & 20 & 20.3 & 20 & 20 & 19.4 & 19.17 \\
\hline Percent w/ Former CEO Chairman & & - & 0 & 0.66 & 0.50 & 0 & 0 & 0 \\
\hline Average CEO Tenure & & - & 12.7 & 1.7 & 5.7 & 2.3 & 3.3 & 2.8 \\
\hline Percent w/ Cap & & - & 0 & 0.33 & 0.50 & 0.40 & 0.40 & 0.5 \\
\hline Percent w/ Initial Investment & & - & 0 & 0 & 0 & 0 & 0 & 0 \\
\hline Average Salary in Mio. $€$ & & - & 2.22 & 3.78 & 3.40 & 3.61 & 2.83 & 2.69 \\
\hline \multicolumn{9}{|c|}{ Panel D: No Equity-Based Compensation } \\
\hline Companies without Equity-Based Co & pensation & 6 & 9 & 9 & 8 & 10 & 10 & 10 \\
\hline Average Free Float & & 0.63 & 0.76 & 0.68 & 0.66 & 0.67 & 0.67 & 0.67 \\
\hline Average Size Supervisory Board & & 11 & 11.1 & 11.9 & 9.5 & 10.2 & 10.7 & 10.6 \\
\hline Percent w/ Former CEO Chairman & & 0.17 & 0.11 & 0.11 & 0.13 & 0.20 & 0.20 & 0.3 \\
\hline Average CEO Tenure & & 2.5 & 3.4 & 3.6 & 4.8 & 5.1 & 5.1 & 6.1 \\
\hline Average Salary in Mio. $€$ & & 0.81 & 0.89 & 1.21 & 1.73 & 1.96 & 1.34 & 1.51 \\
\hline
\end{tabular}

This table provides more detailed summary statistics over the entire sample period, broken down by year and contract. Panel A lists data for stock options, panel B for performance shares, panel C for restricted stock, and panel D for no equity-based compensation. Since neither of the latter two has performance targets, the respective items have been omitted in panel C and D. 


\subsubsection{Regression Results}

As described, those companies that granted stock options out of optimal contracting considerations will have no reason to stop doing so just because of the new situation brought about by IFRS 2. In order to investigate this issue, I use variables that proxy for shareholder power and expertise to help explain a change from stock options to other compensation instruments. Regression results of a probit model for pooled data given by Equation (4.1) are reported in Table 4.4, model (1).

Out of the variables proxying for shareholder power, free float and the size of the supervisory board show the expected positive sign and are significant on a ten and a one percent level, respectively. Although neither former CEO as chairman nor CEO tenure show up significant, the overall results can be seen as support for the hypothesis that low shareholder power leads to a change in equity-based compensation.

All the variables measuring plan sophistication, which are used as proxies for shareholder expertise, have the expected signs with the exception of cap, which is also not significant. This finding indicates that companies whose plans already contain elements associated with optimal contracting were significantly more likely to keep their option plans. Both absolute and relative hurdles are significant at the one percent level and have a negative sign. This supports the view that when characteristics associated with optimal contracting are present, the new accounting rules do not cause a change in compensation instruments. The high significance level of the initial investment coefficient further substantiates this conclusion. The institutional investors measure has a negative sign, as expected, but the coefficient is not significant. Moreover, the relatively high pseudo $R^{2}$ of almost $50 \%$ gives reason to believe that the overall fit of the model is already quite good.

As stated before, it is possible that companies already engaging in optimal contracting still switch to a new instrument, simply to avoid outside criticism from observers who are solely focused on salary levels and not structure (Jensen and Murphy, 1990a). That is why I have included salary as a control variable in the regression. Since it is negative, I find no evidence for this issue in my sample. The five percent significance level is somewhat surprising as it indicates that when managers receive a high salary, their companies continue using stock options. This may indicate that a high level of pay is not per se incompatible with optimal contracting; in fact it can be a consequence of optimal contracting, as, e.g., higher pay-performance sensitivities are likely to be 
Table 4.4: Regression results explaining the switch from stock options to a different form (or no form) of equity-based compensation.

\begin{tabular}{|c|c|c|c|c|}
\hline $\begin{array}{l}\text { Model } \\
\text { Dependent Variable }\end{array}$ & $\begin{array}{c}(1) \\
\text { Change }\end{array}$ & $\begin{array}{c}(2) \\
\text { Change }\end{array}$ & $\begin{array}{c}(3) \\
\text { Change }\end{array}$ & $\begin{array}{c}(4) \\
\text { Instrument }\end{array}$ \\
\hline Free Float & $\begin{array}{c}0.0200^{*} \\
(0.0723)\end{array}$ & $\begin{array}{r}0.0123^{*} \\
(0.0866)\end{array}$ & $\begin{array}{l}0.0341^{* * *} \\
(0.0014)\end{array}$ & $\begin{array}{c}0.0135 \\
(0.1590)\end{array}$ \\
\hline Board Size & $\begin{array}{l}0.1551^{* * *} \\
(0.0026)\end{array}$ & $\begin{array}{l}0.1283^{* * *} \\
(0.0007)\end{array}$ & $\begin{array}{l}0.2855^{* * * *} \\
(0.0001)\end{array}$ & $\begin{array}{l}0.1338^{* * *} \\
(0.0022)\end{array}$ \\
\hline FormerCEOchair & $\begin{array}{c}-0.7698 \\
(0.2252)\end{array}$ & $\begin{array}{c}-0.4092 \\
(0.3121)\end{array}$ & $\begin{array}{c}-0.8454 \\
(0.1680)\end{array}$ & $\begin{array}{c}-1.2214^{* *} \\
(0.0464)\end{array}$ \\
\hline CEO Tenure & $\begin{array}{c}-0.0113 \\
(0.8514)\end{array}$ & $\begin{array}{c}-0.0349 \\
(0.3478)\end{array}$ & $\begin{array}{c}-0.1086 \\
(0.1290)\end{array}$ & $\begin{array}{c}0.0429 \\
(0.5045)\end{array}$ \\
\hline Instit. Investors & $\begin{array}{r}-0.0018 \\
(0.8633)\end{array}$ & & $\begin{array}{r}-0.0188 \\
(0.1137)\end{array}$ & $\begin{array}{r}-0.0006 \\
(0.9551)\end{array}$ \\
\hline Absolute Hurdle & $\begin{array}{l}-1.6584^{* * *} \\
(0.0030)\end{array}$ & $\begin{array}{l}-1.3365^{* * *} \\
(0.0040)\end{array}$ & $\begin{array}{l}-2.4359^{* * *} \\
(0.0000)\end{array}$ & $\begin{array}{l}-1.8039^{* * * *} \\
(0.0078)\end{array}$ \\
\hline Relative Hurdle & $\begin{array}{c}-1.7332^{* * *} \\
(0.0071)\end{array}$ & $\begin{array}{l}-1.2026^{* * *} \\
(0.0001)\end{array}$ & $\begin{array}{l}-1.8076^{* * *} \\
(0.0023)\end{array}$ & $\begin{array}{l}-2.1730^{* * * *} \\
(0.0000)\end{array}$ \\
\hline Cap & $\begin{array}{c}0.6739 \\
(0.2056)\end{array}$ & $\begin{array}{c}0.6629 \\
(0.1069)\end{array}$ & $\begin{array}{r}-0.0730 \\
(0.9017)\end{array}$ & $\begin{array}{c}0.9424 \\
(0.1248)\end{array}$ \\
\hline Initial Investment & $\begin{array}{c}-1.3236^{* *} \\
(0.0250)\end{array}$ & $\begin{array}{l}-1.1224^{* * *} \\
(0.0084)\end{array}$ & $\begin{array}{l}-2.9489^{* * *} \\
(0.0000)\end{array}$ & $\begin{array}{r}-0.9111^{*} \\
(0.0999)\end{array}$ \\
\hline Salary & $\begin{array}{c}-0.3227^{* *} \\
(0.0434)\end{array}$ & $\begin{array}{c}-0.2953^{* *} \\
(0.0241)\end{array}$ & $\begin{array}{c}-0.3490 \\
(0.1161)\end{array}$ & $\begin{array}{c}-0.2054 \\
(0.3360) \\
\end{array}$ \\
\hline Clustered SE & Yes & Yes & $\mathrm{BME}$ & Yes \\
\hline Year Dummies & No & No & No & Yes \\
\hline Observations & 178 & 322 & 178 & 178 \\
\hline Companies & 38 & 54 & 38 & 38 \\
\hline Pseudo $R^{2}$ & $49.98 \%$ & $37.50 \%$ & $15.74 \%$ & $56.14 \%$ \\
\hline
\end{tabular}

Change is an indicator variable showing the value one for companies that discontinue or replace stock options as part of their compensation to executives and zero otherwise. Instrument is an indicator variable coded for the equity instruments used in each year. It is zero for options and one for all other forms. Model (1) is a pooled probit model with Change as the dependent variable. The sample consists of 178 firm-year observations over the fiscal years 2004 to 2009. For model (2), Institutional Investors has been omitted to increase sample size. Model (3) is a random-effects probit model. Model (4) is again a pooled probit model and the dependent variable is now Instrument. This model includes year dummies. Independent variables for all models represent both the power and expertise of shareholders. In all models, Salary is a control variable. P-values are reported in parenthesis and are based on cluster-robust standard errors and the Butler and Moffitt (1982) estimator (BME) for model (3). 
accompanied by higher risk premiums given to managers. I will revisit this issue during one of the robustness checks.

\subsubsection{Robustness Checks}

Before I deal with the question of why other forms of equity-based compensation have been chosen, I subject my previous regression results to several robustness checks. Institutional investors represent a limiting factor in the analysis, as I have many missing observations. Therefore, I run the regression again, this time without that variable, which increases the number of observations to 322. Results are given in the model (2) column of Table 4.4. As can be seen, results from model (1) are robust to the omission of institutional investors. Exactly the same variables show up to be significant at least at the same levels and with the same signs as before, giving support to the hypothesis that high shareholder power and shareholder expertise indicate optimal contracting considerations to be present in firms and decreasing the likelihood of an accounting-motivated change in executive compensation instruments.

Next, I try a different econometric approach by running a panel probit regression with random effects. This allows me to control for unobserved heterogeneity across firms. Results are presented in Table 4.4, model (3) and are almost identical to those of the pooled model. Again I see that low shareholder power as represented by high free float and large supervisory boards point to a higher likelihood of a company changing its equity-based compensation instruments. Unlike before, however, free float is now highly significant at a one percent level. Proxies for shareholder expertise also show the same results with regard to signs and significance, supporting the conclusion that under optimal contracting companies do not alter compensation practices. Another difference to model (1) is given by the fact that salary is no longer significant, making this a non-stable result. Potentially, this is caused by an interaction with the unobserved firm characteristics for which I can now control. At the very least, I can refute the supposition that changes in the choice of equity instruments are caused by a fear of negative reaction to high levels of pay.

Core et al. (2003, p.27) note that "over time, optimal contracting arrangements evolve with changes in contracting technology". In other words, the overall decline in the use of stock options could just be a general time trend and still compatible with optimal contracting. In order to test whether the observed trend towards other forms of equity-based 
compensation is a natural development of optimal contracting, I recode the dependent variable to zero for every year in which stock options are issued by a company and one for all other forms including no equity-based compensation. With this new coding, I introduce some time variation in the dependent variable. I run the regression according to equation (4.1) again and include year dummies to capture any time trend. Results are given in Table 4.4, model (4). Compared with the base model, free float is no longer significant while former CEO chairman is now significant at a five percent level. The negative sign is unexpected. However, this result does not contradict Andres et al.'s (2012) findings of increased executive pay when a former CEO becomes chairman of the supervisory board, because the results refer just to the kind of equity-based contract. If the described hidden cost of the CEO transition in form of the salary increase is also a departure from optimal contracting towards rent extraction, this variable will show up significant in the second stage regression.

Variables measuring plan sophistication point to the same conclusion as before with absolute and relative hurdle showing a negative sign at a one percent significance level and initial investment with a negative sign at a ten percent level. Salary is not significant. More important, though, is the result that the (untabulated) year dummies do not indicate a time trend. The dummy for the year 2004 is the only one that is significant, albeit only barely so (p-value of $9.8 \%$ ), and it has a negative sign, which means that in this year the change from stock options to other forms of compensation was relatively moderate. This fact can also be gleaned from Figure 4.1. Hence, I find no evidence indicating that the observed changes in equity-based compensation are due to optimal contracting and only happen to coincide with the change in accounting rules. Rather, I find that the influence of managerial power and plan sophistication are stable over time.

In a further robustness test, I move the beginning of the sample back to account for earlier signals of a regulatory change concerning equity-based payments that could have prompted companies to adapt their payment practices. The results are provided in Table 4.5. In 2003 the IASB published the exposure draft of IFRS 2. Since such a draft represents the outcome of the technical project and is meant to invite comments or recommendations, it is a clear indication of what the future standard will look like. Therefore, it is likely to have been a trigger for some companies to discontinue the use of stock options. Model (5) is a pooled regression with institutional investors and model (6) without. The results of my base model are confirmed again, with only free float losing in significance. Other than that all the same variables help explain the observed 
changes. The overall impression that shareholder power and shareholder expertise influence companies to keep using stock options is supported.

Models (7) and (8) provide another expansion of the sample size, this time to 2002, the year the IASB put accounting for equity-based compensation on the agenda. Even in this sample, now spanning eight years, I again have the same significant variables as in model (5) and with the same signs. In model (8) CEO tenure, which has a negative sign, is significant at the ten percent level. This is clearly not a robust result, yet it is contrary to expectations and it means that the longer a CEO stays with a company, the less likely a change to other compensation contracts becomes, or in other words, longer tenure would be associated with a tendency towards optimal contracting and not managerial power, previous findings notwithstanding. This can potentially be reconciled with the career concerns hypothesis put forth by Gibbons and Murphy (1992), who argue that CEOs have an implicit incentive early in their careers to make a name for themselves and prove their quality to the market without the need for an incentivizing contract. Only in later years do they need explicit incentives and therefore a higher pay-for-performance sensitivity which can be accomplished by relying more on options. Cremers and Palia (2010) provide empirical support for this hypothesis. ${ }^{82}$ All in all, I find strong support for the original conclusion that the changes in accounting regime have no impact on companies that already exhibited characteristics associated with optimal contracting.

Five companies in the sample provide disclosure for their performance shares on the same level as those that issue stock options ${ }^{83}$. It could be argued that since these companies adhere to the same level of transparency that is mandated for stock options, they are in fact not hiding anything and instead should be seen as companies that continue using stock options, i.e., non-linear transparent instruments. In order to make sure that no companies have been incorrectly categorized, I recode those five companies with a zero in the first stage regression (model (1)) and run the regression again. Results are presented in Table 4.5 model (9). As can be seen, results remain virtually unchanged when transparent performance shares are grouped together with stock options, clearly supporting the conclusions made in Section 4.4.2: optimal contracting is not the sole

82 Additionally, Edmans et al. (2012) develop a model framework that shows that CEO compensation can be dynamic and state-dependent, leading to different levels of pay-for-performance sensitivity at different times.

83 One of those companies, Bayer, does not make it clear whether the valuation parameters are being used to value outstanding option tranches only or also the newly issued performance shares. For this analysis, it will be assumed that they are being used for the performance shares as well. 
Table 4.5: Robustness check with probit regression explaining the change from stock options to a different form (or no form) of equity-based compensation.

\begin{tabular}{|c|c|c|c|c|c|}
\hline Model & $\begin{array}{c}(5) \\
2003-2009\end{array}$ & $\begin{array}{c}(6) \\
2003-2009\end{array}$ & $\begin{array}{c}(7) \\
2002-2009\end{array}$ & $\begin{array}{c}(8) \\
2002-2009\end{array}$ & $\begin{array}{c}(9) \\
2004-2009\end{array}$ \\
\hline Free Float & $\begin{array}{c}0.0158 \\
(0.1366)\end{array}$ & $\begin{array}{c}0.0106 \\
(0.1348)\end{array}$ & $\begin{array}{c}0.0148 \\
(0.1501)\end{array}$ & $\begin{array}{c}0.0112 \\
(0.1026)\end{array}$ & $\begin{array}{c}0.0204^{*} \\
(0.0644)\end{array}$ \\
\hline Board Size & $\begin{array}{l}0.1453^{* * *} \\
(0.0015)\end{array}$ & $\begin{array}{l}0.1115^{* * *} \\
(0.0012)\end{array}$ & $\begin{array}{l}0.1361^{* * *} \\
(0.0009)\end{array}$ & $\begin{array}{l}0.1013^{* * *} \\
(0.0013)\end{array}$ & $\begin{array}{l}0.1126^{* *} \\
(0.0216)\end{array}$ \\
\hline FormerCEOchair & $\begin{array}{c}-0.7618 \\
(0.2266)\end{array}$ & $\begin{array}{c}-0.4454 \\
(0.2626)\end{array}$ & $\begin{array}{c}-0.8612 \\
(0.1206)\end{array}$ & $\begin{array}{c}-0.5055 \\
(0.1805)\end{array}$ & $\begin{array}{r}-0.8297 \\
(0.1976)\end{array}$ \\
\hline CEO Tenure & $\begin{array}{c}-0.0202 \\
(0.7407)\end{array}$ & $\begin{array}{c}-0.0475 \\
(0.1942)\end{array}$ & $\begin{array}{r}-0.0546 \\
(0.3379)\end{array}$ & $\begin{array}{r}-0.0678^{*} \\
(0.0565)\end{array}$ & $\begin{array}{r}-0.0178 \\
(0.7636)\end{array}$ \\
\hline Inst Investors & $\begin{array}{c}-0.0032 \\
(0.7572)\end{array}$ & & $\begin{array}{r}-0.0006 \\
(0.9508)\end{array}$ & & $\begin{array}{c}0.0132 \\
(0.2565)\end{array}$ \\
\hline Absolute Hurdle & $\begin{array}{c}-1.3988^{* * *} \\
(0.0088)\end{array}$ & $\begin{array}{c}-1.1593^{* * *} \\
(0.0056)\end{array}$ & $\begin{array}{c}-1.2170^{* *} \\
(0.0147)\end{array}$ & $\begin{array}{c}-1.0252^{* * *} \\
(0.0074)\end{array}$ & $\begin{array}{c}-1.8007^{* * *} \\
(0.0006)\end{array}$ \\
\hline Relative Hurdle & $\begin{array}{c}-1.4834^{* *} \\
(0.0140)\end{array}$ & $\begin{array}{c}-0.9572^{\text {*** }} \\
(0.0009)\end{array}$ & $\begin{array}{c}-1.3622^{* *} \\
(0.0208)\end{array}$ & $\begin{array}{c}-0.8689^{* * *} \\
(0.0019)\end{array}$ & $\begin{array}{c}-1.7705^{* * *} \\
(0.0068)\end{array}$ \\
\hline Cap & $\begin{array}{c}0.5047 \\
(0.2557)\end{array}$ & $\begin{array}{c}0.4854 \\
(0.1523)\end{array}$ & $\begin{array}{c}0.4010 \\
(0.3410)\end{array}$ & $\begin{array}{c}0.4312 \\
(0.1508)\end{array}$ & $\begin{array}{c}0.7801 \\
(0.1364)\end{array}$ \\
\hline Initial Investment & $\begin{array}{c}-1.1794^{* *} \\
(0.0284)\end{array}$ & $\begin{array}{c}-0.9706^{* *} \\
(0.0205)\end{array}$ & $\begin{array}{c}-1.1130^{* *} \\
(0.0351)\end{array}$ & $\begin{array}{c}-0.8862^{* *} \\
(0.0345)\end{array}$ & $\begin{array}{c}-1.3172^{* *} \\
(0.0226)\end{array}$ \\
\hline Salary & $\begin{array}{r}-0.2482^{*} \\
(0.0906) \\
\end{array}$ & $\begin{array}{r}-0.2153^{*} \\
(0.0823) \\
\end{array}$ & $\begin{array}{r}-0.2497^{*} \\
(0.0701) \\
\end{array}$ & $\begin{array}{r}-0.1963^{*} \\
(0.0932) \\
\end{array}$ & $\begin{array}{r}-0.3124^{*} \\
(0.0561) \\
\end{array}$ \\
\hline Clustered SE & Yes & Yes & Yes & Yes & Yes \\
\hline Observations & 207 & 372 & 233 & 414 & 178 \\
\hline Companies & 39 & 54 & 39 & 54 & 38 \\
\hline Pseudo $R^{2}$ & 44.49 & 32.09 & 41.47 & 29.45 & 49.11 \\
\hline
\end{tabular}

The table reports the results for four pooled probit models where the sample has been expanded to start in 2003 and 2002, respectively, each run once with and without institutional investors (models $5-8$ ) and where companies that use performance shares and disclose all valuation parameters are coded as if they continued using stock options (model 9). The dependent variable is again coded as zero for companies that keep issuing stock options and one for companies that change this practice. P-Values are reported in parenthesis and are based on cluster-robust standard errors. 
reason for granting stock options and in fact, transparency seems to be one of the decisive factors when it comes to the choice of equity-based pay contract.

In a further robustness check, I also included a dummy variable indicating whether all members of the executive board receive the same number of stock options. According to Walker (2011), this lack of individualization of compensation packages is a clear sign against optimal contracting. Unfortunately, the information was only available for a fraction of the firm years, severely limiting the available data for the regressions. Nonetheless, results largely again confirm the above depicted results.

\subsection{Testing for the Effects of IRFS 2 on the Choice of New Equity-Based Instrument}

The previous analysis has clearly demonstrated that the accounting regime change has had an effect, namely it led to a departure from stock options. Because of the differential treatment between stock options and performance shares, it is now also possible to further analyze the reactions and ask how IFRS 2 impacts the use of equity-based compensation. Based on the expected reactions from Table 4.1, it can be tested which instruments companies now pick under the increased transparency and the mandatory expensing. To this end, I only use companies that gave up their stock option plans and switched to either performance shares, or restricted stock, or which stopped equity-based compensation altogether.

\subsubsection{Explanatory Variables}

The dependent variable in this stage, $Y_{2}$, is coded with a one for all companies that switched to performance shares, and zero for the other two possible choices. I put the restricted stock group together with those companies who stopped equity-based compensation as both are a logical choice for shareholders who previously incorrectly perceived option values as too low. Because of their non-linearity and more importantly the lower transparency, I expect performance shares to be the preferred choice for rent seekers: When no valuation parameters have to be disclosed, powerful managers can still camouflage compensation levels as they have the discretion to downwardly bias the reported values of these instruments. 
Since I hypothesize that the non-transparent non-linear performance shares will be preferred by powerful managers to camouflage rent seeking, whereas transparent linear restricted stocks will be preferred by shareholders that previously misperceived the true cost of options, the distinctive feature between the two is now the managerial power. In the former case it is clear that managers have captured the pay-setting process and are choosing the instrument that lets them better camouflage their rent seeking. In the latter case, power lies with the shareholders and they pick an instrument that is easier to understand and value, because they are trying to avoid another situation where they underestimate both the complexity and the cost of the instrument. Expertise of shareholders does not clearly distinguish between managerial power and perceived costs, because it could be lacking in either case ${ }^{84}$. Therefore, variables representing shareholder expertise are not used in this second step.

For the econometric implementation, only two years are included in the regression; the one in which the new instrument is issued and the year before. The decision must have been made in one of them. ${ }^{85}$ As the distinguishing feature between the remaining rationales (rent seeking vs. perceived costs) is the power of the management, all variables that proxy managerial power are included as explanatory variables, leading to the following pooled probit model:

$$
\begin{aligned}
Y_{2 i}= & \beta_{0}+\beta_{1} \text { FreeFloat }_{i t}+\beta_{2} \text { SizeSupervBoard }_{i t}+\beta_{3} \text { FormerCEOChair }_{i t} \\
+ & \beta_{4} \text { CEOTenure }_{i t}+\epsilon_{i t} .
\end{aligned}
$$

\subsubsection{Results and Robustness}

Because of the reduced sample size and the shorter time frame, I end up with a relatively small sample of 54 firm-year observations. Results of a pooled probit regression (model (10)) and a random-effects probit regression (model (11)) are presented in Table 4.6.

In model (10), only former CEO chairman shows up significant and that only at a ten percent level. Moreover, the pseudo $R^{2}$ is below ten percent. Having only four explanatory variables in the regression makes it more likely that there is an unobserved

\footnotetext{
84 See Table 4.1

${ }^{85}$ I cannot apply this logic in the first stage regression as it is not always discernible when companies that continue using stock options make that decision.
} 
Table 4.6: Probit regressions explaining the choice of performance shares over restricted stock.

\begin{tabular}{lcc}
\hline & $(10)$ & $(11)$ \\
\hline Free Float & -0.0072 & $-0.0195^{*}$ \\
& $(0.5381)$ & $(0.0910)$ \\
Board Size & 0.0223 & $0.0771^{*}$ \\
& $(0.6117)$ & $(0.0741)$ \\
FormerCEOchair & $0.9784^{*}$ & $1.7134^{* * *}$ \\
& $(0.0973)$ & $(0.0016)$ \\
CEO Tenure & 0.0834 & $0.1231^{*}$ \\
& $(0.2911)$ & $(0.0816)$ \\
\hline Clustered SE & Yes & BME \\
Observations & 54 & 54 \\
Companies & 28 & 28 \\
Pseudo $R^{2}$ & 9.77 & 62.78 \\
\hline \multicolumn{2}{c}{$* * * \mathrm{p}<0.01, * * \mathrm{p}<0.05, * \mathrm{p}<0.1$}
\end{tabular}

The table reports results from a pooled probit (10) and a random-effects probit regression (10) with the dependent variable being one for companies that adjust top management equity compensation by adopting performance shares and zero for those that use restricted stocks or no equity-based compensation. The sample consists of 54 observations from 28 firms and includes the fiscal year before the change and the year in which the change occurred. Independent variables represent the power of stockholders versus managers. P-values are reported in parenthesis and based on cluster-robust standard errors for model (9) and on the Butler and Moffitt (1982) estimator (BME) for model (11).

variable bias that can be eliminated by the inclusion of random effects. I will therefore focus on model (11), which includes such effects.

The most striking result of model (11) is the influence of the former CEO becoming chair of the supervisory board. The corresponding indicator variable is positive, as expected, and highly significant. I interpret this as evidence for former CEOs preferring granting less transparent equity instruments to their successors, which lends support to the idea that weak shareholder power will allow managers to use less transparent instruments while at the same time confirming that the transition from CEO to chairman represents a hidden cost, as asserted by Andres et al. (2012), that is detrimental to shareholder interests. The size of the supervisory board and CEO tenure both have positive signs, as expected, although their significance levels are considerably lower. I interpret this as (weak) support for the conjecture that companies switch to performance shares when shareholder power is limited. Contrary to my expectations, free float has a negative sign 
in the regression output. With a p-value close to ten percent, however, the statistical significance of this result is limited.

All in all these results provide supportive evidence for two consequences of the change in the accounting regime in Germany. First, lower shareholder power is linked to the choice of less transparent equity-based instruments. Second, even with shareholder power but lacking financial expertise, the new accounting rules will most likely not lead to optimal contracting. The former is clearly a situation of rent extraction as managers are compensated with an instrument that preserves previous payoff structures while at the same time avoiding higher disclosure requirements. As a remedy, companies should make sure to improve their corporate governance mechanisms in that shareholder power is increased and standard setters should strive to level the playing field for all instruments by requiring the same disclosures of performance shares as they already do of stock options. The latter case illustrates that shareholder power without sufficient financial expertise will result in contracts that are most likely not optimal. Hence, corporate governance also needs to be improved by having more expertise on the part of shareholders and their representatives.

\subsection{Summary of Main Results}

This study provides new empirical evidence on the question of whether accounting rules influence equity-based compensation choices. Stock option grants have generally been attributed to either optimal contracting considerations, managerial rent seeking, or the perceived low costs of at-the-money options brought about by their favorable accounting treatment. Only under the latter two of these theories should accounting lead to a discernible effect at all. The immediate exogenous shock that is the introduction of IFRS 2 in Germany changed a setting with a homogenous treatment of all equity-based payment forms to one where very similar instruments now see different disclosure requirements. Together with the mandatory expensing and the heightened transparency, this provides an almost ideal research situation to study those questions.

Previous research has confirmed that the new transparency level in the United States, where SFAS 123r was introduced at about the same time, has indeed led to changes in compensation packages. ${ }^{86}$ While these U.S.-studies document accounting influences,

${ }^{86}$ See, for example Brown and Lee (2011) and Hayes et al. (2012). 
there may be confounding effects, in particular because of the long transition period from SFAS 123 and the unequal treatment of options under APB 25. Moreover, these studies cannot say much at all about how the new accounting regime affects the choice of equity-based compensation on a more detailed level.

I find that there is a general trend away from stock options, yet that proxies for ESO plan sophistication are positively related to the likelihood of a continued use of stock options. This suggests that optimal contracting firms keep stock options and that neither the new transparency nor the requirement to fully expense compensation costs in their income statements affects these firms.

In a second step I analyze the companies that did change their choice of equity-based instrument. Corresponding to the other two rationales, I find supportive evidence for companies with lower shareholder power or expertise to be more likely to use different equity instruments than before, or no equity-based instruments at all. In other words, if optimal contracting is not the underlying reason for the option grant, IFRS 2 does have an influence.

As powerful rent-seeking managers choose options because they allow them to make compensation levels appear substantially lower than they actually are, the new transparency creates a need for a new non-transparent instrument that is available in the form of performance shares. Since my proxies for managerial power are positively related to the likelihood of a change to performance shares, I conclude that under the managerial power approach IFRS 2 drives managers towards the comparatively non-transparent performance shares. Finally, those companies that relied on stock options because of the perceived low accounting costs are now forced to calculate a fair value. The discrepancy between their perception and reality should lead to a substitution effect away from complicated and complex instruments towards something linear and transparent, which is exactly what can be observed in the sample. Here, IFRS 2 has the effect of leading companies towards transparent and easily valued restricted stocks or no equity-based instrument at all.

These results have several policy implications for accounting standard setters, corporate governance regulators, and companies alike. Since rent seekers still have a nontransparent instrument at their disposal that behaves like an option in many ways, yet is not treated as such in financial accounts, IFRS 2 falls short of its own goal of making companies publish all information relevant for understanding the determination of the 
fair value. The IASB should remedy this and hold performance shares to the same transparency standard as stock options. Furthermore, the empirical findings suggest that rent seeking occurs where internal control mechanisms, which are part of a company's corporate governance, prevent shareholders from effectively controlling executives. As the observation of a former CEO serving as chairman of the supervisory board was the major factor increasing the likelihood of non-transparent performance shares being chosen as compensation instruments, I agree with the conclusion made by Andres et al. (2012) that this transition presents a hidden cost to shareholders. Shareholders should thus always strive to improve corporate governance structures in companies.

Finally, my findings are compatible with the notion that companies with low shareholder expertise discontinue using stock options after the adoption of IFRS 2. However, it is very unlikely that the new accounting regulation increases shareholder expertise as such. Making decisions on payment contracts based on inappropriate anchors or, more generally, without sufficient knowledge about the workings of such contracts is unlikely to lead to major improvements. Therefore, it still seems necessary for shareholders to continuously increase the expertise represented on the supervisory board. 


\section{The Effectiveness of IFRS 2}

IFRS 2 clearly states that companies shall include the effect of share-based payment in their profit and loss statements and that "[a]n entity shall disclose information that enables users of the financial statements to understand how $[. .$.$] , the fair value of the$ equity instruments granted, during the period was determined" (International Accounting Standards Board, 2004, p. A106). Not only disclosing the fair value but also the relevant input parameters for that valuation had two implications described in Chapter 4: companies that granted options because of the low perceived cost have reduced their programs and powerful rent-seeking managers have switched to performance shares. It is, however, the question if companies that continue to use options provide complete and correct information on their ESO. It is conceivable that managers trying to camouflage rents will not disclose fully or will bias options values downwards. At the same time, board members may still not fully understand option valuation and arrive at incorrect values. With the attention that management compensation is getting in the media and with much of the discussion focused on how much managers get paid, it is of critical importance to evaluate if fair values are disclosed accurately and with complete information. And thus the study in this chapter will tackle the following research questions. Do companies provide all required disclosure for their plans, and if not, why do they not fully disclose? And for those companies that do report fair values, do they underreport those values and why? Taken together, both issues will determine how effective the standard is in accomplishing its goal. ${ }^{87}$

\subsection{Previous Findings on Underreporting of Option Values}

In contracting theory, stock options represent an instrument with which the agency problem between management and owners can be resolved (e.g., Jensen and Meckling, 1976). Expensing them should not change anything about their use, nor should the

87 A variant of this study can be found in Merz (2013). 
increased transparency. Nonetheless, trying to change the accounting rules in the U.S. to that effect has been one of the most controversial projects of the Financial Accounting Standards Board with the strongest resistance coming from companies that award more of their executive pay in the form of options and that would incur the most political costs from reporting higher pay (Dechow, Hutton, and Sloan, 1996). This implies that managers have used options to hide the true extent of their remuneration and that, under an accounting regime with more transparency, there would be a need or an incentive to find other means of 'camouflaging' the true value.

A variety of papers have demonstrated that firms go to some lengths to avoid either having an expense related to stock options at all or to reduce the amount of the charged or disclosed expense. Analyzing the influence of SEC disclosure rules in the early 1990's, Yermack (1998) finds that companies underreport option values by applying discounts to the Black-Scholes value and by reducing expected option life. Botosan and Plumlee (2001) find that about one in ten companies do not provide all the information on their option valuation required by SFAS 123. For the first year of footnote disclosure under that standard, Balsam et al. (2003) find no evidence that firms deliberately manipulate stock option values, however they do find that companies with an incentive to reduce option expenses (i.e., start-up firms that want to appear profitable and poorly performing companies that want to avoid the perception of excessive pay) allocate less of the expense to that particular year. Johnston (2006) shows that companies underreport option values in order to improve share price performance and that this is more prevalent in companies that voluntarily recognize option expenses under SFAS 123. Aboody et al. (2004a) reveal that only those companies expense options that have a need to reduce information asymmetry in order to participate in capital markets.

Firms that chose to only disclose option values have been shown to underreport that value by reducing expected option life and expected volatility (Aboody et al., 2006). Aboody et al. (2006) also establish that the downward bias in the reported fair values is greater for firms with weaker corporate governance, higher excessive pay, and higher option expense. Hodder et al. (2006) look at the discretion managers have over the four major input parameters and find that while some adjustments convey additional private information to the market, on average they have a negative impact on the accuracy of the disclosed options values. In addition, they show that underreporting is linked to incentives to reduce compensation values. Bartov et al. (2007) investigate the choice between historical and implied volatility from traded call options as a model input 
and find that managers use the forward-looking implied volatility only when it is lower than historical volatility which leads to a lower fair value estimate. Moreover, they find that this behavior is more pronounced the more heavily a company relies on stock options in managerial compensation. Choudharay et al. (2009) report that companies with high pro forma options expenses, weaker corporate governance, and higher option numbers granted to top executives accelerated the vesting of their stock option before the introduction of SFAS 123r in order to avoid accounting charges. Finally, Bechmann and Hjortshøj (2009) analyze stock option valuation in Denmark and find weak evidence for underreporting. They surmise that strong influential (institutional) investors have a disciplining effect on managers' discretion.

Taken together the research suggests that underreporting is promoted by two factors: an incentive to hide the true value of the remuneration and the possibility to do so within weak corporate governance structures. It remains to be seen, however, if the findings from the U.S. can be transferred to Germany. First and foremost, these studies have used samples predominantly consisting of plain-vanilla at-the-money options which are considerably less difficult to value. Stated differently, the additional vesting conditions that are being used in Germany offer much more potential to influence valuation. At the same time, these kinds of options have a longer history in Germany than in the U.S. and thus it is unlikely that any potential valuation problems could be attributed to an unfamiliarity with the instruments. In addition, the differences in corporate governance and enforcement regimes, both of which have a huge bearing on financial reporting outcomes, at least make it questionable that previous results are likewise valid in a German setting.

\subsection{Data Set and Descriptive Statistics on Plan Design}

In order to investigate whether companies underreport option values in Germany, I first identify all companies from the large-cap, mid-cap, or small-cap stock index (DAX, MDAX, SDAX, respectively $)^{88}$ that have issued executive stock options in at least one year between 2005 (the year in which IFRS 2 took effect) and 2011. I then hand-collect 
Table 5.1: Descriptive Statistics of ESO Performance Conditions

\begin{tabular}{lllllllll}
\hline & $\mathbf{2 0 0 5}$ & $\mathbf{2 0 0 6}$ & $\mathbf{2 0 0 7}$ & $\mathbf{2 0 0 8}$ & $\mathbf{2 0 0 9}$ & $\mathbf{2 0 1 0}$ & $\mathbf{2 0 1 1}$ & total \\
\hline $\begin{array}{l}\text { Number of plans } \\
\text { Types of plans }\end{array}$ & 34 & 34 & 30 & 31 & 26 & 22 & 20 & 197 \\
$\begin{array}{l}\text { Absolute hurdles } \\
\text { 1) premium option }\end{array}$ & 20 & 22 & 18 & 19 & 16 & 13 & 11 & 119 \\
2) barrier options & 10 & 11 & 8 & 7 & 8 & 6 & 7 & 57 \\
3) performance options & 9 & 2 & 2 & 2 & 2 & 2 & 1 & 12 \\
Relative hurdles & 5 & 4 & 2 & 2 & 1 & 0 & 0 & 14 \\
4) outperformance hurdle & 4 & 3 & 2 & 2 & 1 & 0 & 0 & 12 \\
5) exchange option & 1 & 1 & 0 & 0 & 0 & 0 & 0 & 2 \\
Accounting hurdles & & & & & & & & \\
6) EPS increase & 0 & 1 & 1 & 1 & 1 & 1 & 1 & 6 \\
Combined hurdles & 9 & 7 & 9 & 9 & 8 & 8 & 8 & 58 \\
3) and 4) & 5 & 4 & 4 & 4 & 5 & 4 & 4 & 30 \\
3) or 4) & 0 & 0 & 1 & 1 & 1 & 1 & 1 & 5 \\
3) and 5) & 1 & 1 & 1 & 1 & 0 & 0 & 0 & 4 \\
4) and 6) & 1 & 0 & 1 & 1 & 0 & 1 & 1 & 5 \\
2) and 4) & 2 & 2 & 2 & 2 & 2 & 2 & 2 & 14 \\
\hline
\end{tabular}

The table shows the number of plans in each year and the kind of exercise condition attached to it. The first panel shows plans with only absolute hurdles, the second with only relative hurdles, the third with only accounting-based hurdles, and the bottom panel shows plans that have a combination of the different types. 
data on the options, namely plan characteristics, valuation model, input parameters and reported fair values from annual reports, creating a unique data set.

Table 5.1 gives an overview over the number of ESO tranches in my sample and the exercise conditions attached to them. It can be seen that the number of plans per year is declining after the introduction of IFRS 2. A similar trend has also been observed in, for example, the United States after the introduction of SFAS 123. Furthermore, the table shows that there are a variety of different exercise conditions in use in German ESO, which makes this data set distinctly different from the ones used in previous U.S. based studies. The most popular conditions are the out-of-the-money (premium) option and the absolute performance options, clearly outweighing the other types. The absolute performance option is usually granted at the money, yet can only be exercised when the stock price is at or above a predetermined threshold. In other words, this is a portfolio consisting of an out-of-the money option with an exercise price equal to the performance target and a digital option that pays the difference between the performance goal and $\mathrm{S}_{0}$. There are also a lot of plans that have more than one vesting condition, making up more than one quarter of the sample. For most of these options the conditions have an "and" connection, meaning that both have to be fulfilled before exercise becomes possible.

The table also confirms the trends reported by Winter (2003) and Langmann (2007): exchange options are less relevant than those that have an external barrier and make exercise conditional on the outperformance of an index. Accounting hurdles hardly play any role in Germany, and plans tend to be generally more complex. This has important consequences for the question of ESO valuation as these plans offer more possibilities to influence the fair value estimates and results in more complicated valuation. It also casts doubt on the transferability of results from U.S. studies, which have predominantly plain-vanilla options without any special performance conditions.

\footnotetext{
88 Together the indices account for roughly $90 \%$ of the market capitalization in Germany.
} 


\subsection{Analysis of Disclosure and Underreporting}

\subsubsection{Empirical Findings on Disclosure Practices}

Disclosure of the relevant input parameters and the fair values of the option tranches is depicted in Table 5.2. The first panel shows the instances in which a fair value, the maturity, and both these figures have been published. They are separated from the other parameters as they are the ones that are absolutely necessary in order to calculate a fair value and look for potential underreporting. The other parameters, namely the interest rate, the volatility, and the dividend yield (listed in Panel B) can all be obtained from other sources. Panel $\mathrm{C}$ indicates the percentage of firms that have provided all the information required by IFRS 2 while Panel D gives an overview over the valuation models used.

The first panel shows that overall disclosure of the minimum values is quite good with most individual values being reported in $80 \%$ or more of the cases, the one exception being the year 2010. It can also be seen that this is rather stable over time. Similar results are obtained for the other parameters, except for the dividend yield which is reported in the context of ESO valuation surprisingly rarely. In 2009 for example, only $44 \%$ of firms report it. It may be possible that some firms do not pay dividends and therefore not comment on that specifically in the footnotes of the annual report. Nonetheless, this is not in line with IFRS 2 and most likely the reason why overall disclosure as reported in Panel $\mathrm{C}$ is so low.

Panel D of the Table 5.2 shows the valuation models employed by the companies. The Black/Scholes (Merton) Model is the most popular one, especially when considering that some firms stated that they solved the Black/Scholes equation numerically via a Monte Carlo Simulation. These instances are included under "Monte Carlo" in the table, which is the second most popular model. Again there are a number of companies that do not comply with IFRS 2 as they do not specifically name a model, but rather use formulations such as "used a generally accepted option valuation model". Previous studies have always had samples where the overwhelming majority of companies used the Black/Scholes Model. Even Bechmann and Hjortshøj (2009) have only one company in their sample that does not rely on that model, although they state that most Danish companies incorporate intricate exercise conditions in their plans. For my sample the 
Table 5.2: Disclosure of Valuation and Parameters over Time

\begin{tabular}{|c|c|c|c|c|c|c|c|c|}
\hline & 2005 & 2006 & 2007 & 2008 & 2009 & 2010 & 2011 & average \\
\hline \multicolumn{9}{|c|}{ Panel A: Minimum Disclosure } \\
\hline Fair Value & 0.88 & 0.94 & 0.90 & 0.90 & 0.85 & 0.82 & 0.85 & 0.88 \\
\hline Maturity & 1.00 & 0.97 & 0.97 & 0.97 & 0.96 & 0.91 & 0.80 & 0.96 \\
\hline Both & 0.88 & 0.91 & 0.87 & 0.87 & 0.81 & 0.77 & 0.80 & 0.85 \\
\hline \multicolumn{9}{|c|}{ Panel B: Parameters } \\
\hline Interest Rate & 0.88 & 0.85 & 0.87 & 0.87 & 0.85 & 0.82 & 0.80 & 0.85 \\
\hline Volatility & 0.88 & 0.85 & 0.86 & 0.87 & 0.85 & 0.82 & 0.80 & 0.85 \\
\hline Dividend Yield & 0.71 & 0.65 & 0.70 & 0.59 & 0.44 & 0.59 & 0.65 & 0.68 \\
\hline \multicolumn{9}{|c|}{ Panel C: Full Disclosure } \\
\hline Full Disclosure & 0.56 & 0.62 & 0.63 & 0.65 & 0.65 & 0.50 & 0.60 & 0.60 \\
\hline \multicolumn{8}{|c|}{ Panel D: Valuation Models } & total \\
\hline Black/Scholes & 16 & 15 & 9 & 10 & 8 & 6 & 5 & 69 \\
\hline Binomial & 4 & 7 & 9 & 10 & 8 & 5 & 5 & 48 \\
\hline Trinomial & 1 & 1 & 0 & 0 & 0 & 0 & 0 & 2 \\
\hline Monte Carlo & 8 & 8 & 10 & 9 & 8 & 9 & 9 & 61 \\
\hline not specified & 5 & 3 & 2 & 2 & 2 & 2 & 1 & 17 \\
\hline
\end{tabular}

Panel A shows the percentage of companies that disclose the fair value and the maturity in a given year and over the entire sample. These are the two parameters that are absolutely necessary for valuing the option grants. Panel B shows the same for the remaining valuation parameters. "Dividend yield" also includes dividends in levels and information about dividend protection of the options, in which case dividends no longer need to be included in the valuation. Panel $\mathrm{C}$ combines the information from the two previous panels to show the percentages of companies that provide all required information. Finally, panel D shows the option pricing models used by the companies. "Monte Carlo" includes those instances where a company used Monte Carlo simulations to solve Black/Scholes models. 
variety in models can certainly be attributed to the many different exercise conditions present in German ESO.

Table 5.3 provides an overview over the compliance with the disclosure requirements broken down by the different plan types, namely those with absolute performance hurdles, relative performance hurdles, accounting-based hurdles, and a combination of the former. The striking thing to see here is that plans that fall into the "combined" category exhibit a staggeringly bad disclosure practice. For only $63 \%$ of the tranches do companies also report a fair value. This is clearly below the values for the other types and could indicate that companies that employ these already complex plans still have an incentive to hide option values. For the other plans, the low values for full disclosure depend mostly on the dividend yield being omitted so frequently.

Table 5.3: Disclosure of Valuation and Parameters per Plan Category

\begin{tabular}{lllll}
\hline Performance Condition & Absolute & Relative & Acc.-based & Combined \\
\hline Tranches & 119 & 14 & 6 & 54 \\
$\begin{array}{l}\text { Panel A: Minimum Disclosure } \\
\text { Fair Value }\end{array}$ & 0.96 & 1.00 & 1.00 & 0.63 \\
Maturity & 0.93 & 1.00 & 1.00 & 1.00 \\
Both & 0.90 & 1.00 & 1.00 & 0.63 \\
& & & & \\
Panel B: Parameters & & & & 0.70 \\
Interest Rate & 0.92 & 0.71 & 1.00 & 0.70 \\
Volatility & 0.92 & 0.71 & 1.00 & 0.53 \\
Dividend Yield & 0.77 & 0.50 & 1.00 & \\
& & & & 0.52 \\
Panel C: Full Disclosure & & & & \\
Full Disclosure & 0.61 & 0.50 & 1.00 & \\
\hline
\end{tabular}

This table shows the compliance with the disclosure requirements broken down by plan categories. Panel A shows the percentage that disclose the fair value and the maturity over the entire sample. These are the two parameters that are absolutely necessary for valuing the option grants. Panel B shows the same for the remaining valuation parameters. Panel $\mathrm{C}$ combines the information from the two previous panels to show the percentages of companies that provide all required information. 


\subsubsection{Empirical Findings on Underreporting}

\subsubsection{Calculating Option Values}

In order to determine whether or not companies underreport the option values in their annual reports, I first determine all the necessary input variables as objectively as possible, i.e., strictly according to the guidelines from IFRS 2. ${ }^{89}$ All I require from the annual reports are general information such as the exercise conditions and caps as well as the (expected) maturity. Further, I only include companies that report the fair value either at grant date or at the end of the fiscal year. ${ }^{90}$ This has the advantage that I do not have to eliminate option issues for which not all the parameters are disclosed. This results in 125 observations.

The other inputs are determined as follows. Since the expected dividend yield may only be based on publicly available information, I rely on I/B/E/S consensus estimates for the relevant years. Historical annualized volatilities and correlations with an index, when necessary, are calculated based on the continuously compounded daily returns over a period that corresponds to the expected life of the option or the maximum stock price history, whichever is shorter. Finally, I calculate risk-free interest rates from the term structure based on traded German government bonds. ${ }^{91}$

Uncertainty about the exercise of ESO is one of the major difficulties in option valuation (e.g., Maris et al., 2003). As stated above, I use the expected time to maturity from annual reports whenever it is available. When companies make no mention of the expected life, I assume the maximum time to maturity is the expected one. ${ }^{92}$ With the time of exercise known, all options are de facto European-style options which simplifies valuation greatly.

To obtain option values, I use a common framework, based on standard no-arbitrage pricing. It assumes that stock prices and, whenever necessary, index levels follow correlated geometric Brownian motion processes under the risk-neutral measure. All exercise

\footnotetext{
89 See Section 3.2.2.

90 SAR have to be revalued at the end of each fiscal year until they are exercised or expire. In this case I evaluate the underreporting at the end of the year in which they were first issued, since that is the one that is relevant for the income statement.

91 The German Bundesbank uses the Svensson method (Svensson, 1994) and publishes daily values for the parameters, available at www.bundesbank.de.

92 Five companies state that they model a specific exercise behavior, which I cannot reproduce because of insufficient information. I will, however, account for this in my regression analyses.
} 
conditions and caps are considered, except for the accounting hurdles that exist for two plans. The price computations use Monte Carlo simulations with daily time steps and 100,000 replications. The resulting option values are the ones to be expected under strict adherence to the IFRS rules. Based on these values and the disclosed ones from the financial statements, I measure underreporting as

$$
\frac{\text { disclosed value - expected value }}{\text { disclosed value }} \text {. }
$$

This ratio will be below zero when the options are undervalued and above zero when they are overvalued.

\subsubsection{Underreporting}

For those companies that provide enough information to calculate a fair value, I set that expected fair value in relation to the fair value stated in the annual reports. Results are presented in Table 5.4 and values below zero indicate underreporting while values above zero indicate overreporting. 
Table 5.4: Underreporting by Year

\begin{tabular}{|c|c|c|c|c|c|c|c|c|}
\hline & 2005 & 2006 & 2007 & 2008 & 2009 & 2010 & 2011 & total \\
\hline Observations & 22 & 23 & 20 & 21 & 16 & 12 & 11 & 125 \\
\hline Mean & -0.512 & -0.139 & -0.424 & -2.469 & 0.007 & -0.278 & -0.518 & -0.670 \\
\hline Median & 0.054 & 0.007 & -0.151 & -0.0745 & 0.082 & -0.217 & -0.427 & -0.052 \\
\hline $\mathrm{SD}$ & 1.453 & 0.626 & 0.714 & 6.060 & 0.450 & 0.892 & 0.549 & 2.690 \\
\hline $\operatorname{Max}$ & 0.777 & 0.549 & 0.349 & 0.372 & 0.787 & 0.545 & 0.307 & 0.787 \\
\hline Min & -4.726 & -2.433 & -2.074 & -21.66 & -0.956 & -2.819 & -1.735 & -21.66 \\
\hline T mean (1-sided) & $0.057^{*}$ & 0.149 & $0.008^{* * *}$ & $0.038^{* *}$ & 0.525 & 0.152 & $0.005^{* * *}$ & $0.003^{* * *}$ \\
\hline T mean (2-sided) & 0.113 & 0.300 & $0.016^{* *}$ & $0.077^{*}$ & 0.950 & 0.304 & $0.011^{* *}$ & $0.006^{* * *}$ \\
\hline
\end{tabular}

This table shows the means and medians of the underreporting for each year, calculated as the difference between disclosed value and the expected value, divided by the disclosed value. SD refers to the standard deviation. T-tests were performed with the null hypothesis that the mean is equal to zero and the alternative hypothesis that the mean is below zero (one-sided) and unequal to zero (two-sided). Values are the p-values for said hypothesis tests. 
It can be seen that the mean of the underreporting ratio is negative for the complete sample and in every year, except for 2009. Moreover, the years differ quite a bit, both in terms of the standard deviation and in terms of the minimum value (i.e., the maximum underreporting). 2005 and 2008 had the most dispersion of the underreporting values. The maximum values, that is overreporting, appear to be rather stable over the years. I performed t-tests in order to determine if the underreporting is statistically significant. The null hypothesis that the mean is equal to zero can be rejected in favor of the alternative that it is below zero (one-sided tests) in four of the seven years and for the overall sample. For the two-sided tests with the alternative hypothesis that the mean is unequal to zero, the p-values for the t-test are only significant in three of the seven years.

In 2008, the low mean and the high standard deviation are caused by two outliers with underreporting ratios of -21.66 and -18.96 . Both are cases in which the respective companies reported extremely low fair values. One case can probably be attributed to a data error: the company reports to have used a dividend yield of $18 \%$ in estimating the fair value. When I use a dividend yield of $1.8 \%$ along all the other parameters used by the company, the result is quite close to the value I have determined with the objective market parameters. For the other outlier there seems to be no apparent reason. Results remain the same, however, even if I leave the two outliers out of the analysis. The underreporting mean in 2008 is then -0.591 with a standard deviation of 1.229 . Both the one-sided and the two-sided T-test are still significant at the same confidence level. The same holds true for the entire sample when the outliers are eliminated; the mean falls to -0.35 but the significance levels remain unchanged. Since it is the objective of this study to identify underreporting regardless of the cause, I will not exclude the outliers from further analysis.

Table 5.5 shows the underreporting broken down by plan category. It can be seen that statistically significant underreporting is limited to plans with absolute performance conditions and those with a combination of different types of hurdles. Those are also the two categories with the worst disclosure performance. It should be noted, though, that the median for the category of absolute performance hurdles is positive, while that for the combined category is also negative. As before the statistical significance does persist even when the two aforementioned outliers are excluded..$^{93}$

93 The mean underreporting drops to -0.201 in the first column of Table 5.5, yet the significance level for the one-sided t-test remains at $5 \%$ and the one for the two-sided test is increased to $5 \%$ (p-value of 0.021$)$. 
Table 5.5: Underreporting by Plan Category

\begin{tabular}{lcccc}
\hline Performance Condition & Absolute & Relative & Acc.-based & Combined \\
\hline N & 81 & 9 & 6 & 29 \\
Mean & -0.466 & -2.102 & -0.200 & -0.891 \\
Median & 0.017 & 0.007 & -0.259 & -0.421 \\
SD & 2.503 & 6.338 & 0.510 & 1.326 \\
Max & 0.787 & 0.521 & 0.549 & 0.545 \\
Min & -21.66 & -18.96 & -0.690 & -4.726 \\
T mean (1-sided) & $0.049^{* *}$ & 0.175 & 0.191 & $0.001^{* * *}$ \\
T mean (2-sided) & $0.098^{*}$ & 0.349 & 0.381 & $0.001^{* * *}$ \\
\hline
\end{tabular}

This table shows the means and medians of the underreporting for each plan category, calculated as the difference between disclosed value and the expected value, divided by the disclosed value. SD refers to the standard deviation. T-tests were performed with the null hypothesis that the mean is equal to zero and the alternative hypothesis that the mean is below zero (one-sided) and unequal to zero (two-sided). Values are the p-values for said hypothesis tests.

The findings presented in theses two tables clearly show that underreporting is a statistically significant issue in German executive stock options. Similar to the results in Bechmann and Hjortshøj (2009) not all years show underreporting though. But in contrast to that study, I use the expected time to maturity and not the contractual time and still find significantly downwardly biased option values. ${ }^{94}$ Thus, underreporting may be of more concern in this setting and potentially caused by the more intricate stock option design elements. It is therefore a logical next step to investigate which companies underreport the value of their ESO.

\subsubsection{Determinants of Inadequate Reporting}

Now that it has been established that there is both incomplete and incorrect reporting, the latter in the form of underreporting, the following section will attempt to explain what drives the two phenomena.

\subsubsection{Methodology and Explanatory Variables}

\section{Heckman Correction}

${ }^{94}$ In a robustness check Bechmann and Hjortshøj (2009) also use the expected life but they only find weak evidence of underreporting in that case. 
Since several companies do not provide all required data in every year, regressing deviations of stated option values from expected ones on some explanatory variables is subject to a potential selection bias. Companies that want to hide the true option values may be the ones that do not provide all required information in the first place. This will be dealt with by performing a two-stage Heckman (1979) correction, where at first a probit regression will be run to determine which characteristics explain whether a company provides full disclosure or not. The dependent variable will be coded one if all necessary parameters are disclosed and zero if not. Necessary parameters in this case does not refer to the ones listed in IFRS 2, but to the ones I require for my valuation. Those are also the ones without which it is not possible to check the parameters disclosed in the annual report. ${ }^{95}$ The sign of the significant coefficients will reveal the impact of the variable on the likelihood of compliance with IFRS 2. Then, Heckman's lambda (also known as the inverted Mill's ratio) will be included in the second stage regression, which will contain the same explanatory variables, but the dependent variable will be the deviation ratio defined above. ${ }^{96}$ If lambda is significant in the second regression, it is likely that there is a selection bias that is being corrected by the inclusion of the labmda.

Lennox, Francis, and Wang (2012) point out the importance of including relevant exclusion restrictions in the first stage that can be validly omitted from the second stage. Ideally, this must be a variable that has explanatory value on the first stage of the selection model, but not the second one. The introduction of IFRS presents a fundamental change in the way companies have to prepare financial statements in Germany. ${ }^{97}$ Whether a company then fully and correctly complies with a new standard, such as IFRS 2, will depend on how adapt the accountants are at following the new system. Prior literature has documented that accounting experience is positively related to the quality of financial statements (e.g., Abbott, Parker, and Peters, 2004) and so I try to measure the accounting experience by including a dummy that is one if the company has prepared at least one IFRS-based annual report prior to the year(s) in the analysis. Application of the new standards became mandatory in 2005, but companies were allowed to adopt them in earlier years. The question of any gathered IRFS-related expertise is entirely different from the question of whether the options values have been

\footnotetext{
95 For example, a company might list all four input parameters, yet without knowing the grant date it is impossible to check if, for example, the volatility is calculated correctly.

96 This procedure follows Bechmann and Hjortshøj (2009) and, for the second stage, Johnston (2006).

97 See Ernstberger and Vogler (2008) for a description of the differences and Bae, Tan, and Welker (2008) for a formal analysis of "distances" between different international GAAPs.
} 
correctly determined. Consequently, the variable IFRSexperience can be excluded from the second stage regression.

\section{Explanatory Variables}

According to Bebchuk et al. (2002), managers will engage in camouflaging the value of their pay to avoid outrage costs. This suggests that variables explaining underreporting can fall in two broad categories: managers must have the power to influence the underreporting and they must have an incentive to do so.

\section{Managerial Power Variables}

Managerial power has often been linked to both rent extraction and reduction of outrage costs through camouflage. A recent study by Abernethy et al. (2013), for example, finds that powerful managers use their influence in order to attach weak performance targets to their option grants and Morse, Nanda, and Seru (2011) show that the more powerful managers are, the more their compensation hinges on measures on which the company has traditionally performed well. In accordance with prior literature, I use the following variables to capture managerial power:

A high Free float is often synonymous with dispersed ownership, which has been shown to lead to less effective compensation control by shareholders, especially without large blockholders (Shleifer and Vishny, 1986). Elston and Goldberg (2003) have confirmed this relationship for Germany where highly concentrated ownership acts as a monitoring device for executive compensation. Since less oversight means more possibilities for managers to bias option valuations, high free float is expected to have a negative sign in both stages of the regression. The positive role of institutional investors in monitoring and influencing executive compensation is well established (e.g., Hartzell and Starks, 2003). Moreover, Bechmann and Hjortshøj (2009) show that higher institutional ownership translates into better adherence to the disclosure requirements. I collect the percentage held by institutional investors from company reports and expect it to counteract underreporting.

A more direct oversight function is to be carried out by the supervisory board, yet it has been found that larger boards more often experience communication and free-rider problems (Hermalin and Weisbach, 2003) which can lead to rent extraction (Jensen, 1993). Although most studies on this subject refer to one-tier board systems, there is no reason to doubt that these results can be transferred to the German two-tier system, especially because companies are free to go above the minimum number of supervisory 
board members dictated by law. I expect Boardsize to positively affect the likelihood of a company not disclosing all required information and/or biasing fair values downward.

Because of the two-tier system a CEO cannot concurrently serve as chairman of the board, yet a retiring CEO oftentimes will assume that position. Andres et al. (2012) have found that this represents a hidden cost to companies, as former CEOs will increase their former colleagues' pay. It is possible that the former CEO will also adopt a more lenient way when it comes to supervision of the compensation reporting and I therefore include the dummy variable FormerCEOchair which I expect to be conducive to the underreporting. ${ }^{98}$ In addition, CEOs will amass more influence the longer they serve in that position (Bebchuk et al., 2002) and Hill and Phan (1991) have shown that the influence associated with tenure leads to pay that is more aligned with CEO preferences, which in turn might need to be hidden. At the same time, Beasley (1996) finds that longer (board) tenure reduces instances of accounting fraud, which could mean that the experience accumulated by the CEO helps him or her to better monitor the financial reporting. The effect of CEOtenure is thus not clear.

Finally, I include Size here, measured as the natural log of market capitalization. Aboody et al. (2004a) report that larger companies are more likely to voluntarily give option values under SFAS 123 and Bechmann and Hjortshøj (2009) find that size is positively linked to the likelihood of complete disclosure in Denmark. They surmise that it is easier for larger firms to have specialized and more experienced accounting divisions and that they are more scrutinized by the public.

\section{Managerial Incentive Variables}

Managers will engage in underreporting if they feel that they have something to hide, i.e., want to avoid outrage costs, or if they have reason to reduce information asymmetry. A logical first step in this category is the salary that executives are paid because that will lead to outrage costs. Consequently, Salary will measure the average yearly remuneration of the members of the executive board and it is expected to be associated with less stringent adherence to the disclosure requirements. Similarly, if the number of new options is high, managers might want to hide valuation information or underreport the fair values. Aboody et al. (2006) find that the magnitude of option-based compensation does in fact work this way for the U.S. whereas Bechmann and Hjortshøj (2009) cannot

98 Because of this variable I exclude companies with a one-tier board system which leads to a loss of four observations. 
show this relation in Denmark. I include OptionsGranted as the number of options granted in a particular year.

Executive compensation in general is often criticized in the media, especially when companies are performing badly. In years with negative profits, it is all the more difficult to argue in favor of high salaries. Aboody et al. (2004a), Hodder et al. (2006) and Bechmann and Hjortshøj (2009) have all found that companies that experience negative profits underreport more. For this reason I include the dummy variable Loss that is one if the company has a negative income.

Related to the previous point is the influence of the capital structure. Highly leveraged companies may want to avoid the appearance of overpaying executives in the face of financial difficulties (Aboody et al., 2004a). Therefore, I include Market Leverage measured as total debt divided by the market capitalization. As Aboody et al. (2004a) also point out that high leverage can indicate that companies are active in capital markets, it may be the case that companies strive to disclose fully in order to reduce information asymmetry. Like Bechmann and Hjortshøj (2009) I include the dummy RaisedCapital which is one if the company has had a seasoned equity offering in that year.

I also include the Book-to-market (BTM) ratio as the book value of equity divided by the market value of equity. Bechmann and Hjortshøj (2009) find that this is significant in explaining underreporting in their sample. They surmise that companies with growths options, which are typically measured by the BTM, may want to reduce their information quality. Indeed, high growth companies exhibit more underreporting of ESO values in their sample.

Lastly, I use a dummy variable (Combined goals) that is one if the option plan has two combined exercise conditions. These plans have shown worse disclosure and higher underreporting than the other categories and it should therefore be ascertained if the plan design is a determining factor in this.

\subsubsection{Determinants of Incomplete Disclosure}

I begin by first estimating pooled probit regressions in order to determine which companies do not provide enough information on their ESO to calculate a fair value. For this I code companies that provide at a minimum the grant date, the fair value, the exercise 
conditions, and the maturity with a one. ${ }^{99}$ Results for this regression are presented in Table 5.6.

Model (1) contains all managerial power and managerial incentive variables as well as the exclusion restriction. As expected, the higher the percentage held by institutional investors, the more likely it is that a company provides disclosure of fair values and maturities, the absolute minimum in order to reproduce the option valuation. CEO tenure is also positive and significant at a five percent level, indicating that the longer a CEO serves in that capacity the better the disclosure becomes. This speaks against the idea that longer-serving CEOs also become self-serving CEOs with an incentive to hide remuneration disclosure. The effect of the number of options granted, which is likewise significant at the five percent level, works in the opposite direction. The greater the magnitude of the option expense is, the less likely the companies are to provide full disclosure, confirming previous studies on this effect. IFRS experience also leads to better disclosure, as the sign on the coefficient is positive and statistically significant. This points to the notion that it might take some time for companies to fully understand the idea of the new accounting rules and the more experience they have in this matter, the more likely they are to correctly comply with what the standards ask of them.

I submit these initial results to a several robustness checks. First, as Table 5.2 showed that there was some variety in the degree to which companies adhered to the publication requirements of IFRS 2, I include year dummies in order to filter out any time effects. The results of model (2) are almost unchanged. The same four variables are significant and for both CEO tenure and the IFRS experience dummy, the significance level has increased, confirming the conjecture that large option grants lead to weaker disclosure while institutional investors, CEO tenure, and IFRS experience improve it. The pseudo $R^{2}$ has also increased, indicating a slightly better model fit.

Next, I check for the effect of plan design by including the type dummy. Again, the same four variables show up as significant in the regression: the more of the shares are held by institutional investors and the longer a CEO has that position, the more likely it is that a company will disclose appropriately. This likelihood is also again increased by the IFRS experience and reduced when companies give out more options. Conditional

${ }^{99}$ As stated before, in the case of virtual stock options, options have to be revalued at the end of each fiscal year. So if the grant date is not given, I value the options at the date at which the fiscal year ends. 
Table 5.6: 1st stage Heckman: participation regression

\begin{tabular}{|c|c|c|c|c|}
\hline & (1) & $(2)$ & (3) & (4) \\
\hline Free float & $\begin{array}{c}-0.0121 \\
(0.2602)\end{array}$ & $\begin{array}{r}-0.0139 \\
(0.1732)\end{array}$ & $\begin{array}{c}-0.0121 \\
(0.2465)\end{array}$ & $\begin{array}{c}0.0007 \\
(0.9823)\end{array}$ \\
\hline Inst. investors & $\begin{array}{l}0.0243^{* *} \\
(0.0374)\end{array}$ & $\begin{array}{l}0.0269^{* *} \\
(0.0187)\end{array}$ & $\begin{array}{l}0.0243^{* *} \\
(0.0372)\end{array}$ & $\begin{array}{c}0.0402 \\
(0.2687)\end{array}$ \\
\hline Board size & $\begin{array}{c}0.1134 \\
(0.1651)\end{array}$ & $\begin{array}{c}0.1236 \\
(0.1745)\end{array}$ & $\begin{array}{c}0.1134 \\
(0.1640)\end{array}$ & $\begin{array}{c}0.2590 \\
(0.1162)\end{array}$ \\
\hline FormerCEOchair & $\begin{array}{c}1.1018 \\
(0.2183)\end{array}$ & $\begin{array}{c}1.2593 \\
(0.1220)\end{array}$ & $\begin{array}{c}1.1006 \\
(0.2187)\end{array}$ & $\begin{array}{c}1.1901 \\
(0.4604)\end{array}$ \\
\hline CEO tenure & $\begin{array}{l}0.1115^{* *} \\
(0.0146)\end{array}$ & $\begin{array}{l}0.1117^{* * *} \\
(0.0095)\end{array}$ & $\begin{array}{l}0.1116^{* *} \\
(0.0165)\end{array}$ & $\begin{array}{c}0.0389 \\
(0.7705)\end{array}$ \\
\hline Size & $\begin{array}{r}-0.1772 \\
(0.5514)\end{array}$ & $\begin{array}{c}-0.2379 \\
(0.4052)\end{array}$ & $\begin{array}{c}-0.1770 \\
(0.5573)\end{array}$ & $\begin{array}{r}-0.2374 \\
(0.7997)\end{array}$ \\
\hline Salary & $\begin{array}{c}0.3283 \\
(0.4428)\end{array}$ & $\begin{array}{c}0.3970 \\
(0.3668)\end{array}$ & $\begin{array}{c}0.3280 \\
(0.4358)\end{array}$ & $\begin{array}{c}1.2502 \\
(0.2762)\end{array}$ \\
\hline Opt. granted & $\begin{array}{c}-0.3462^{* *} \\
(0.0220)\end{array}$ & $\begin{array}{c}-0.3631^{* *} \\
(0.0191)\end{array}$ & $\begin{array}{c}-0.3460^{* *} \\
(0.0243)\end{array}$ & $\begin{array}{c}-0.8673^{* * *} \\
(0.0076)\end{array}$ \\
\hline Loss & $\begin{array}{c}0.4403 \\
(0.1304)\end{array}$ & $\begin{array}{c}0.4721 \\
(0.1339)\end{array}$ & $\begin{array}{c}0.4407 \\
(0.1494)\end{array}$ & $\begin{array}{c}1.0027 \\
(0.6925)\end{array}$ \\
\hline Market leverage & $\begin{array}{c}0.1750 \\
(0.5581)\end{array}$ & $\begin{array}{c}0.1870 \\
(0.5385)\end{array}$ & $\begin{array}{c}0.1743 \\
(0.5694)\end{array}$ & $\begin{array}{c}0.0382 \\
(0.9049)\end{array}$ \\
\hline Capital increase & $\begin{array}{r}-0.3710 \\
(0.4180)\end{array}$ & $\begin{array}{c}-0.4390 \\
(0.3638)\end{array}$ & $\begin{array}{r}-0.3708 \\
(0.4159)\end{array}$ & $\begin{array}{c}0.1994 \\
(0.9015)\end{array}$ \\
\hline BTM & $\begin{array}{c}0.2432 \\
(0.6760)\end{array}$ & $\begin{array}{c}0.3994 \\
(0.5889)\end{array}$ & $\begin{array}{c}0.2439 \\
(0.6863)\end{array}$ & $\begin{array}{c}0.7896 \\
(0.6018)\end{array}$ \\
\hline IFRS Experience & $\begin{array}{c}1.2206^{*} \\
(0.0583)\end{array}$ & $\begin{array}{l}1.2632^{* *} \\
(0.0460)\end{array}$ & $\begin{array}{c}1.2210^{*} \\
(0.0611)\end{array}$ & $\begin{array}{l}2.8147^{* *} \\
(0.0308)\end{array}$ \\
\hline Combined goals & & & $\begin{array}{c}-0.0035 \\
(0.9955)\end{array}$ & \\
\hline Year Dummies & No & Yes & No & No \\
\hline Pseudo- $R^{2}$ & 31.7 & 32.2 & 31.7 & 24.2 \\
\hline Observations & 106 & 106 & 106 & 106 \\
\hline
\end{tabular}

This table reports the probit participation regression with p-values based on cluster-robust standard errors given in parentheses for models (1) through (3). The dependent variable is a binary variable that is one whenever companies report enough to calculate a fair value for the option grant and zero otherwise. Model (2) includes year dummies to check for time effects, model (3) includes the type dummy, and model (4) is estimated as a random-effects panel model to check for unobserved heterogeneity and p-values are bootstrapped. 
on these effects, the type of plan has no explanatory power, suggesting that it is not so much the plan design that affects the disclosure, but the other four characteristics.

After having checked for time and plan effects, I also control for unobserved heterogeneity by specifying a random-effects panel model (model 4). Fixed-effects produce inconsistent estimates in a discrete choice model and with the rather small sample size, they also lead to a loss in degrees of freedom. Results confirm that the incentives to reduce disclosure are a major factor in explaining incomplete disclosure, as the coefficient for number of options granted is now significant at a one percent level. Also, IFRS experience is significantly positive at a five percent level again.

All in all the results suggest that the drivers to (not) disclose in Germany are similar to those in other studies. Institutional investors who represent a controlling mechanism act against deficient financial reports while managers with incentives to hide information, as measured by the magnitude of the ESO grant, tend to not provide the necessary disclosure of the valuation parameters. Longer tenured CEOs have a positive influence on the likelihood of disclosure which could be due to greater experience. Finally, if companies have already applied IFRS prior to the first option valuation, they are less likely to withhold some or all the relevant information on the valuation. This may point to the fact that not all deficient reporting may be caused by a deliberate obfuscation, but rather by inexperience with the new accounting rules. Year dummies and the plan dummy were not significant, indicating that they are not drivers for non-disclosure.

\subsubsection{Determinants of Underreporting}

I run pooled regressions with the underreporting ratio as the dependent variable and the results are reported in Table 5.7. Lambda has always been calculated from the corresponding participation regression presented in Table 5.6. The exclusion restriction IFRS experience is no longer included in these regressions. Exercise is a dummy variable that is one if the company stated that it had modeled a specific exercise behavior. In those cases, using the time to maturity would potentially lead to a too high expected value. If the effect on the value is similar for all companies, this should be controlled for by the dummy.

The baseline model (1a) includes all variables from the first stage and some variables show the expected effect. Companies that grant a large amount of options tend to report a lower fair value for those options than is obtained with more objective measures 
Table 5.7: 2nd stage Heckman: explaining underreporting

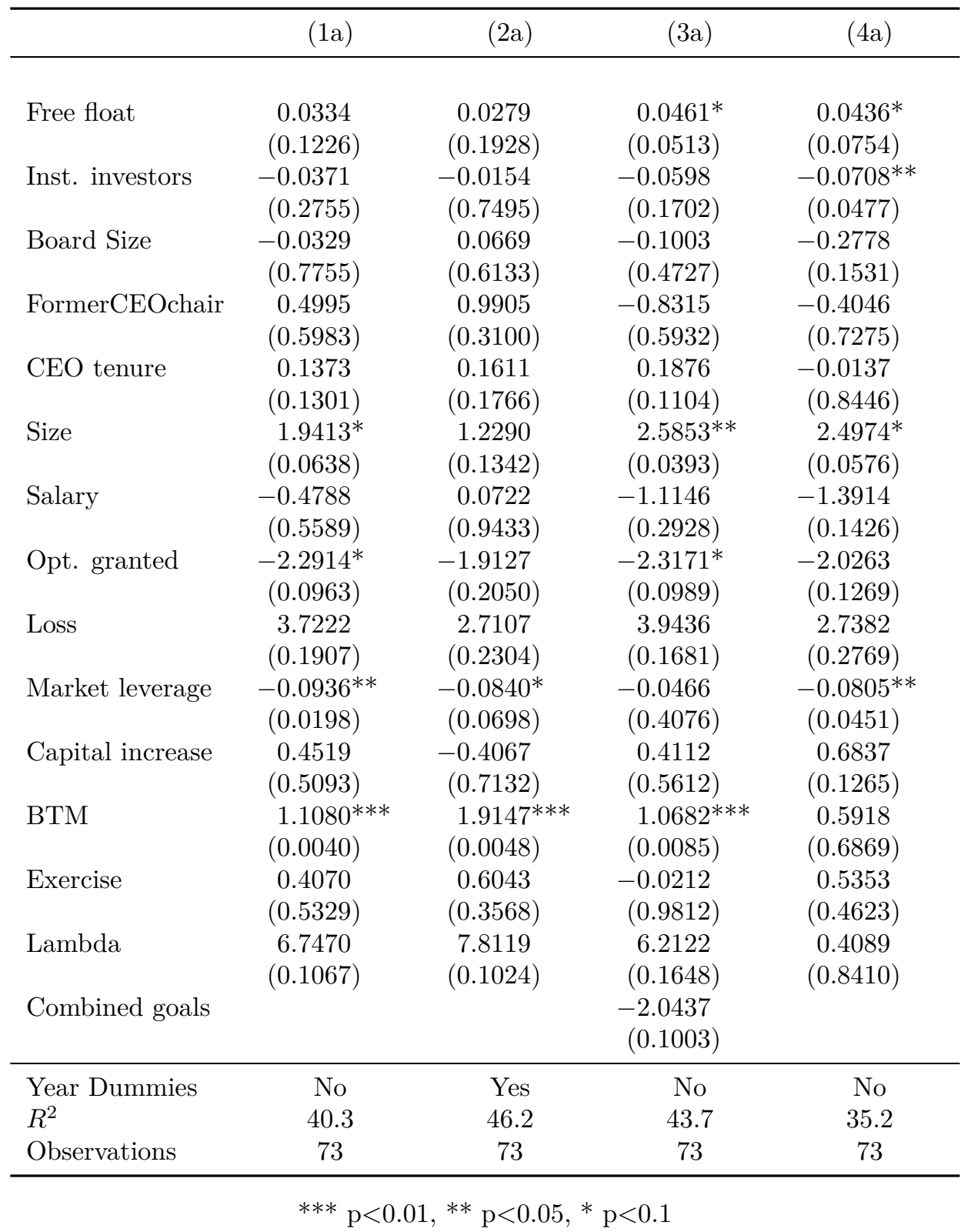

The table shows regression results for the second stage of the Heckman correction. The dependent variable is the underreporting ratio. Exercise is a dummy variable that is one if companies modeled exercise behavior. Lambda (also known as the inverse Mill's ratio) was obtained from the first stage participation equation. Regressions (1a) through (3a) are pooled regressions, while model (4a) is a random-effects panel model. P-values are given in parentheses and are based on cluster-robust standard errors. 
of the parameters. Likewise, companies with a high market leverage, which could indicate financial difficulties, underreport more than other companies. This contradicts the conclusion made in Aboody et al. (2004a), who argue that a high leverage means that companies are active in capital markets and want to reduce information asymmetries. My results indicate that incentives for underreporting are what drives companies to make executive compensation appear lower than it actually is.

Both size and the book-to-market ratio have positive signs and are significant, the latter one even at a one percent level. The size effect indicates that large companies reduce underreporting, which fits with previous studies that find that larger companies are more adapt at following accounting standards and/or are more in public eye and cannot as easily bias reported figures. Companies with low growth opportunities as measured by higher BTM also correct the underreporting upward. This is in line with prior studies that have found that high growth companies tend to underreport option values in order to appear more profitable. No other variables are significant, including the lambda.

I repeat the regression, this time with year dummies included, in order to account for any time effects in the underreporting. Size and the number of options granted are no longer significant, yet the effect of market leverage and the book-to-market value persist. Again, the lambda is not significant, indicating that there is no selection bias. Model (3a) includes the type dummy and it again shows the influence of firm size, options granted, and the book-to-market ratio. While for larger firms the underreporting seems to be corrected, large option grants provide an incentive for managers to hide the value of such grants. As before, companies without growth opportunities also seem to correct the underreporting upward.

Finally, I control for unobserved heterogeneity by running a random-effects probit regression, which yields some unexpected results. At first, the incentive to hide the true value of the option expense caused by high market leverage is again confirmed at a five percent level. The size effect, which says that larger companies tend to correct the underreporting, also persists. Surprisingly, free float and institutional investors are also significant, but with unanticipated signs. Firms with highly dispersed ownership and thus low influence of controlling shareholders tend to correct the underreporting upwards, while those with more shares held by institutional investors tend do underreport more. Both results are contradictory to previous findings and therefore puzzling. When analyzing why companies might voluntarily recognize option expense under SFAS 123, Aboody et al. (2004a) argue that companies with large information asymmetries between 
insiders and outsiders might want to expense options for its signaling effect. By doing so, they demonstrate to users of financial statements, and especially creditors, that they can "afford" to lower their net income. Consistent with this interpretation they find that firms with less ownership by institutional investors (i.e., more information asymmetry) are more likely to expense options. But while this supports the notion that there may be a need to reduce information asymmetries when it comes to accounting for equity-based compensation, it is doubtful whether it can convincingly explain the findings here.

It is also possible that high multicollinearity plays into these unexpected results. Untabulated correlation coefficients and variance inflation factors reveal possible multicollinearity between institutional investors, board size, firm size, and salary, all of which in a way measure company size. Thus I drop the two variables that have not shown up significant in any model, namely board size and salary, and rerun both the first and the second stage of the random-effects panel model. Results are presented in Table 5.8.

The first stage results are almost unchanged compared to model (4). IFRS experience and the size of the option grant have the same effect as before and now size is positive and significant, which it was not before. This indicates that in the previous regression, this effect was obscured by the multicollinearity. More interestingly, though, on the second stage free float and institutional investors are no longer significant, the size effect is now fully absorbed by the size variable, whose p-value has decreased slightly. This model also confirms that market leverage acts as a strong incentive to underreport option values, while size presents a correcting influence. On a different note, the lambda is not significant in any of the models. This strongly speaks to the fact that a selection bias is not an issue here. ${ }^{100}$

\subsection{Summary of Main Results}

Executive stock options are one of the most important compensation tools in many companies. They are, however, not free from criticism. Many argue that they are primarily used because managers can extract excessive payments with them as their payoff is not initially visible. New accounting regulations in the United States and other countries have recently made option values more transparent. While the disclosure of

100 As mentioned by Lennox et al. (2012) this result can possibly be distorted by multicollinearity. The variance inflation factor for the lambda is, however, below five for all models. 
Table 5.8: Robustness Check: Panel Estimation

\begin{tabular}{|c|c|c|}
\hline & $(5)$ & $(6)$ \\
\hline Free float & $\begin{array}{c}0.0080 \\
(0.8173)\end{array}$ & $\begin{array}{c}0.0321 \\
(0.2005)\end{array}$ \\
\hline Inst. investors & $\begin{array}{c}0.0315 \\
(0.2789)\end{array}$ & $\begin{array}{c}-0.0218 \\
(0.4058)\end{array}$ \\
\hline FormerCEOchair & $\begin{array}{c}0.5368 \\
(0.7697)\end{array}$ & $\begin{array}{c}0.0348 \\
(0.9680)\end{array}$ \\
\hline CEO tenure & $\begin{array}{c}-0.0459 \\
(0.7110)\end{array}$ & $\begin{array}{c}0.0285 \\
(0.7280)\end{array}$ \\
\hline Size & $\begin{array}{c}0.8145^{*} \\
(0.0880)\end{array}$ & $\begin{array}{c}0.9969^{*} \\
(0.0513)\end{array}$ \\
\hline Opt. granted & $\begin{array}{c}-0.7879^{* *} \\
(0.0323)\end{array}$ & $\begin{array}{c}-1.8100 \\
(0.1280)\end{array}$ \\
\hline Loss & $\begin{array}{c}0.4087 \\
(0.8759)\end{array}$ & $\begin{array}{c}2.6709 \\
(0.3521)\end{array}$ \\
\hline Market leverage & $\begin{array}{c}0.2069 \\
(0.6511)\end{array}$ & $\begin{array}{c}-0.1210^{* *} \\
(0.0160)\end{array}$ \\
\hline Capital increase & $\begin{array}{c}0.0687 \\
(0.9670)\end{array}$ & $\begin{array}{c}0.9698 \\
(0.7132)\end{array}$ \\
\hline BTM & $\begin{array}{c}0.8237 \\
(0.5878)\end{array}$ & $\begin{array}{c}0.7029 \\
(0.1418)\end{array}$ \\
\hline IFRS experience & $\begin{array}{c}3.0788^{*} \\
(0.0543)\end{array}$ & \\
\hline Exercise & & $\begin{array}{c}0.1136 \\
(0.8517)\end{array}$ \\
\hline Lambda & & $\begin{array}{c}5.5691 \\
(0.2818)\end{array}$ \\
\hline Year Dummies & No & No \\
\hline$R^{2}$ & 24.8 & 26.3 \\
\hline Observations & 106 & 73 \\
\hline
\end{tabular}

The table shows regression results for the first and second stage of the Heckman correction. The dependent variable in model (5) is the disclosure dummy and in model (6) it is the underreporting ratio. Exercise is a dummy variable that is one if companies modeled exercise behavior. Lambda (also known as the inverse Mill's ratio) was obtained from model (5). P-values are based on cluster-robust standard errors. 
valuation models and input parameters is meant to make it possible for users of financial statements to check the overall payment levels, studies from the United States have shown that managers with high remuneration are likely to either not fully disclose or underreport the value of their options.

The new accounting standards have also led to new forms of ESO, most notably with performance-vesting or exercise conditions. No study so far has analyzed the underreporting issue for a mandatory expensing regime or for performance-vested stock. This study fills this gap by analyzing German ESO, which have traditionally been equipped with performance conditions.

First, it could be shown that not all companies provide all the information that is necessary to understand how the fair value of the option has been determined. Probit regressions reveal that companies with large option grants are less likely to provide sufficient disclosure, while firms with a higher ownership of institutional investors, longer serving CEOs and more IFRS experience are more likely to disclose appropriately. The result that IFRS experience is significant in all model specifications may point to the fact that incomplete disclosure is at least in part caused by confusion about the new accounting rules and not deliberate malfeasance.

As for the underreporting, I find that it also occurs in this new institutional setting in Germany under the full-expense regime that has been created by IFRS 2. While being statistically significant for the whole sample, it is not detectable in some years, which is similar to results from Denmark (Bechmann and Hjortshøj, 2009). Drivers of underreported options values are mostly linked to incentives for managers to conceal the true value of their remuneration. The more options are granted in a firm and the more highly it is levered (i.e., the higher potential financial distress is), the higher is the underreporting of the ESO values. This suggests that German companies use ESO valuations in a similar way as some American companies do and that is to improve financial performance by reducing compensation expenses. On the other hand, when companies are larger and when they do not have relevant growth opportunities, they correct the underreporting upward.

Like any other study, this one too suffers from potential pitfalls, in particular as it is based on a rather small sample size. At any rate, the results illustrate that those companies that do report enough information for a fair value calculation underreport for similar reasons as detected in previous studies and that IFRS 2 not completely fulfills 
its own goals of making ESO valuation more transparent and reproducible. This signals to standard setters and enforcement authorities that there is a need to more strictly check adherence to IFRS 2 so that there can be real informed control by shareholders and so that the benefits of performance vested ESO are not outweighed by negligent or perhaps even fraudulent reporting. 


\section{Conclusion}

This thesis set out to investigate the influence and the effectiveness of the International Financial Reporting Standard 2 in Germany which had consequences for one of the most hotly debated issues in business economics: management compensation. This standard revolutionized accounting for equity-based compensation by making its valuation transparent for the first time and by requiring expensing of these forms of compensation. Since the introduction of the standard represented an exogenous shock in an institutional environment without prior expensing of equity-based compensation, the German setting presents an ideal opportunity to study the effects of new accounting rules on the use of equity-based compensation.

The first main question of this thesis deals with the influence of IFRS 2: Does accounting have an impact on equity-based pay? Besides providing new international empirical evidence on the issue, the German setting much better allows linking the introduction of the new standard to observed changes in the choice of payment for different reasons. First, there was no transition period as there was in the United States. Second, IFRS 2 only led to expensing of equity-based pay and transparency of the valuation process. It did not change a preferential treatment that was awarded to at-the-money options with fixed terms in the U.S., which could have had a confounding effect in previous studies. Third, German law has long since required companies to attach performance vesting conditions to their options, so payment practices may well have been much closer to optimal contracting, in which case IFRS 2 would not be expected to have any influence. Finally, if the standard does have an impact, the differential treatment between stock options and performance shares allows a much better identification of the particular way the new standard influences the choice of equity-based pay by making use of the established theories about the use of stock options.

With the new transparency provided by IFRS 2, it is possible to make predictions about the reactions based on the three rationales optimal contracting, managerial rent seeking, and the perceived cost hypothesis. Under optimal contracting, no changes should be expected because providing information to a third party via the annual reports should not impact the pay setting process. For rent-seeking managers, however, heightened 
disclosure requirements take away the supposedly most appealing characteristic of stock options, the ability to camouflage actual pay levels. These managers would need a new, less transparent instrument that provides similar cash benefits. And finally, those companies guided by a perception of low option values will realize their mistake and will adapt their pay packages to include less complicated and more transparent instruments.

Empirical evidence provides support for the supposition that accounting has a different influence based on what the underlying motive for stock options grants has been. Companies that are characterized by strong corporate governance and more sophisticated stock option plans, both of which are generally associated with optimal contracting, have kept using stock options. Here IFRS 2 did not appear to have any effect. For the other companies there was an effect, though. As predicted, companies characterized by strong managerial power chose the rather non-transparent and non-linear performance shares in order to continue camouflaging their pay. Contrarily, for companies with weaker managerial power IFRS 2 revealed the true cost of their compensation. As a consequence they switched to transparent and linear restricted stocks, which is the expected reaction for perceived cost companies.

Taken together, these findings illustrate on the one hand that the new accounting standard does have an impact on the choice of compensation instrument. On the other hand, it also reveals that while transparency has been increased, rent seeking is still going on and not all payment contracts are designed optimally. This has important real-world implication as it shows the need for further improvement both in corporate governance and in the standard itself. At first, shareholders may want to improve control mechanisms in order to prevent managers from taking charge of the pay-setting process, while at the same time making sure that there is enough (financial) expertise to understand the valuation process of such highly complex instruments as stock options and performance shares. At the same time, standard setters should strongly consider revising the standard to subject performance shares to the same transparency requirements as stock options, so that there is no non-transparent instrument available to rent-seeking managers.

In another analysis, the second main research question asks whether the standard effectively achieves its goal of making ESO valuation more transparent and more reproducible. To this end, IFRS 2 lays out several disclosure requirements that companies have to adhere to in order to improve the understandability of ESO fair values for users of financial statements. Previous research for the U.S. and for Denmark has shown, how- 
ever, that not all companies fully comply with the mandated disclosure and some have been found to reduce, or underreport, the option values. Theory suggests, that this is mostly undertaken by companies with managers who have an incentive to hide excessive compensation and also have the means to do it because of weaker corporate governance in their firms. It is thus of great importance to verify that options are valued correctly. Otherwise managers can continue to engage in detrimental rent seeking, unbeknownst to the shareholders and investors.

The empirical analysis is the first of its kind to investigate the issue for a full-expense regime and with a sample fully governed by IFRS 2. Moreover, ESO in Germany have traditionally been equipped with performance-vesting conditions, a feature that is also gaining in popularity in other countries, but has so far not been explicitly included in any analysis of underreporting. Thus, this study provides some genuinely new insights into the effectiveness of IFRS 2 that can potentially be transferred to other IFRS adopting countries.

Results indicate that companies with large option grants tend to be the ones that do not disclose fully, while larger ownership by institutional investors, which is a sign of stronger corporate governance, acts as a counter measure to this. The fact that IFRS experience and longer CEO tenure, which also is a measure of experience, make full and correct disclosure more likely, might suggest that the failure to correctly follow the standard is not always caused by bad intent but rather inexperience.

Underreporting is significant in four out of seven years in my sample and when it occurs, it is connected to incentives to hide high remuneration such as large option grants or high leverage-a possible sign of financial distress. There is also some evidence that large companies and those with few growth opportunities tend to correct the underreporting upward. While the latter corroborates previous results that say that high-growth companies underreport more to appear more profitable, the former might again speak to the experience/expertise issue: larger companies often have more experienced accounting departments that have more resources and can better react to the new standards.

In summary, these results show that the standard, while definitely achieving higher transparency, does not fully succeed in creating complete and full disclosure. Furthermore, they reveal that underreporting is an issue in Germany as well, albeit not as extremely so as detected in previous U.S.-based studies. Nevertheless, this too has important implications. On the one hand, shareholders should make sure that there are enough 
accounting resources and that there is sufficient expertise to correctly value options. On the other hand, the high instances of incomplete disclosure reveal that there is room for improvement in both the auditing firms that singed off on the annual reports and the enforcement agencies DPR and BaFin that failed to detect these issues.

The research presented here offers up several avenues for future research. Collecting more information for further years could potentially improve the validity of the study, in particular in relation to the question if inappropriate disclosure practices are truly improving over time, as the significance of the experience variables suggests. Additionally, the regulatory background of executive compensation is ever changing as several new laws and regulations show. New amendments to the German Corporate Governance Code, for example, have some pundits believing that stock options will soon be a thing of the past. ${ }^{101}$ It will be interesting to see if new forms will emerge, like performance shares have in the last decade. Also, with these instruments becoming more and more popular, it might be worth to reevaluate if they are still mostly chosen by companies with a propensity to camouflage executive pay. So far performance shares have escaped scrutiny of their ability to convey incentives the way stocks and stock options have been subjected to rigorous analyses. Only when that is fully understood can they be used efficiently to overcome agency problems in management. Another new regulation has recently been presented by the European Parliament which voted in 2013 to cap bonuses for bankers at their fixed salary. This could present a new opportunity to study the trade-off between pay-for-performance sensitivity and the desire to curb excessive pay. All in all, there is much left to discover and investigate in the field of executive compensation. For now, this must, however, be left to future research endeavors.

101 See, for example, the interview with Michael Kramarsch of Hostettler, Kramarsch \& Partner in Börsen Zeitung, November 19, 2013, p. 13. 


\section{Bibliography}

Abbott, L. J., S. Parker, and G. F. Peters (2004). Audit committee characteristics and restatements. Auditing 23(1), $69-87$.

Abernethy, M. A., Y. F. Kuang, and B. Qin (2013). Do powerful CEOs influence compensation contract design? Working paper, The University of Melbourne.

Aboody, D. (1996). Market valuation of employee stock options. Journal of Accounting E Economics 22(1-3), 357 - 391.

Aboody, D., M. E. Barth, and R. Kasznik (2004a). Firms' voluntary recognition of stock-based compensation expense. Journal of Accounting Research 42(2), 123 - 150.

Aboody, D., M. E. Barth, and R. Kasznik (2004b). SFAS no. 123 stock-based compensation expense and equity market values. Accounting Review 79(2), 251 - 275.

Aboody, D., M. E. Barth, and R. Kasznik (2006). Do firms understate stock option-based compensation expense disclosed under SFAS 123? Review of Accounting Studies 11(4), $429-461$.

Aboody, D., J. Hughes, L. Jing, and S. Wei (2008). Are executive stock option exercises driven by private information? Review of Accounting Studies 13(4), 551 - 570.

Aboody, D., N. B. Johnson, and R. Kasznik (2010). Employee stock options and future firm performance: Evidence from option repricings. Journal of Accounting $\&$ Economics 50(1), $74-92$.

Aboody, D. and R. Kasznik (2008). Executive stock-based compensation and firms' cash payout: The role of shareholders' tax-related payout preferences. Review of Accounting Studies 13(2/3), $216-251$.

Accounting Principles Board (1972). Opinions of the Accounting Principles Board 25 - Accounting for Stock Issued to Employees. American Institute of Certified Public Accountants. 
Achleitner, A.-K. and D. Wichels (2002). Stock-Option-Pläne als Vergütungsbestandteil wertorientierter Entlohnungssysteme - Eine Einführung. In A.-K. Achleitner and P. Wollmert (Eds.), Stock Options (2nd ed.). Stuttgart: Schäffer-Poeschel.

Aggarwal, R., I. Erel, R. Stulz, and R. Williamson (2009). Differences in governance practices between U.S. and foreign firms: Measurement, causes, and consequences. Review of Financial Studies 22(8), 3131 - 3169.

Ammann, M. and R. Seiz (2004). Valuing employee stock options: Does the model matter? Financial Analysts Journal 60(5), 21 - 37.

Andres, C., E. Fernau, and E. Theissen (2012). Is it better to say goodbye? When (former) executives set executive pay. Working paper, CFR.

Arnold, M. C. and R. M. Gillenkirch (2005). Stock options and dividend protection. Journal of Institutional and Theoretical Economics 161(3), 453 - 472.

Arnold, M. C. and R. M. Gillenkirch (2007). Leistungsanreize durch Aktien oder Optionen? Eine Diskussion des State of the Art. Zeitschrift fur Betriebswirtschaft 77(1), $75-99$.

Bae, K.-H., H. Tan, and M. Welker (2008). International GAAP differences: The impact on foreign analysts. Accounting Review 83(3), $593-628$.

Balsam, S. (2012). Taxes and executive compensation. Briefing Paper 344, Economic Policy Institute.

Balsam, S., H. A. Mozes, and H. A. Newman (2003). Managing pro forma stock option expense under SFAS No. 123. Accounting Horizons 17(1), 31 - 45.

Barnea, A., R. A. Haugen, and L. W. Senbet (1985). Agency Problems and Financial Contracting. Prentice-Hall Foundations of Finance Series. Englewood Cliffs, NJ: Prentice-Hall.

Barth, M. E., G. Clinch, and T. Shibanio (2003). Market effects of recognition and disclosure. Journal of Accounting Research 41(4), 581 - 609.

Bartov, E., P. Mohanram, and D. Nissim (2007). Managerial discretion and the economic determinants of the disclosed volatility parameter for valuing esos. Review of Accounting Studies 12(1), 155 - 179. 
Beasley, M. S. (1996). An empirical analysis of the relation between the board of director composition and financial statement fraud. Accounting Review 71(4), 443 - 465.

Bebchuk, L., A. Cohen, and A. Ferrell (2009). What matters in corporate governance? Review of Financial Studies 22(2), 783 - 827.

Bebchuk, L. A. and J. M. Fried (2003). Executive compensation as an agency problem. Journal of Economic Perspectives 17(3), 71 - 92.

Bebchuk, L. A. and J. M. Fried (2004). Stealth compensation via retirement benefits. Berkeley Business Law Journal 1(2), 291-326.

Bebchuk, L. A. and J. M. Fried (2006). Pay without performance: The unfulfilled promise of executive compensation. Camebridge, MA: Harvard University Press.

Bebchuk, L. A., J. M. Fried, and D. I. Walker (2002). Managerial power and rent extraction in the design of executive compensation. University of Chicago Law Review 69 (3), 751.

Bechmann, K. L. and T. K. Hjortshøj (2009). Disclosed values of option-based compensation - Incompetence, deliberate underreporting or the use of expected option life? European Accounting Review 18(3), 475 - 513.

Bell, T. B., W. R. Landsman, B. L. Miller, and Y. Shu (2002). The valuation implications of employee stock option accounting for profitable computer software firms. Accounting Review r7(4), 971 - 996.

Bens, D. A., V. Nagar, D. J. Skinner, and M. F. Wong (2003). Employee stock options, EPS dilution, and stock repurchases. Journal of Accounting \& Economics 36(1-3), 51.

Bergman, N. K. and D. Jenter (2007). Employee sentiment and stock option compensation. Journal of Financial Economics 84(3), 667 - 712.

Bergstresser, D. and T. Philippon (2006). CEO incentives and earnings management. Journal of Financial Economics $80(3), 511$ - 529.

Berle, A. A. and G. G. C. Means (1932). The modern corporation and private property. New York: The Macmillan Company. 
Bertrand, M. and S. Mullainathan (2000). Agents with and without principals. American Economic Review 90(2), 203 - 208.

Bertrand, M. and S. Mullainathan (2001). Are CEOs rewarded for luck? The ones without principals are. Quarterly Journal of Economics 116(3), 901 - 932.

Bettis, C., J. Bizjak, J. Coles, and S. Kalpathy (2010). Stock and option grants with performance-based vesting provisions. Review of Financial Studies 23(10), 3849 3888 .

Bettis, J. C., J. Bizjak, J. Coles, and S. Kalpathy (2013). Performance-vesting provisions in executive compensation. Working paper, Arizona State University.

Bettis, J. C., J. M. Bizjak, and M. L. Lemmon (2005). Exercise behavior, valuation, and the incentive effects of employee stock options. Journal of Financial Economics 76(2), $445-470$.

Bizjak, J., S. Kalpathy, and R. Thompson (2012). Estimating the payoffs and approximate present value of performance-based equity awards in executive compensation. Working paper, Texas Christian University.

Bizjak, J., M. Lemmon, and T. Nguyen (2011). Are all CEOs above average? An empirical analysis of compensation peer groups and pay design. Journal of Financial Economics $100(3), 538-555$.

Bizjak, J. M., M. L. Lemmon, and L. Naveen (2008). Does the use of peer groups contribute to higher pay and less efficient compensation? Journal of Financial Economics 90(2), $152-168$.

Bloomfield, R. and R. Libby (1996). Market reactions to differentially available information in the laboratory. Journal of Accounting Research 34(2), 183 - 207.

Bodie, Z., R. S. Kaplan, and R. C. Merton (2003). For the last time: Stock options are an expense. Harvard Business Review 81(3), 62 - 71.

Borokhovich, K. A., K. R. Brunarski, and R. Parrino (1997). CEO contracting and antitakeover amendments. Journal of Finance 52(4), 1495 - 1517.

Botosan, C. A. and M. A. Plumlee (2001). Stock option expense: The sword of damocles revealed. Accounting Horizons 15 (4), 311 - 327. 
Brown, L. D. and Y.-J. Lee (2010). The relation between corporate governance and CEOs' equity grants. Journal of Accounting 83 Public Policy 29(6), 533 - 558.

Brown, L. D. and Y.-J. Lee (2011). Changes in option-based compensation around the issuance of SFAS 123r. Journal of Business Finance \&6 Accounting 38(9/10), 1053 1095 .

Bryan, S., L. Hwang, and S. Lilien (2000). CEO stock-based compensation: An empirical analysis of incentive-intensity, relative mix, and economic determinants. The Journal of Business 73(4), pp. 661-693.

Butler, J. S. and R. Moffitt (1982). A computationally efficient quadrature procedure for the one-factor multinomial probit model. Econometrica 50(3), 761-764.

CalPERS (2011). Global Principles of Accountable Corporate Governance. CalPERS.

Carpenter, J. N. (1998). The exercise and valuation of executive stock options. Journal of Financial Economics 48(2), 127 - 158.

Carter, M. E., C. Ittner, and S. Zechman (2009). Explicit relative performance evaluation in performance-vested equity grants. Review of Accounting Studies 14(2/3), 269 - 306.

Carter, M. E., L. J. Lynch, and İ. Tuna (2007). The role of accounting in the design of CEO equity compensation. Accounting Review 82(2), 327 - 357.

Choudharay, P., S. Rajgopal, and M. Venkatachalam (2009). Accelerated vesting of employee stock options in anticipation of FAS 123-R. Journal of Accounting Research $47(1), 105-146$.

Chow, C. C. and R. K. Sarin (2002). Known, unknown, and unknowable uncertainties. Theory and Decision 52(2), 127 - 138.

Conyon, M. J. (2006). Executive compensation and incentives. Academy of Management Perspectives 20(1), $25-44$.

Core, J. E. and W. R. Guay (1999). The use of equity grants to manage optimal equity incentive levels. Journal of Accounting \& Economics 28(2), 151 - 184.

Core, J. E. and W. R. Guay (2001). Stock option plans for non-executive employees. Journal of Financial Economics 61(2), 253 - 287. 
Core, J. E. and W. R. Guay (2010). Is CEO pay too high and are incentives too low? A wealth-based contracting framework. Academy of Management Perspectives 24(1), $5-19$.

Core, J. E., W. R. Guay, and D. F. Larcker (2003). Executive equity compensation and incentives: A survey. Federal Reserve Bank of New York Economic Policy Review 9(1), $27-50$.

Core, J. E., W. R. Guay, and D. F. Larcker (2008). The power of the pen and executive compensation. Journal of Financial Economics 88(1), 1 - 25.

Core, J. E., W. R. Guay, and R. S. Thomas (2005). Is U.S. CEO compensation broken? Journal of Applied Corporate Finance 17(4), 97 - 104.

Core, J. E., R. W. Holthausen, and D. F. Larcker (1999). Corporate governance, chief executive officer compensation, and firm performance. Journal of Financial Economics 51(3), $371-406$.

Crasselt, N. (2008). Einfluss von Erfolgszielen auf den Wert von MitarbeiterAktienoptionen. Betriebswirtschaft/Business Administration Review 68(3), 273 - 296.

Cremers, K. and D. Palia (2010). Tenure and CEO pay. Working paper, Yale School of Management.

Cronqvist, H. and R. Fahlenbrach (2013). CEO contract design: How do strong principals do it?. Journal of Financial Economics 108(3), 659 - 674.

Cyert, R. M., K. Sok-Hyon, and P. Kumar (2002). Corporate governance, takeovers, and top-management compensation: Theory and evidence. Management Science 48(4), $453-469$.

David, P., R. Kochhar, and E. Levitas (1998). Research notes. The effect of institutional investors on the level and mix of CEO compensation. Academy of Management Journal 41(2), 200 - 208.

Davis-Friday, P. Y., L. Chao-Shin, and H. F. Mittelstaedt (2004). Recognition and disclosure reliability: Evidence from SFAS No. 106. Contemporary Accounting Research $21(2), 399$ - 429. 
Davis-Friday, P. Y., L. B. Folami, L. Chao-Shin, and H. F. Mittelstaedt (1999). The value relevance of financial statement recognition vs. disclosure: Evidence from SFAS No. 106. Accounting Review 74(4), 403.

De Angelis, D. and Y. Grinstein (2010). Pay for the right performance. Working paper, Cornell University.

Dechow, P. M., A. P. Hutton, and R. G. Sloan (1996). Economic consequences of accounting for stock-based compensation. Journal of Accounting Research 34(3), 1 20.

Dittmann, I. and E. Maug (2007). Lower salaries and no options? On the optimal structure of executive pay. Journal of Finance 62(1), 303 - 343.

Dittmann, I., E. Maug, and C. Schneider (2010). Bankers on the boards of German firms: What they do, what they are worth, and why they are (still) there. Review of Finance 14(1), $35-71$.

Dittmann, I., E. Maug, and O. Spalt (2010). Sticks or carrots? Optimal CEO compensation when managers are loss averse. Journal of Finance 65(6), 2015 - 2050.

Dittmann, I., E. Maug, and O. Spalt (2013). Indexing executive contracts. Review of Financial Studies 26(12), 3182-3224.

Dittmann, I., E. Maug, and D. Zhang (2011). Restricting CEO pay. Journal of Corporate Finance 17(4), $1200-1220$.

Dittmann, I. and K.-C. Yu (2011). How important are risk-taking incentives in executive compensation? Working paper, Erasmus University Rotterdam.

Dittmar, A. K. (2000). Why do firms repurchase stock? Journal of Business 73(3), 331.

Dodonova, A. and Y. Khoroshilov (2006). Optimal incentive contracts for loss-averse managers: Stock options versus restricted stock grants. Financial Review 41(4), 451 -482 .

Doidge, C., A. G. Karolyi, and R. M. Stulz (2007). Why do countries matter so much for corporate governance? Journal of Financial Economics 86(1), 1 - 39.

Duan, J.-C. and J. Wei (2005). Executive stock options and incentive effects due to systematic risk. Journal of Banking E Finance 29(5), 1185 - 1211. 
Dyck, A. and L. Zingales (2004). Private benefits of control: An international comparison. The Journal of Finance 59(2), 537-600.

Edmans, A. and X. Gabaix (2009). Is CEO pay really inefficient? A survey of new optimal contracting theories. European Financial Management 15(3), 486 - 496.

Edmans, A., X. Gabaix, T. Sadzik, and Y. Sannikov (2012). Dynamic CEO compensation. Journal of Finance 67(5), 1603-1647.

Eisenberg, T., S. Sundgren, and M. T. Wells (1998). Larger board size and decreasing firm value in small firms. Journal of Financial Economics 48(1), 35 - 54.

Eisenhardt, K. M. (1989). Agency theory: An assessment and review. Academy of Management Review 14(1), 57 - 74 .

Elston, J. A. and L. G. Goldberg (2003). Executive compensation and agency costs in Germany. Journal of Banking \& Finance 27(7), 1391.

Epstein, K. and E. Javers (2006). How Bill Clinton helped boost CEO pay. BusinessWeek (4011), $64-65$.

Ernstberger, J., M. Stich, and O. Vogler (2012). Economic consequences of accounting enforcement reforms: The case of Germany. European Accounting Review 21(2), 217 $-251$.

Ernstberger, J. and O. Vogler (2008). Analyzing the German accounting triad - "Accounting Premium" for IAS/IFRS and U.S. GAAP vis-à-vis German GAAP? International Journal of Accounting 43(4), 339 - 386.

Espahbodi, H., P. Espahbodi, Z. Rezaee, and H. Tehranian (2002). Stock price reaction and value relevance of recognition versus disclosure: The case of stock-based compensation. Journal of Accounting \&5 Economics 33(3), 343.

Fabbri, F. and D. Marin (2012). What explains the rise in CEO pay in Germany? A panel data analysis for 1977-2009. Working paper, CESifo.

Fahlenbrach, R. (2009). Shareholder rights, boards, and CEO compensation. Review of Finance 13(1), 81.

Farrell, A. M., S. D. Krische, and K. L. Sedatole (2011). Employees' subjective valuations of their stock options: Evidence on the distribution of valuations and the use of simple anchors. Contemporary Accounting Research 28(3), 747 - 793. 
Faulkender, M. and J. Yang (2013). Is disclosure an effective cleansing mechanism? The dynamics of compensation peer benchmarking. Review of Financial Studies 26(3), $806-839$.

Feltham, G. A. and M. G. H. Wu (2001). Incentive efficiency of stock versus options. Review of Accounting Studies 6(1), 7 - 28.

Feng, Y. and Y. S. Tian (2009). Option expensing and managerial equity incentives. Financial Markets, Institutions and Instruments 18(3), 195 - 241.

Fenn, G. W. and N. Liang (2001). Corporate payout policy and managerial stock incentives. Journal of Financial Economics 60(1), 45 - 72.

Financial Accounting Standards Board (1995). Statement of Financial Accounting Standards No. 123. Financial Accounting Foundation.

Financial Accounting Standards Board (2004). Statement of Financial Accounting Standards No. 123 (revised 2004). Financial Accounting Foundation.

Fisher, I. (1930). The theory of interest. New York: The Macmillan Company.

Fox, C. R. and A. Tversky (1995). Ambiguity aversion and comparative ignorance. Quarterly Journal of Economics $110(3), 585$.

Franks, J. and C. Mayer (2001). Ownership and control of German corporations. Review of Financial Studies 14(4), 943.

Frydman, C. and D. Jenter (2010). CEO compensation. Annual Review of Financial Economics 2(1), 75 - 102.

Gabaix, X. and A. Landier (2008). Why has CEO pay increased so much? Quarterly Journal of Economics 123(1), 49 - 100.

Garvey, G. T. and T. T. Milbourn (2006). Asymmetric benchmarking in compensation: Executives are rewarded for good luck but not penalized for bad. Journal of Financial Economics 82(1), $197-225$.

Gerakos, J. J., C. D. Ittner, and D. F. Larcker (2007). The structure of performancevested stock option grants. In R. Antle, F. Gjesdal, and P. J. Liang (Eds.), Essays in Accounting Theory in Honour of Joel S. Demski, pp. 227-249. Springer New York. 
Gibbons, R. and K. J. Murphy (1992). Optimal incentive contracts in the presence of career concerns: Theory and evidence. Journal of Political Economy $100(3), 468$.

Gillenkirch, R. M., O. Korn, and A. Merz (2013). After the stock option boom: What explains the changes in equity-based pay? Working paper, Universität Göttingen.

Gopalan, R., T. Milbourn, and F. Song (2010). Strategic flexibility and the optimality of pay for sector performance. Review of Financial Studies 23(5), 2060 - 2098.

Grossman, S. J. and O. D. Hart (1983). An analysis of the principal-agent problem. Econometrica 51(1), 7 - 45.

Guay, W., S. P. Kothari, and R. Sloan (2003). Accounting for employee stock options. American Economic Review 93(2), 405 - 409.

Habib, M. A. and A. Ljungqvist (2005). Firm value and managerial incentives: A stochastic frontier approach. Journal of Business 78(6), 2053 - 2093.

Haid, A. and B. B. Yurtoglu (2006). Ownership structure and executive compensation in Germany. Working paper, Universität Erlangen-Nürnberg.

Hall, B. J. (1998). The pay to performance incentives of executive stock options. Working Paper 6674, National Bureau of Economic Research.

Hall, B. J. (2000). What you need to know about stock options. Harvard Business Review 78(2), 121 - 129.

Hall, B. J. and J. B. Liebman (1998). Are CEOs really paid like bureaucrats? Quarterly Journal of Economics 113(3), 653 - 691.

Hall, B. J. and K. J. Murphy (2002). Stock options for undiversified executives. Journal of Accounting \& Economics 33(1), 3 - 42.

Hall, B. J. and K. J. Murphy (2003). The trouble with stock options. Journal of Economic Perspectives 17(3), $49-70$.

Hand, J. R. (1990). A test of the extended functional fixation hypothesis. Accounting Review 65(4), $740-763$.

Hanlon, M., S. Rajgopal, and T. Shevlin (2003). Are executive stock options associated with future earnings? Journal of Accounting and Economics 36(1-3), 3 - 43. 
Harris, M. and A. Raviv (1979). Optimal incentive contracts with imperfect information. Journal of Economic Theory 20(2), 231 - 259.

Hartzell, J. C. and L. T. Starks (2003). Institutional investors and executive compensation. Journal of Finance 58(6), 2351 - 2374.

Hayes, R. M., M. Lemmon, and M. Qiu (2012). Stock options and managerial incentives for risk taking: Evidence from FAS 123R. Journal of Financial Economics 105(1), $174-190$.

Healy, P. M. and K. G. Palepu (2001). Information asymmetry, corporate disclosure, and the capital markets: A review of the empirical disclosure literature. Journal of Accounting \& Economics 31(1-3), 405 - 440.

Healy, P. M. and J. M. Wahlen (1999). A review of the earnings management literature and its implications for standard setting. Accounting Horizons 13(4), 365 - 383.

Heath, C. and A. Tversky (1991). Preference and belief: Ambiguity and competence in choice under uncertainty. Journal of Risk $\mathscr{E}$ Uncertainty 4(1), 5- 28.

Heckman, J. J. (1979). Sample selection bias as a specification error. Econometrica $47(1), 153-161$.

Hermalin, B. E. and M. S. Weisbach (2003). Boards of directors as an endogenously determined institution: A survey of the economic literature. Economic Policy Review $9(1), 7$.

Hermalin, B. E. and M. S. Weisbach (2012). Information disclosure and corporate governance. Journal of Finance 67(1), 195 - 234.

Herzig, N. (1999). Steuerliche und bilanzielle Probleme bei Stock Options und Stock Appreciation Rights. Der Betrieb 52(1), 1-12.

Hill, C. W. L. and P. Phan (1991). CEO tenure as a determinant of CEO pay. Academy of Management Journal $34(3), 707-717$.

Hirshleifer, D. and S. H. Teoh (2003). Limited attention, information disclosure, and financial reporting. Journal of Accounting 63 Economics 36(1-3), 337 - 386.

Hitz, J.-M., J. Ernstberger, and M. Stich (2012). Enforcement of accounting standards in Europe: Capital-market-based evidence for the two-tier mechanism in Germany. European Accounting Review 21 (2), 253 - 281. 
Hochberg, Y. V. and L. Lindsey (2010). Incentives, targeting, and firm performance: An analysis of non-executive stock options. Review of Financial Studies 23(11), 41484186.

Hodder, L., W. J. Mayew, M. L. McAnally, and C. D. Weaver (2006). Employee stock option fair-value estimates: Do managerial discretion and incentives explain accuracy? Contemporary Accounting Research 23(4), 933 - 975.

Hodge, F. D., S. Rajgopal, and T. Shevlin (2009). Do managers value stock options and restricted stock consistent with economic theory? Contemporary Accounting Research 26(3), $899-932$.

Holden, C. and D. Kim (2012). Performance share plans: Valuation and optimal design. Working paper, Indiana University Bloomington.

Holmberg, S. R. and L. Austin (2013). Fixing a hole: How the tax code for executive pay destorts economic incentives and burdens tax payers. White paper, Roosevelt Institute.

Holmström, B. (1979). Moral hazard and observability. Bell Journal of Economics 10(1), $74-91$.

Holthausen, R. W. (2009). Accounting standards, financial reporting outcomes, and enforcement. Journal of Accounting Research 47(2), 447 - 458.

Hope, O.-K. (2003). Disclosure practices, enforcement of accounting standards, and analysts' forecast accuracy: An international study. Journal of Accounting Research $41(2), 235-272$.

Huddart, S. and M. Lang (2003). Information distribution within firms: Evidence from stock option exercises. Journal of Accounting $\&$ Economics 34 (1-3), 3 - 31.

Hull, J. (2012). Options, Futures, and Other Derivatives (8th ed.). Upper Saddle River, NJ: Pearson Education.

Hull, J. and A. White (2004). How to value employee stock options. Financial Analysts Journal 60(1), 114 - 119.

Ikäheimo, S., N. Kuosa, and V. Puttonen (2006). 'The True and Fair View' of executive stock option valuation. European Accounting Review 15(3), 351 - 366. 
International Accounting Standards Board (2004). International Financial Reporting Standard 2 - Share-based Payment. IFRS Foundation.

Irving, J. H., W. R. Landsman, and B. P. Lindsey (2011). The valuation differences between stock option and restricted stock grants for US firms. Journal of Business Finance \& Accounting 38(3/4), 395 - 412.

Jensen, M. C. (1993). The modern industrial revolution, exit, and the failure of internal control systems. Journal of Finance 48(3), 831 - 880.

Jensen, M. C. and W. H. Meckling (1976). Theory of the firm: Managerial behavior, agency costs and ownership structure. Journal of Financial Economics 3(4), 305 360.

Jensen, M. C. and K. J. Murphy (1990a). CEO incentives - It's not how much you pay, but how. Harvard Business Review 68(3), 138 - 149.

Jensen, M. C. and K. J. Murphy (1990b). Performance pay and top-management incentives. Journal of Political Economy 98(2), 225 - 264.

Jensen, M. C., K. J. Murphy, and E. G. Wruck (2004). Remuneration: Where we've been, how we got to here, what are the problems, and how to fix them. Harvard NOM working paper, Harvard Business School.

Jenter, D. (2002). Executive compensation, incentives, and risk. Working paper, MIT.

Johnson, M., S. Porter, and M. Shackell-Dowell (1997). Stakeholder pressure and the structure of executive compensation. Working paper, University of Michigan.

Johnson, S. A. and Y. S. Tian (2000a). Indexed executive stock options. Journal of Financial Economics 57(1), 35 - 64.

Johnson, S. A. and Y. S. Tian (2000b). The value and incentive effects of nontraditional executive stock option plans. Journal of Financial Economics 57(1), 3 - 34 .

Johnston, D. (2006). Managing stock option expense: The manipulation of optionpricing model assumptions. Contemporary Accounting Research 23(2), 395 - 425.

Kahl, M., J. Liu, and F. A. Longstaff (2003). Paper millionaires: How valuable is stock to a stockholder who is restricted from selling it? Journal of Financial Economics 67(3), 385. 
Kahlert, A. and S. Würz (2003). Long-Term-Incentives als On-Top-Vergütung. Personalwirtschaft 30(3), 66-70.

Kaplan, R. S. and K. G. Palepu (2003). Expensing stock options: A fair-value approach. Harvard Business Review 81(12), 105 - 108.

Kaplan, S. N. (2013). CEO pay and corporate governance in the U.S.: Perceptions, facts, and challenges. Journal of Applied Corporate Finance 25(2), 8-25.

Kaserer, C. and B. Moldenhauer (2008). Insider ownership and corporate performance: Evidence from Germany. Review of Managerial Science 2(1), 1-35.

Kaserer, C. and N. Wagner (2004). Executive pay, free float, and firm performance: Evidence from Germany. Working paper, Technische Universität München (TUM).

Knoll, L. (1998). Besteuerung von stock options - Anmerkungen zu einer juristischen Frontlinie im ökonomischen Niemandsland. Steuer und Wirtschaft 75 (2), 133-137.

Kole, S. R. (1997). The complexity of compensation contracts. Journal of Financial Economics 43(1), 79 - 104.

Korn, O., C. Paschke, and M. Uhrig-Homburg (2012). Robust stock option plans. Review of Quantitative Finance \& Accounting 39(1), 77 - 103.

Kuang, Y. F. (2008). Performance-vested stock options and earnings management. Journal of Business Finance \& Accounting 35 (9/10), 1049 - 1078.

Kuang, Y. F. and B. Qin (2009). Performance-vested stock options and interest alignment. British Accounting Review 41(1), 46 - 61.

Kuhnen, C. M. and A. Niessen (2012). Public opinion and executive compensation. Management Science 58(7), 1249 - 2172.

La Porta, R., F. Lopez-De-Silanes, and A. Shleifer (2006). What works in securities laws? Journal of Finance 61(1), 1 - 32 .

La Porta, R., F. Lopez-De-Silanes, A. Shleifer, and R. W. Vishny (1997). Legal determinants of external finance. Journal of Finance 52(3), 1131 - 1150.

La Porta, R., F. Lopez-de Silanes, A. Shleifer, and R. W. Vishny (1998). Law and finance. Journal of Political Economy 106(6), 1113. 
Lambert, R. A. (2001). Contracting theory and accounting. Journal of Accounting $\&$ Economics 32(1-3), 3 - 87.

Lambert, R. A., W. N. Lanen, and D. F. Larcker (1989). Executive stock option plans and corporate dividend policy. Journal of Financial $\&$ Quantitative Analysis 24 (4), $409-425$.

Lambert, R. A. and D. F. Larcker (2003). Stock options, restricted stock, and incentives. Working paper, The Wharton School, University of Pennsylvania.

Lambert, R. A., D. F. Larcker, and R. E. Verrecchia (1991). Portfolio considerations in valuing executive compensation. Journal of Accounting Research 29(1), 129 - 149.

Langmann, C. (2007). Stock market reaction and stock option plans: Evidence from Germany. Schmalenbach Business Review (SBR) 59(1), 85 - 106.

Larcker, D. F. (1983). The association between performance plan adoption and corporate capital investment. Journal of Accounting \& Economics 5(1), 3 - 30.

Laux, H. (2006). Unternehmensrechnung, Anreiz und Kontrolle (3rd ed.). Berlin: Springer-Verlag.

Lennox, C. S., J. R. Francis, and Z. Wang (2012). Selection models in accounting research. Accounting Review 87(2), $589-616$.

Leuz, C., D. Nanda, and P. D. Wysocki (2003). Earnings management and investor protection: An international comparison. Journal of Financial Economics 69(3), 505 $-527$.

Lew, A. Y. and J. F. Schirger (1994). Accounting for employee stock options as contingencies. Journal of Applied Business Research 10(1), 19.

Liljeblom, E., D. Pasternack, and M. Rosenberg (2011). What determines stock option contract design? Journal of Financial Economics 102(2), 293 - 316.

Lipton, M. and J. W. Lorsch (1992). A modest proposal for improved corporate governance. Business Lawyer 48(1), 59.

Maris, B. A., J.-M. Maris, and T. T. Yang (2003). The effect of exercise date uncertainty on employee stock option value. Journal of Business Finance 85 Accounting 30(5/6), $669-697$. 
Maug, E. and B. Albrecht (2011). Struktur und Höhe der Vorstandsvergütung: Fakten und Mythen. Schmalenbachs Zeitschrift für betriebswirtschaftliche Forschung 63(8), $858-881$.

McConnell, J. J. and H. Servaes (1990). Additional evidence on equity ownership and corporate value. Journal of Financial Economics $27(2), 595$ - 612.

Mehran, H. (1995). Executive compensation structure, ownership, and firm performance. Journal of Financial Economics 38(2), 163 - 184.

Merz, A. (2013). Expensing performance-vested executive stock options - Is there underreporting under IFRS 2? Working paper, Universität Göttingen.

Meulbroek, L. K. (2001a). Designing an option plan that rewards relative performance: Indexed options revisited. Working Paper 02-022, Harvard Business School.

Meulbroek, L. K. (2001b). The efficiency of equity-linked compensation: Understanding the full cost of awarding executive stock options. Financial Management 30(2), 5 44 .

Mirrlees, J. A. (1976). The optimal structure of incentives and authority within an organization. Bell Journal of Economics 7(1), 105 - 131.

Mishra, C. S., D. H. Gobelia, and D. L. McConaughy (2000). Effectiveness of CEO pay-for-performance. Review of Financial Economics 9(1), 1.

Morck, R., A. Shleifer, and R. W. Vishny (1988). Management ownership and market valuation: An empirical analysis. Journal of Financial Economics 20(1/2), 293 - 315.

Morse, A., V. Nanda, and A. Seru (2011). Are incentive contracts rigged by powerful CEOs? Journal of Finance 66(5), 1779 - 1821.

Murphy, K. J. (1999). Executive compensation. In O. Ashenfelter and D. Card (Eds.), Handbook of Labor Economics, Volume 3B. Amsterdam: North-Holland Publishing Company.

Murphy, K. J. (2002). Explaining executive compensation: Managerial power versus the perceived cost of stock options. University of Chicago Law Review 69 (3), 847.

Murphy, K. J. and M. C. Jensen (2011). CEO bonus plans: And how to fix them. Working paper, Harvard Business School. 
Myers, S. C. (1977). Determinants of corporate borrowing. Journal of Financial Economics 5(2), $147-175$.

Naumann, T. K. (1998). Zur Bilanzierung von Stock Options. Der Betrieb 51, 1428 1433.

Nelson, J., G. Gallery, and M. Percy (2010). Role of corporate governance in mitigating the selective disclosure of executive stock option information. Accounting \& Finance 50(3), $685-717$.

Nohel, T. and T. Todd (2004). Stock options and managerial incentives to invest. Journal of Derivatives Accounting 01 (01), 29-46.

Ofek, E. and D. Yermack (2000). Taking stock: Equity-based compensation and the evolution of managerial ownership. The Journal of Finance 55(3), 1367-1384.

Oyer, P. (2004). Why do firms use incentives that have no incentive effects? Journal of Finance 59(4), 1619 - 1649.

Oyer, P. and S. Schaefer (2005). Why do some firms give stock options to all employees?: An empirical examination of alternative theories. Journal of Financial Economics 76(1), $99-133$.

Oyer, P. and S. Schaefer (2006). Costs of broad-based stock option plans. Journal of Financial Intermediation 15(4), 511 - 534.

Ozkan, N. (2007). Do corporate governance mechanisms influence CEO compensation? An empirical investigation of UK companies. Journal of Multinational Financial Management 17(5), $349-364$.

Ozkan, N. (2011). CEO compensation and firm performance: An empirical investigation of UK panel data. European Financial Management 17(2), 260 - 285.

Paschke, C. (2008). Aktienoptionsprogramme - Bewertungsspielräume und Anreizgestaltung. Lohmar - Köln: Josef Eul Verlag.

Pellens, B. and N. Crasselt (1998a). Aktienkursorientierte Entlohnungssysteme im Jahresabschluß. In B. Pellens (Ed.), Unternehmenswertorientierte Entlohnungssysteme. Stuttgart: Schäffer-Poeschel. 
Pellens, B. and N. Crasselt (1998b). Bilanzierung von Stock Options. Der Betrieb 51(5), $217-223$.

Pellens, B. and N. Crasselt (2002). Bilanzierung virtueller Aktienoptionsprogramme (Stock Appreciation Rights) aus finanzwirtschaftlicher Sicht. In A.-K. Achleitner and P. Wollmert (Eds.), Stock Options (2nd ed.). Schäffer-Poeschel.

Perry, T. and M. Zenner (2001). Pay for performance? Government regulation and the structure of compensation contracts. Journal of Financial Economics 62(3), 453 488.

Petra, S. T. and N. T. Dorata (2012). Restricted stock awards and taxes: What employees and employers should know. Journal of Accountancy 213(2), $44-48$.

Qin, B. (2012). The influence of firm and executive characteristics on performance-vested stock option grants. International Business Review 21(5), 906 - 928.

Rammert, S. (1998). Die Bilanzierung von Aktienoptionen für Manager - Überlegungen zur Anwendung von US-GAAP im handelsrechtlichen Jahresabschluß. Die Wirtschaftsprüfung 51(17), 766-777.

Rapp, M. S., P. Schaller, and M. Wolff (2011). Aktienbasierte Langfristanreize im Rahmen der Vorstandsvergütung: Evidenz auf Basis Deutscher Prime Standard Unternehmen. Betriebswirtschaft/Business Administration Review 71(4), 311 - 330.

Rappaport, A. (1998). Creating Shareholder Value - A guide for managers and investors (2nd ed.). New York: The Free Press.

Rappaport, A. (1999). New thinking on how to link executive pay with performance. Harvard Business Review r7(2), 91 - 101.

Rees, R. (1985). The theory of principal and agent: Part I. Bulletin of Economic Research $37(1), 3$.

Rose, N. L. and C. Wolfram (2002). Regulating executive pay: Using the tax code to influence chief executive officer compensation. Journal of Labor Economics 20(2), S138.

Ross, S. A. (1973). The economic theory of agency: The principal's problem. American Economic Review 63(2), $134-139$. 
Ross, S. A. (1974). On the economic theory of agency and the principle of similarity. In M. Balch, D. McFadden, and S. Wu (Eds.), Essays on Economic Behavior under Uncertainty. Amsterdam: North-Holland Publishing Company.

Sappington, D. E. (1991). Incentives in principal-agent relationships. Journal of Economic Perspectives 5(2), $45-66$.

Sautner, Z. and M. Weber (2011). Corporate governance and the design of stock option contracts. Betriebswirtschaft/Business Administration Review 71(4), 331 - 354.

Schmidt, C. (2012). Does transparency increase executive compensation? Working paper, University of Lausanne.

Shleifer, A. and R. W. Vishny (1986). Large shareholders and corporate control. Journal of Political Economy 94(3), 461 - 488.

Shleifer, A. and R. W. Vishny (1989). Management entrenchment: The case of managerspecific investments. Journal of Financial Economics 25(1), 123 - 139.

Siddiqui, S. (1999). Aktienoptionsmodelle als Instrument der unternehmenswertorientierten Vergütungsgestaltung. Aktuelle Durchführungsformen und neuere Entwicklungen. Zeitschrift für Personalforschung 2, 162-187.

Silber, W. L. (1991). Discounts on restricted stock: The impact of illiquidity on stock prices. Financial Analysts Journal 47(4), 60 - 64.

Silliman, B. (2005). Convergence of accounting standards: A comparative analysis of the US revised standard on share-based payment and the International Accounting Standards Board's IFRS 2. Review of Business-Saint Johns University 26(2), 24.

Skantz, T. R. (2012). CEO pay, managerial power, and SFAS 123(R). Accounting Review 87(6), $2151-2179$.

Spence, M. and R. Zeckhauser (1971). Insurance, information, and individual action. American Economic Review 61(2), 380 - 387.

Spreemann, K. (1989). Agency theory and risk sharing. In G. Bamberg and K. Spreemann (Eds.), Agency Theory, Information, and Incentives. Berlin: Springer-Verlag.

Stiglitz, J. E. (1974). Incentives and risk sharing in sharecropping. Review of Economic Studies 41(126), 219. 
Subramaniam, C. and J. Tsay (2012). Mandated recognition of employee stock option expense - The case of Canada. Journal of International Financial Management 8 Accounting 23(1), $62-91$.

Svensson, L. E. (1994, September). Estimating and interpreting forward interest rates: Sweden 1992 - 1994. Working Paper 4871, National Bureau of Economic Research.

Tian, Y. S. (2004). Too much of a good incentive? The case of executive stock options. Journal of Banking \& Finance 28(6), 1225.

Union Investment (2006). Union Investment Studie: Aktienoptionsprogramme der DAX 30 Unternehmen 2006. Union Investment.

Vater, H. (2000). Bilanzielle und körperschaftssteuerliche Behandlung von Stock Options. Der Betrieb 53(44), 2177-2186.

Velthuis, L. J. (2004). Anreizkompatible Erfolgsteilung und Erfolgsrechnung. Wiesbaden: DUV Gabler Edition Wissenschaft.

Walker, D. (2011). Evolving executive equity compensation and the limits of optimal contracting. Vanderbilt Law Review 64, 609.

Weisbach, M. S. (2007). Optimal executive compensation versus managerial power: A review of Lucian Bebchuk and Jesse Fried's Pay without performance: The unfulfilled promise of executive compensation. Journal of Economic Literature 45(2), 419 - 428.

Winter, S. (2000). Optionspläne als Instrument wertorientierter Managementvergütung. Frankfurt: Peter Lang.

Winter, S. (2003). Erfolgsziele deutscher Aktienoptionsprogramme. Schmalenbachs Zeitschrift für betriebswirtschaftliche Forschung Sonderheft 50(6), 121-144.

Wollmert, P. and J. Hey (2002). Bilanzierung von Stock Options nach internationalen Grundsätzen (US-GAAP und IAS). In A.-K. Achleitner and P. Wollmert (Eds.), Stock Options (2nd ed.). Stuttgart: Schäffer-Poeschel.

Yermack, D. (1995). Do corporations award CEO stock options effectively? Journal of Financial Economics 39(2/3), 237 - 269.

Yermack, D. (1996). Higher market valuation of companies with a small board of directors. Journal of Financial Economics 40(2), 185 - 211. 
Yermack, D. (1998). Companies' modest claims about the value of CEO stock option awards. Review of Quantitative Finance and Accounting 10(2), 207 - 226. 